Revue des patrimoines

\title{
Paris au pied du mur. "Crédit des 10 millions ", décoration murale et crise économique dans les années 1930
}

\section{Marc Verdure}

\section{OpenEdition}

\section{Journals}

Édition électronique

URL : http://journals.openedition.org/insitu/10732

DOI : 10.4000/insitu. 10732

ISSN : 1630-7305

Éditeur

Ministère de la culture

Référence électronique

Marc Verdure, "Paris au pied du mur. "Crédit des 10 millions », décoration murale et crise économique dans les années 1930 », In Situ [En ligne], 22 | 2013, mis en ligne le 15 novembre 2013, consulté le 19 avril 2019. URL : http://journals.openedition.org/insitu/10732 ; DOI : 10.4000/ insitu. 10732

Ce document a été généré automatiquement le 19 avril 2019

\section{(c) (i) (3)}

In Situ Revues des patrimoines est mis à disposition selon les termes de la licence Creative Commons Attribution - Pas d'Utilisation Commerciale - Pas de Modification 4.0 International. 


\title{
Paris au pied du mur. « Crédit des 10 millions ", décoration murale et crise économique dans les années 1930
}

\author{
Marc Verdure
}

1 La Ville de Paris est rarement citée en exemple pour ses constructions scolaires dans l'entre-deux-guerres, la banlieue étant surtout le théâtre des expérimentations les plus médiatisées. Pourtant, la capitale voit la mise en place, pour contrer les effets désastreux de la crise économique après 1929, d'un dispositif original de grands travaux. Une dizaine de groupes scolaires sont ainsi construits en deux ans, entre 1932 et 1934, et des décors leur sont adjoints grâce à un emprunt exceptionnel de 10 millions de francs. La spécificité de cette commande est d'autant plus remarquable que décor et architecture sont conçus simultanément, l'architecte définissant pendant l'opération, ou un peu après, l'emplacement et la typologie de l'œuvre décorative, et proposant même parfois certains noms d'artistes. Cette politique, qualifiée à l'époque d'« outillage municipal » par les élus parisiens, répond à plusieurs objectifs faciles à cerner en raison d'une documentation archivistique abondante qui offre un aperçu quasiment complet et révélateur sur l'élaboration et le fonctionnement d'un grand projet politique et administratif. Cette politique dont les jalons sont posés au fil des débats au conseil municipal en 1932 est aussi la première manifestation, depuis les déclarations de Viollet-le-Duc en 1875 et $1879^{1}$ sur la nécessité d'un décor civil, d'un engagement politique fort en faveur des arts à l'école.

2 Nous nous proposons d'étudier ces sources inédites en nous limitant au domaine de la décoration picturale en milieu scolaire, excluant les dépenses qui ont intéressé d'autres secteurs. Cela permettra d'analyser précisément les enjeux à l'œuvre dans la décision politique (intérêt pour le rôle pédagogique de l'art, lutte contre le chômage, défense du savoir-faire français) et d'illustrer l'action d'une administration préparant des dossiers techniques (sollicitation de réseaux d'artistes, rédaction des rapports définissant les programmes avec les architectes). La prosopographie des acteurs (élus, architectes, 
artistes) et une analyse précise des fonds conservés aux Archives de Paris permettront de faire sortir de l'ombre le " crédit des 10 millions ", un des grands programmes de travaux conçus dans l'urgence de la crise.

\section{État des lieux : la crise économique et la politique scolaire parisienne}

\section{L'apparition du chômage de masse et la réaction politique parisienne}

3 Le nombre de chômeurs inscrits à Paris, quasiment nul en 1929, passe à 70000 en octobre 1933, soit 2,5\% de la population ${ }^{2}$. L'assemblée municipale élue en 1929, en majorité à droite, se mobilise devant ce danger économique qu'elle associe à un danger social ${ }^{3}$. Les débats en Conseil municipal abordent ainsi régulièrement la lutte contre ce nouveau spectre, et ils se concluent fréquemment par la décision d'organiser de grands travaux ou celle d'accroître la part consacrée aux secours dans le budget. De fréquents vœux sont également adressés par le Conseil municipal au Parlement, attirant l'attention sur l'utilité des secours financiers et sur l'intérêt d'une politique de grands travaux. Les années d'entre-deux-guerres abondent d'ailleurs en plans de relance d'inspiration vaguement keynésienne ${ }^{4}$, après celui $\mathrm{d}^{\prime}$ André Tardieu, initiateur du premier «plan d'outillage national » en 1929,'imité par Pierre Laval (1931), Adrien Marquet (1934) ou Léon Blum (1936).

Lors du débat du 23 mars 1932 toutefois, alors que l'assemblée évoque « l'aggravation de l'enlisement économique à Paris et du fléau du chômage qui en résulte " ${ }^{5}$, l'annonce est faite du lancement d'un emprunt destiné à favoriser « ouvriers et artisans d'art français ». Prenant acte de ce que la plupart des efforts nationaux sont effectués en faveur de la construction et l'aménagement, les élus décident d'aider « une des catégories les plus touchées par la crise économique, celle des industries d'art ». La décision annoncée par Georges Contenot $^{6}$, rapporteur de la $4^{\mathrm{e}}$ commission dédiée aux Beaux-Arts, s'appuie sur un document de l'administration définissant un avant-programme de travaux concernant par exemple l'acquisition de mobilier et la décoration de l'Hôtel de Ville, des aménagements de toute nature dans les musées municipaux et dans les bibliothèques municipales, la commande d'œuvres d'art et l'achèvement de la décoration picturale des mairies de Paris et des préaux d'école (fig. $\left.\mathbf{n}^{\circ} \mathbf{1}, \mathbf{n}^{\circ} \mathbf{2}, \mathbf{n}^{\circ} \mathbf{3}\right)$. 
Figure 1

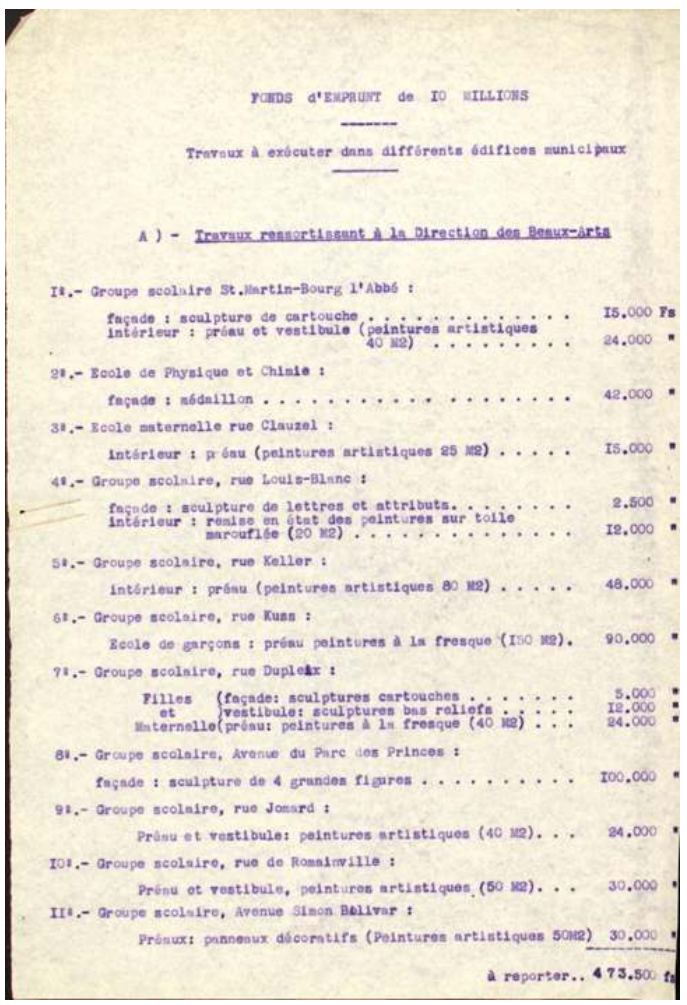

Travaux à exécuter dans différents édifices municipaux, page 1, sans date. Cote Archives de Paris VR 588.

Phot. service photographique des Archives de Paris. (C) Archives de Paris, 2012 
Figure 2

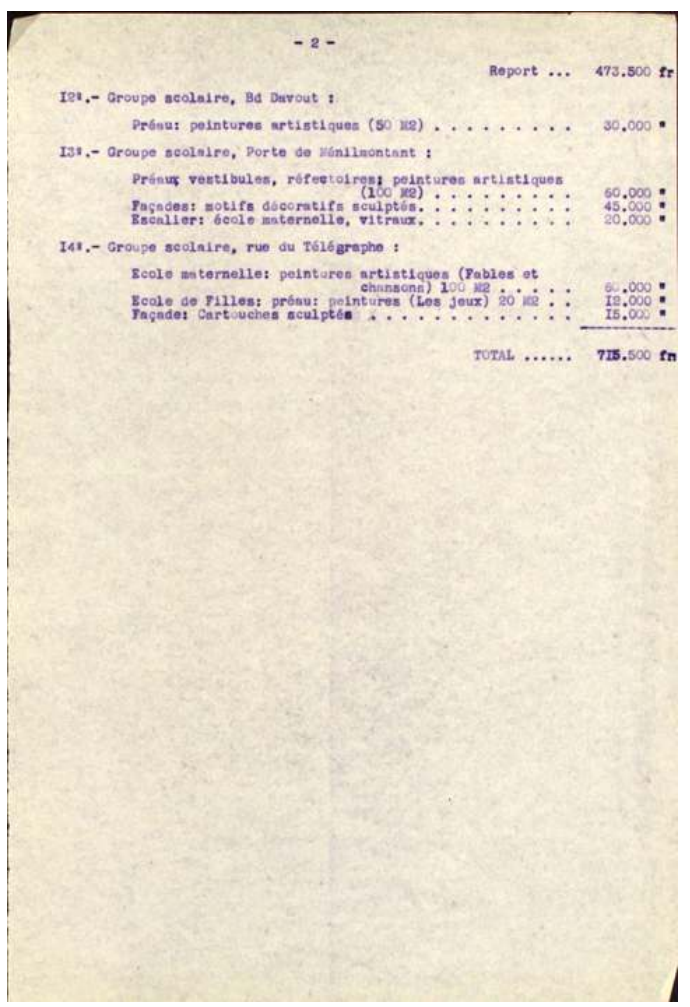

Travaux à exécuter dans différents édifices municipaux, page 2, sans date. Cote Archives de Paris VR 588.

Phot. service photographique des Archives de Paris. (C) Archives de Paris, 2012 
Figure 3

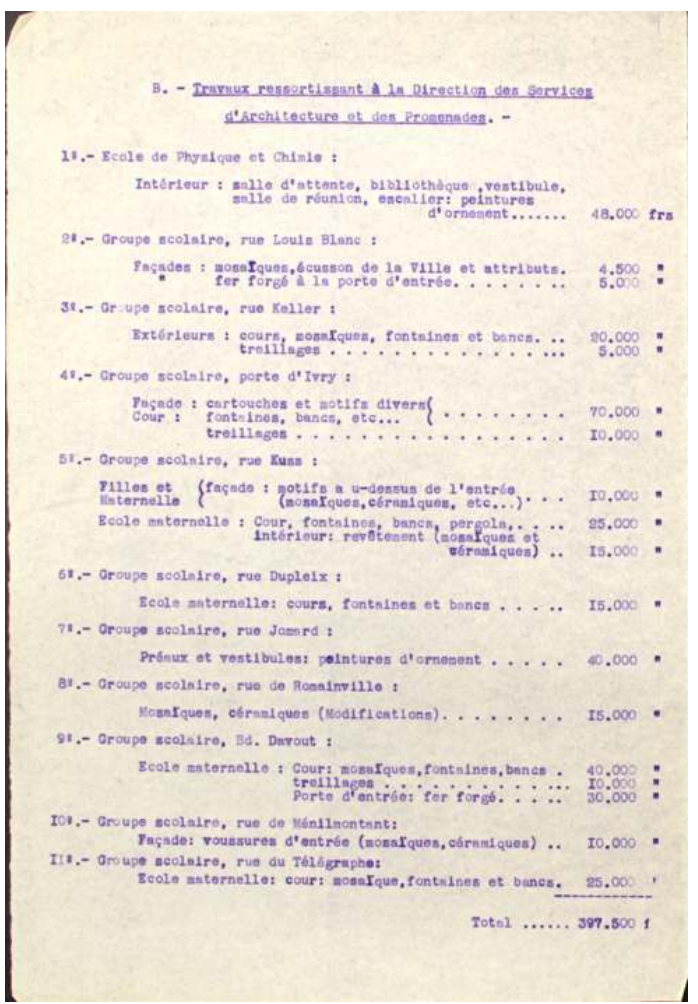

Travaux à exécuter dans différents édifices municipaux, page 3, sans date. Cote Archives de Paris VR 588.

Phot. service photographique des Archives de Paris. (C) Archives de Paris, 2012.

L'historien ne peut qu'être frappé par la filiation directe de ce projet avec celui de Violletle-Duc à la fin des années 1870. Il ne s'agissait pas, pour ce dernier, d'utiliser les fonds publics à seule fin de constituer une caisse de secours des artistes mais, en nourrissant une ambition de "haute moralité civile", de développer par la décoration des édifices publics le « goût des choses de l'art dans la population et favoriser l'initiative (...), suivant un programme défini, au lieu d'être disséminé un peu au hasard ${ }^{7}$ ». Le rapport de 1879, avec celui de 1875, constitue la pierre angulaire de l'action municipale de l'entre-deuxguerres, de façon consciente ou non: on verra que, si nulle allusion n'est faite à l'architecte théoricien dans les débats qui nous intéressent, en revanche la mémoire de ses idées perdure chez certains. Il faut ainsi retenir que l'école constituait, dans ses interventions à l'assemblée, « pour l'enfance une initiation à l'art (...). Nous souhaiterions $\mathrm{y}$ voir figurer des représentations très simplement traitées des divers travaux des champs et des métiers, des actes importants de la vie civile, avec légendes sommaires (...). Ces peintures des écoles, traitées en manière de frises, pourraient être disposées dans les préaux couverts, dans les classes de dessin, dans les galeries et vestibules ${ }^{8} »$.

\section{L'outillage scolaire à Paris dans les années 1920}

Les cartes publiées par Anne-Marie Châtelet ${ }^{9}$ révèlent une activité permanente de construction durant l'entre-deux-guerres, puisque 35 écoles élémentaires et maternelles sont édifiées entre 1914 et 1945. Le Conseil municipal ne ménage donc pas ses efforts, accompagné par l'État qui apporte sa contribution par des subventions. Mais la Ville bute 
souvent sur deux points principaux, l'extrême rareté des terrains, exigus et complexes, et les moyens réduits qui posent le problème du prix. Si le développement démographique de Paris reste assez stable au cours des années 1920 et 1930 (autour de 2,9 millions d'habitants en 1921 et 2,7 millions en 1945), en revanche l'évolution des méthodes pédagogiques et le besoin en équipements adaptés fournissent les données de base d'une équation que Paris, tout comme les autres villes de France, a à résoudre : construire des écoles en quantité et qualité suffisantes, et en temps voulu, et faire face au besoin d'instruction de la population.

7 Les projets sont confiés, en premier lieu, aux architectes de la Ville de Paris et du Département de la Seine, en vertu de l'arrêté préfectoral du 27 février 1925. C'est notamment le cas, pour le corpus des écoles qui intéresse notre sujet, des architectes suivants: André Berry ${ }^{10}$ architecte-voyer, Raoul Brandon ${ }^{11}$ architecte et membre du conseil municipal de 1925 à sa mort, Édouard Boegner ${ }^{12}$ architecte général de la Ville de Paris et de la Seine en 1948 après une carrière au sein des services d'architecture, JulienFrançois Froux ${ }^{13}$ architecte-voyer adjoint, Raymond Rousselot ${ }^{14}$ architecte des Services Techniques (fig. $\left.\mathbf{n}^{\circ} \mathbf{4}\right)$. Ce mode de recrutement n'empêche pas l'emploi de personnalités extérieures, comme Louis-Hippolyte Boileau ${ }^{15}$, Germain Debré ${ }^{16}$, Roger-Henri Expert ${ }^{17}$, Victor-Abel Mahieu ${ }^{18}$, Albert Alexandre Melissent ${ }^{19}$ ou Pierre Winter ${ }^{20}$. Si les architectes d'opération ainsi nommés travaillent sur un avant-projet défini par le Bureau Central d'Études de la Direction des Services d'Architecture et des Promenades qui fixe notamment une enveloppe budgétaire, ils ont toutefois le loisir de modifier tout ou partie de ce programme, avant examen et validation par les élus et le Bureau Central.

Figure 4

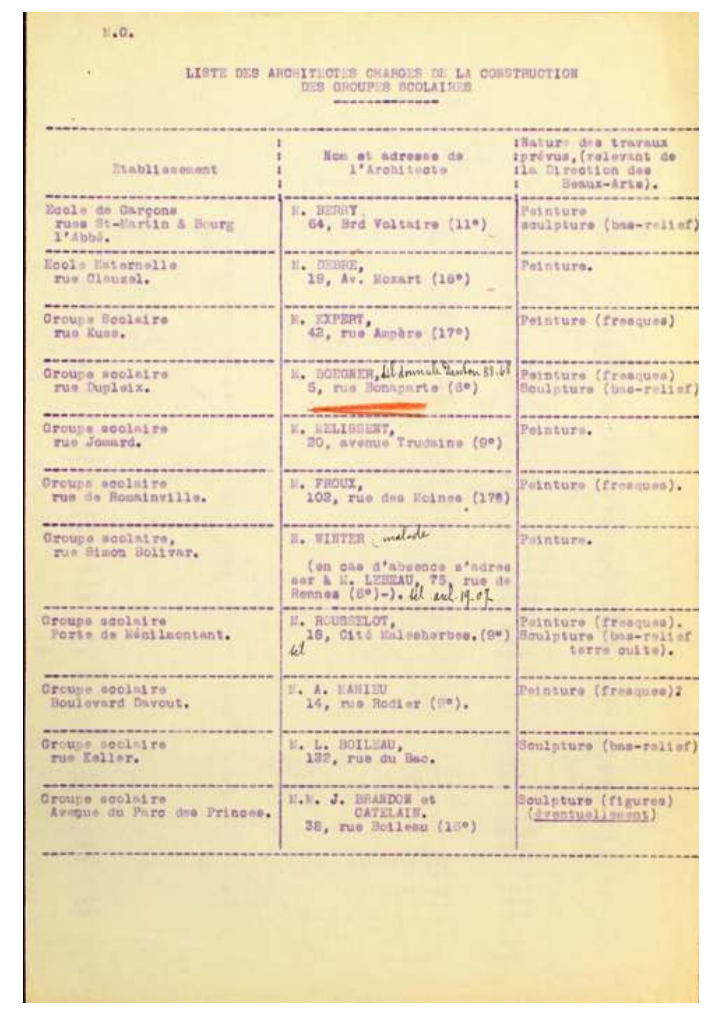

Liste des architectes chargés de la construction, sans date. Cote Archives de Paris VR 588.

Phot. service photographique des Archives de Paris. (c) Archives de Paris, 2012. 
La diversité des personnalités recrutées explique peut-être le "modernisme tempéré » qui régit la construction scolaire parisienne, entre modernité formelle et technique et distribution traditionnelle ${ }^{21}$. Un extrait des Instructions relatives à la construction des bâtiments scolaires de la Ville de Paris (du 12 septembre 1923) publié par la revue L'Architecture d'aujourd'hui montre en effet que tout effet de luxe est banni, au profit d'une «simplicité de distribution et de forme, sobriété de décoration, suppression de toutes choses dont l'utilité ne serait pas reconnue ${ }^{22}$ ». Les débats en Conseil municipal, durant les années 1920, n'abordent jamais la question de l'ambition architecturale, de la qualité à apporter au dessin d'architecture, encore moins du décor, ces questions étant probablement laissées au soin des commissions ad hoc ou de l'administration.

\section{L'action de Paul Baudoüin sur les programmes décoratifs scolaires dans les années 1920}

9 Malgré le silence des politiques, depuis Viollet-le-Duc jusqu'aux années 1920, il s'avère que la municipalité s'essaie tout de même à la décoration des écoles. Après deux tentatives documentées en 1880 aux écoles de la rue Dombasle (XVe arrondissement) et de la rue Château-Landon ( $\mathrm{X}^{\mathrm{e}}$ arrondissement) ${ }^{23}$, probablement motivées par les déclarations d'Eugène Viollet-le-Duc à l'assemblée municipale en 1875 et 1879, les archives indiquent l'existence de plusieurs initiatives: un projet de décor conçu en 1880 par l'architecte Cazaux pendant la construction de l'école située au croisement de la rue Damrémont et de la rue Vauvenargues (XVIII $)$ ou plusieurs autres commandes de décors sculptés ${ }^{24}$. Ces projets semblent ponctuels et n'abordent fondamentalement ni la valeur artistique ni l'aspect pédagogique du décor; il semble que la Ville de Paris laisse le soin de décorer les écoles à la Société française de l'Art à l'école, qui dispose d'un stock de reproductions d'œuvres d'art (peintures, sculpture, architecture) abondant et développe la pratique du décor au pochoir ${ }^{25}$. La proximité de cette structure avec la Ville est confirmée d'ailleurs par la présence, dans ses instances, de plusieurs élus (ou de futurs élus) municipaux.

Après la Grande Guerre, la Ville semble adopter une posture plus ambitieuse et moins empirique, s'appuyant notamment sur un artiste dont l'influence va croissante au cours des années 1920, et sur une technique encore peu pratiquée en France. En effet, c'est à Paul-Albert Baudoüin ${ }^{26}$ (1844-1931) que, lors de sa séance du 31 mars 1920, le Conseil municipal confie «la décoration par la fresque du mur du fond du préau de l'école du boulevard Raspail, à l'angle de la rue de Rennes ${ }^{27}$ ».

11 Paul Baudoüin est loin d'être inconnu des services et des élus parisiens, ayant été élève de Puvis de Chavannes et chargé de plusieurs décors à Paris, à l'école de la rue Dombasle, au Panthéon et dans le péristyle du musée du Petit-Palais. Son nom est également associé à la restauration de la technique de la fresque, après la publication en 1914 de son manuel La Fresque, sa technique, ses applications où il propose une synthèse de toutes les informations recueillies au cours de ses voyages et lectures. C'est ainsi à lui que l'École nationale des Beaux-Arts confie en 1919 la mission de diriger un atelier créé à ce sujet en $1911^{28}$. Il est donc, après la guerre, au sommet de sa notoriété et il est probablement à l'origine de la reprise de l'idée de Viollet-le-Duc d'intervenir dans les écoles : « on ne doit pas oublier que c'est la ville de Paris (...) qui, la première, en appliquant l'idée de Violletle-Duc, a fait peindre à fresque des préaux dans ses Écoles ${ }^{29}$ ». 
Figure 5

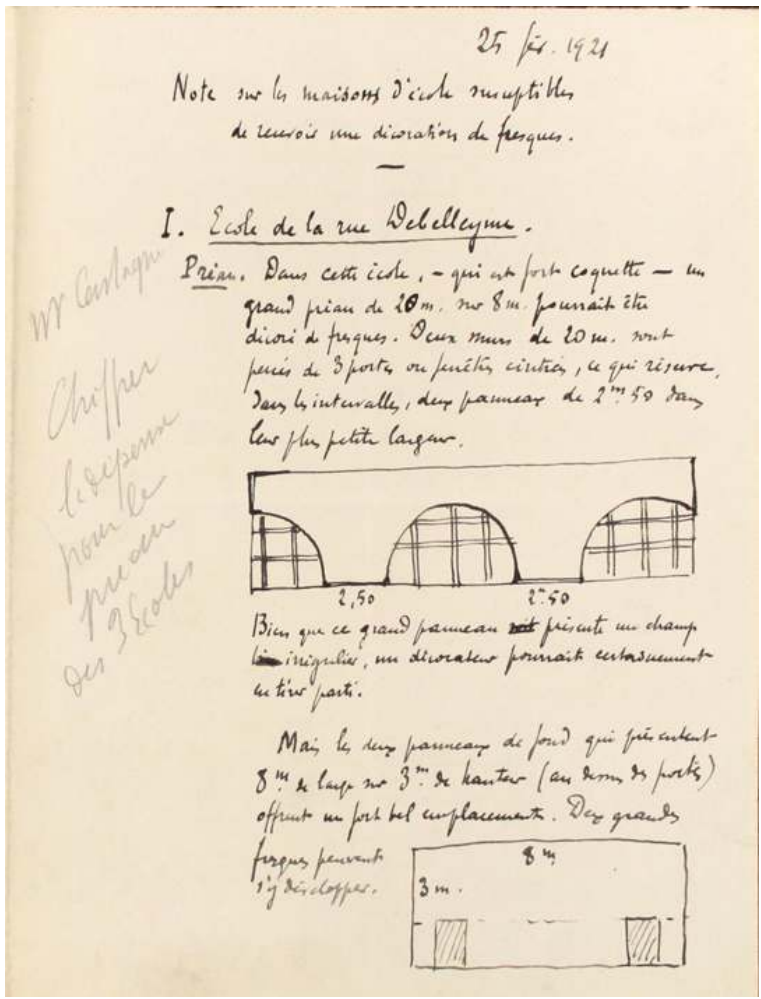

Note sur les maisons d'écoles susceptibles de recevoir une décoration de fresques, 25 février 1921, page 1. Cote Archives de Paris VR 573.

Phot. service photographique des Archives de Paris. (C) Archives de Paris, 2012. 
Figure 6

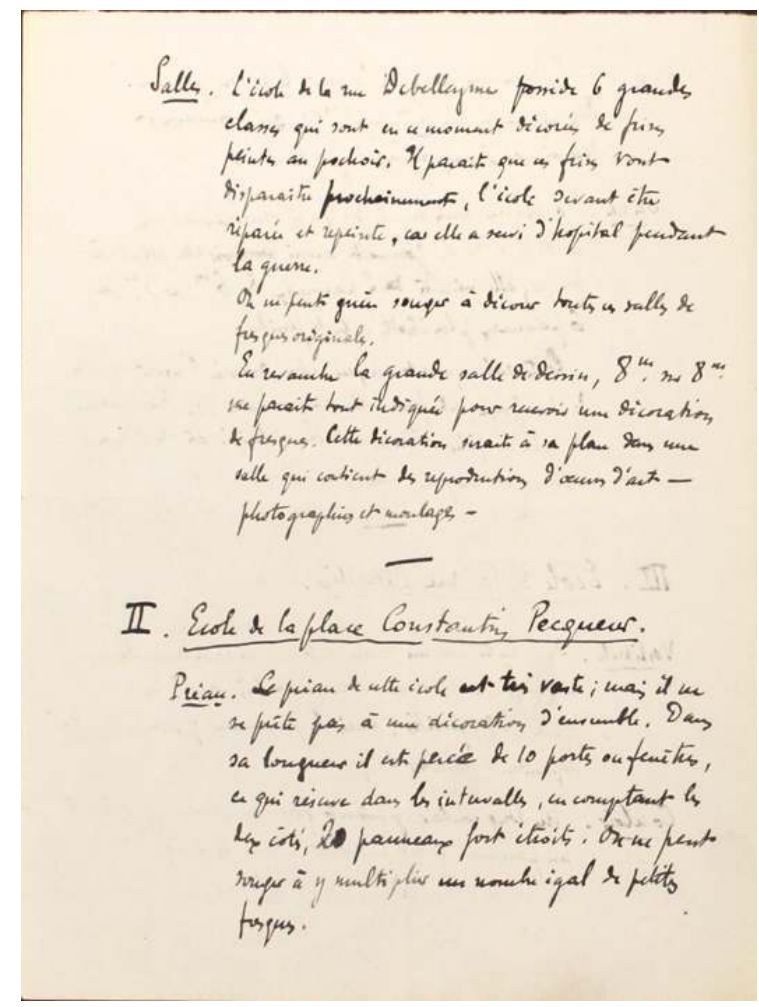

Note sur les maisons d'écoles susceptibles de recevoir une décoration de fresques, 25 février 1921, page 2. Cote Archives de Paris VR 573.

Phot. service photographique des Archives de Paris. (C) Archives de Paris, 2012 
Figure 7

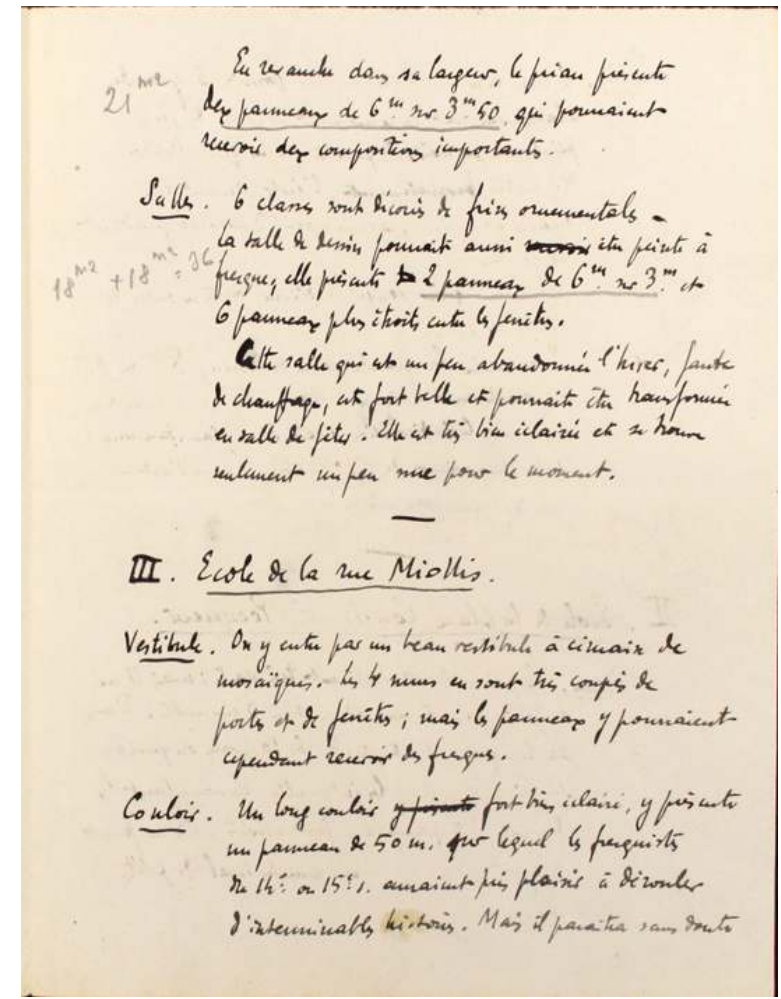

Note sur les maisons d'écoles susceptibles de recevoir une décoration de fresques, 25 février 1921 page 3. Cote Archives de Paris VR 573.

Phot. service photographique des Archives de Paris. (C) Archives de Paris, 2012 


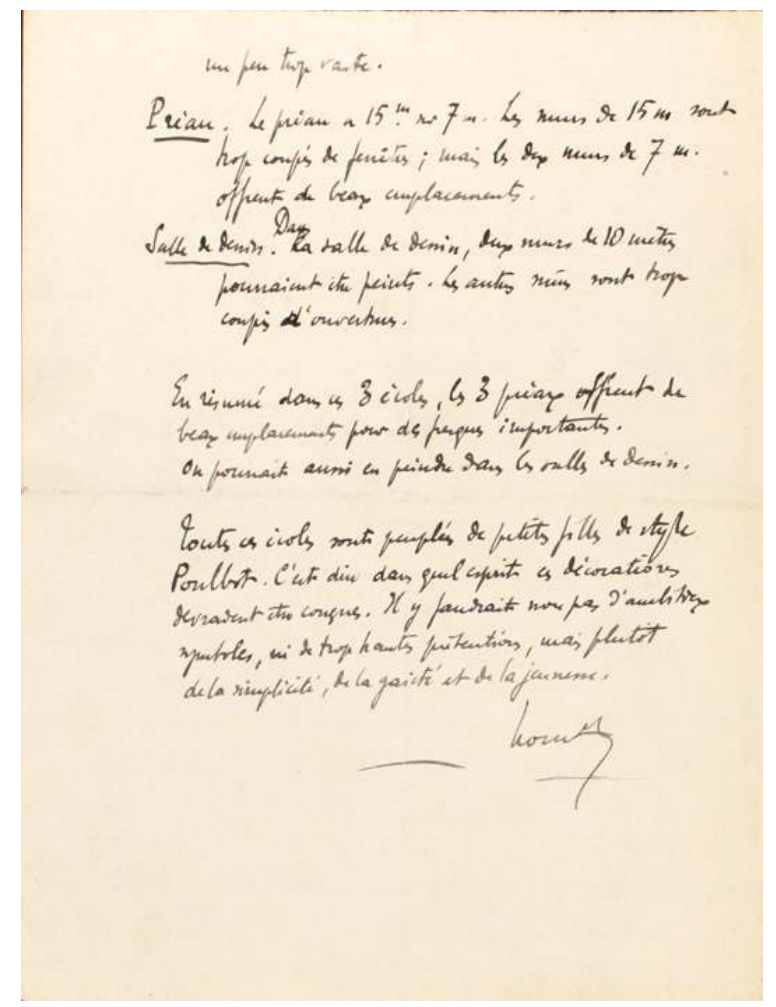

Note sur les maisons d'écoles susceptibles de recevoir une décoration de fresques, 25 février 1921, page 4. Cote Archives de Paris VR 573.

Phot. service photographique des Archives de Paris. (C) Archives de Paris, 2012.

Probablement en raison du succès de l'entreprise à l'école Raspail, la $4^{\mathrm{e}}$ commission des Beaux-Arts du Conseil municipal demande ensuite à l'administration des Beaux-Arts et des Musées, ainsi qu'à celle de l'Architecture, en mai 1921, une Note sur les maisons d'écoles susceptibles de recevoir une décoration de fresques (fig. $\mathbf{n}^{\circ} 5, \mathbf{n}^{\circ} 6, \mathbf{n}^{\circ} 7, \mathbf{n}^{\circ} 8$ ) qui fait état d'un premier repérage puis désigne les écoles des rues Debelleyme (III ${ }^{\mathrm{e}}$ ), des Jeûneurs (III ${ }^{\mathrm{e}}$, Brisemiche (IV $)$ et Miollis $\left(\mathrm{XV}^{\mathrm{e}}\right)$. Immédiatement après, en avril 1922, un arrêté est pris qui confie la décoration à plusieurs artistes, sous la direction et la surveillance de Paul Baudoüin $^{30}$ (fig. $\left.\mathbf{n}^{\circ} \mathbf{9}\right)$ (fig. $\mathbf{n}^{\circ} \mathbf{1 0}$ ). Le préau de l'école de filles la rue Debelleyme est attribué à Jean-Robert La Montagne Saint-Hubert ${ }^{31}$, celui de l'école de filles de la rue Brisemiche à Étienne Hauville ${ }^{32}$, celui de l'école de garçons de la rue Miollis à Loÿs Prat ${ }^{33}$ et celui de l'école de garçons de la rue des Jeûneurs (aujourd'hui lycée Jean-Baptiste Lully) à Pierre Ducos de la Haille ${ }^{34}$. Ces artistes sont tous des disciples de Paul Baudoüin et la mission collective dirigée par ce dernier préfigure le fonctionnement de sa future structure associative créée en $1928^{35}$. De tous ces décors, seul subsiste celui du lycée JeanBaptiste Lully, sur le thème des éléments, La Terre et la Mer ${ }^{36}$ (fig. $\mathbf{n}^{\circ} \mathbf{1 1}$ ). 
Figure 9

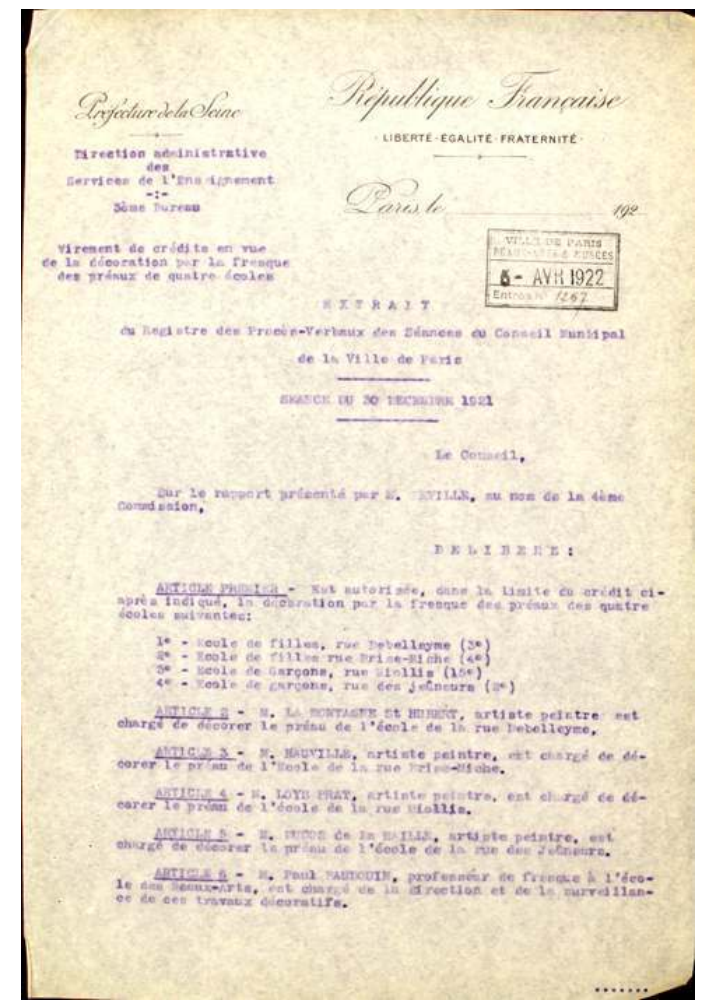

Arrêté confiant la supervision des décors à Paul Baudoüin, page 1, 25 mars 1922. Cote Archives de Paris VR 573.

Phot. service photographique des Archives de Paris. (c) Archives de Paris, 2012. 
Figure 10

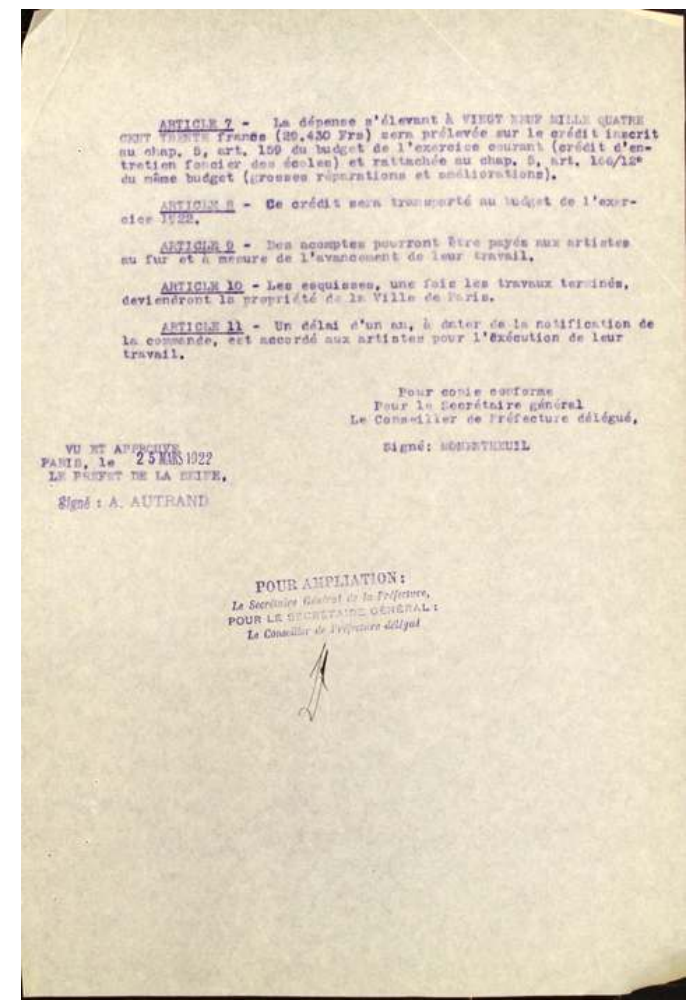

Arrêté confiant la supervision des décors à Paul Baudoüin, page 2, 25 mars 1922. Cote Archives de Paris VR 573.

Phot. service photographique des Archives de Paris. (c) Archives de Paris, 2012. 


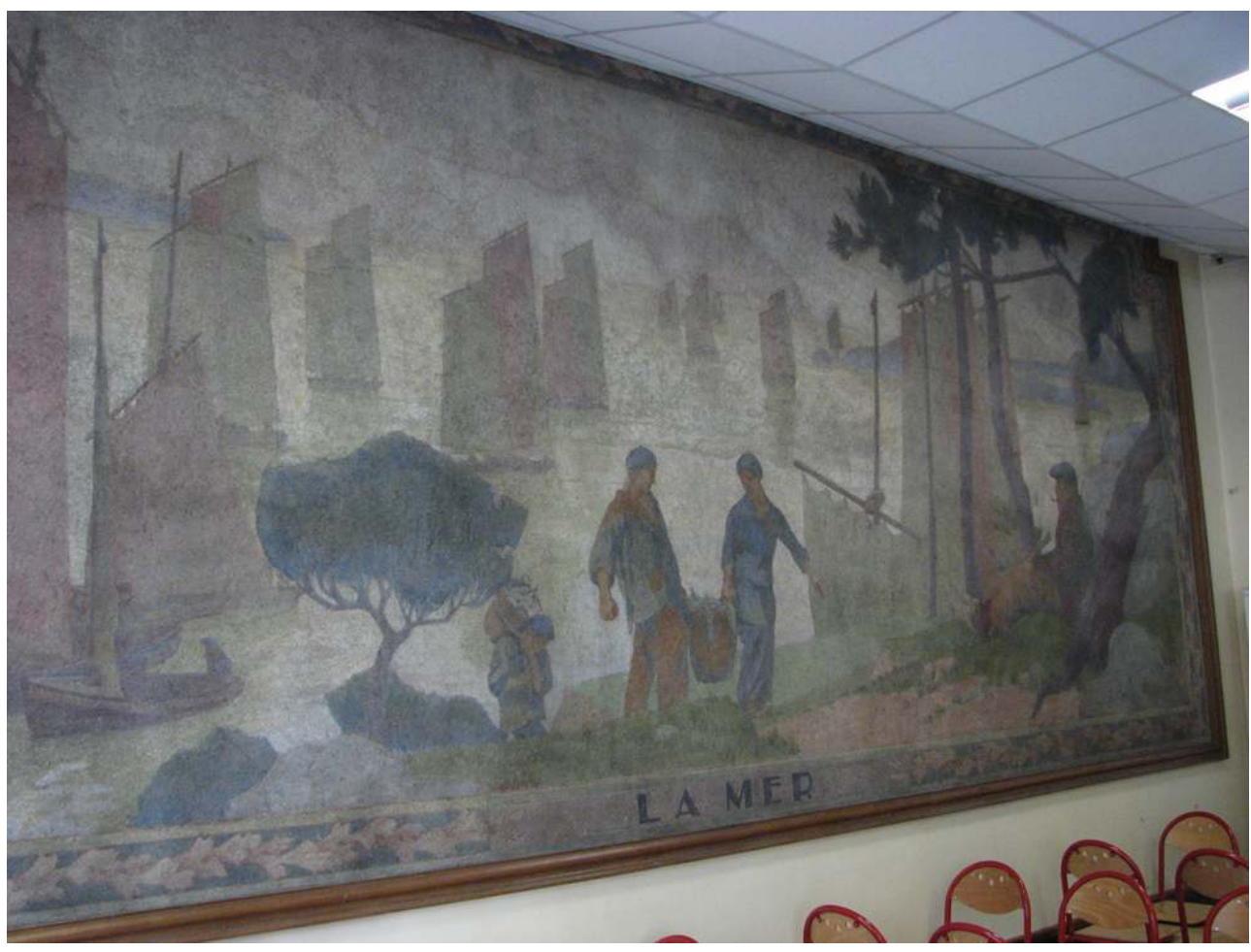

Pierre Ducos de la Haille, La mer, peinture à fresque, lycée Jean-Baptiste Lully, 1922.

Phot. Verdure, Marc, 2012. (c) Marc Verdure.

13 Si elle ne repose pas sur un socle théorique clairement exprimé, aucun rapport n'étant rendu public entre 1919 et 1930, l'ambition décorative parisienne reste pourtant bien réelle ${ }^{37}$, et les archives indiquent que l'ornementation des écoles se poursuit avec des interventions ponctuelles, comme en 1923 avec la commande à Eugène Chapleau ${ }^{38}$ du décor à fresque du préau de l'école de la rue Dussoubs (III $\left.{ }^{\mathrm{e}}\right)$ sur le thème des Fables ${ }^{39}$. Cette réalisation est probablement rendue possible par la volonté d'un élu de l'arrondissement, Rebeillard, qui mobilise les crédits et définit le programme décoratif du préau ; toutefois, sans que les archives en révèlent la raison, c'est finalement Constant Louche $^{40}$ qui signe les deux panneaux, réalisés à l'huile sur toile marouflée (fig. $\mathbf{n}^{\circ} \mathbf{1 2}$ ). 
Figure 12

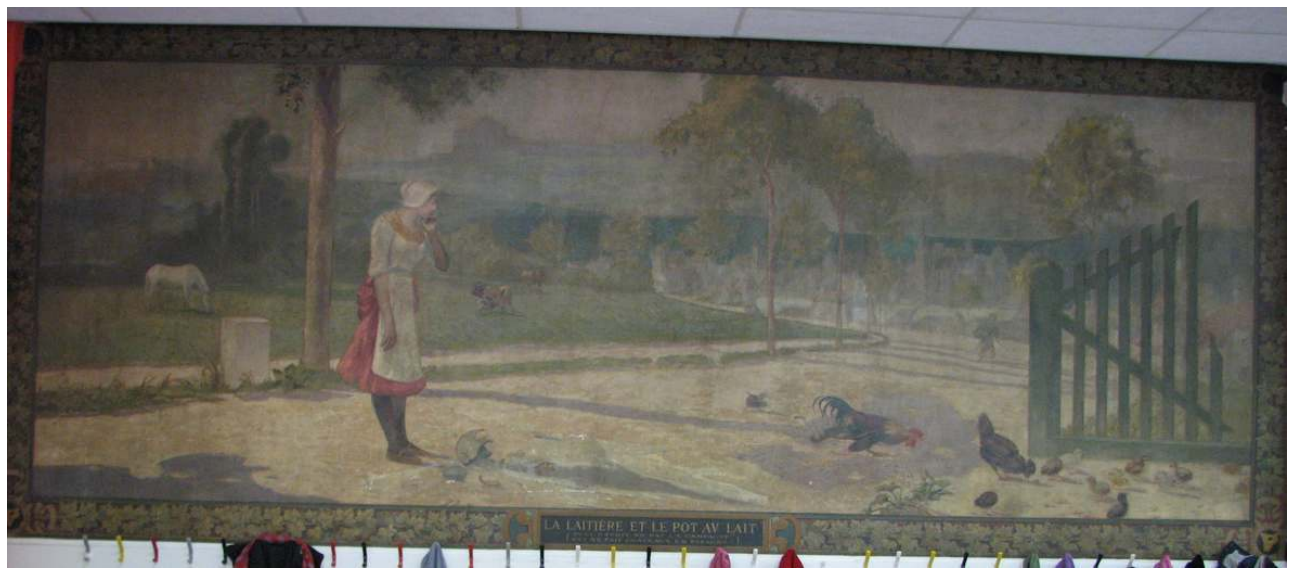

Constant Louche, La laitière et le pot au lait, huile sur toile, école de la rue Dussoubs, 1923.

Phot. Verdure, Marc, 2012. (c) Marc Verdure.

14 Au début des années 1930, peut-être du fait de la crise économique qui limite les budgets, la Ville de Paris ne finance plus les projets que mentionnent les archives. Celles-ci signalent plusieurs décors conçus par "La Fresque ", association d'artistes fresquistes fondée vers 1925 par Paul Baudoüin pour enseigner et propager l'art de la fresque. L'association propose ici ses services gratuitement, sans réclamer à la Ville aucun financement, ni honoraire ni paiement des matériaux. L'association semble avoir eu pour ambition de trouver des espaces où exercer ses élèves, et d'assurer la promotion de l'art de la fresque, les initiatives étant peu nombreuses en France.

Le préau fermé de l'école de la rue Beauregard (II $)$ est ainsi signé et daté par plusieurs artistes sur le thème des Fables de la Fontaine : Margaret Baer Austin (1930), Madeleine Massonneau (1930), membre de l'association « La Fresque », et Margaret Ann Dorson (fig. $\left.\mathbf{n}^{\circ} 13\right)$. Aucun document ne subsiste plus à propos de cette décoration, si ce n'est une lettre de Madeleine Massonneau sollicitant un emploi en 1936 et rappelant les fresques exécutées à cet endroit « avec quelques-uns de mes camarades ${ }^{41}$ ». 
Figure 13

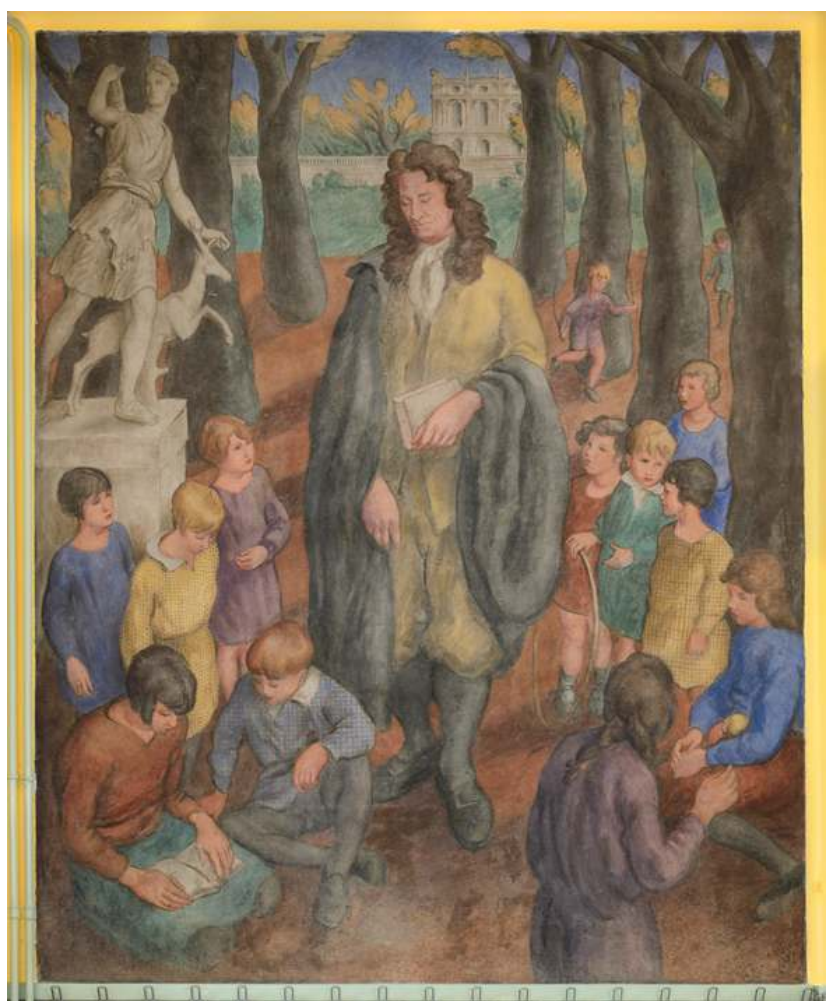

Margaret Baer Austin, La Fontaine et les enfants, peinture à fresque, école de la rue Beauregard, 1930. Phot. Pignol, Claire @ Claire Pignol / COARC / Roger-Viollet.

Les archives en disent un peu plus long au sujet du décor du préau de l'école de la rue Littré $\left(\mathrm{VI}^{\mathrm{e}}\right)$. Une note interne de l'Administration datée du 3 mars 1931 indique que Baudoüin avait proposé à la Ville de faire décorer une école par ses élèves. Le Directeur des Beaux-Arts, qui se souvient que ce dernier "a déjà orné de manière magnifique plusieurs écoles ", oriente le choix vers les écoles neuves de la rue Littré, après accord des élus locaux. Un programme décoratif, non signé et non daté, est alors conçu sur le thème "Les enfants dans la nature », au sein duquel neuf peintures doivent orner les murs et les trumeaux du vaste préau (fig. $\left.\mathbf{n}^{\mathbf{0}} \mathbf{1 4}\right)$. On sait, par la même lettre citée précédemment, que Madeleine Massonneau participe au projet mais seul est conservé le grand mur peint à fresque et signé par Myrthée Baillon de Wailly ${ }^{42}$, Les enfants et les animaux (fig. $\mathbf{n}^{\circ} \mathbf{1 5}$ ). 
Figure 14

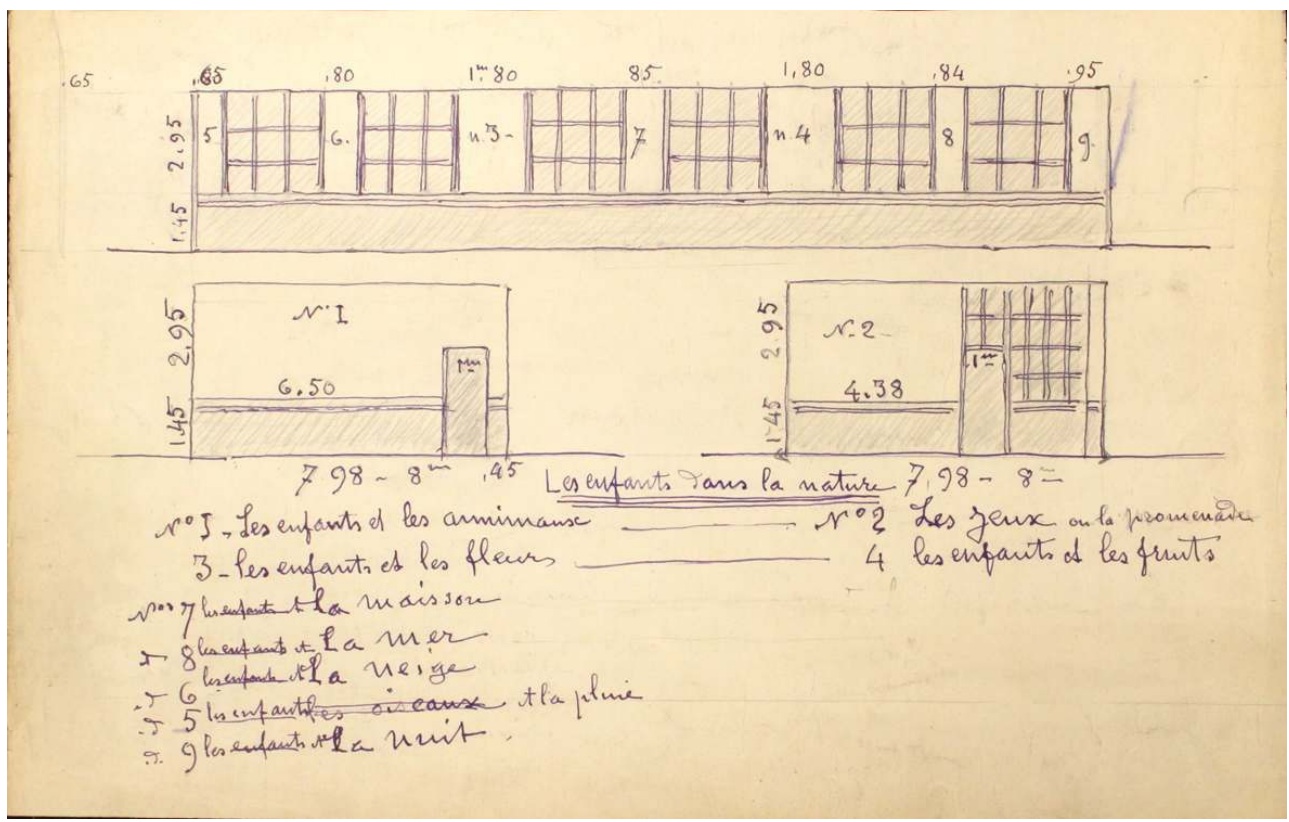

Élévation du préau de l'école de la rue Littré et programme décoratif, sans date. Cote Archives de Paris VR 573.

Phot. service photographique des Archives de Paris ( Archives de Paris, 2012.

\section{Figure 15}

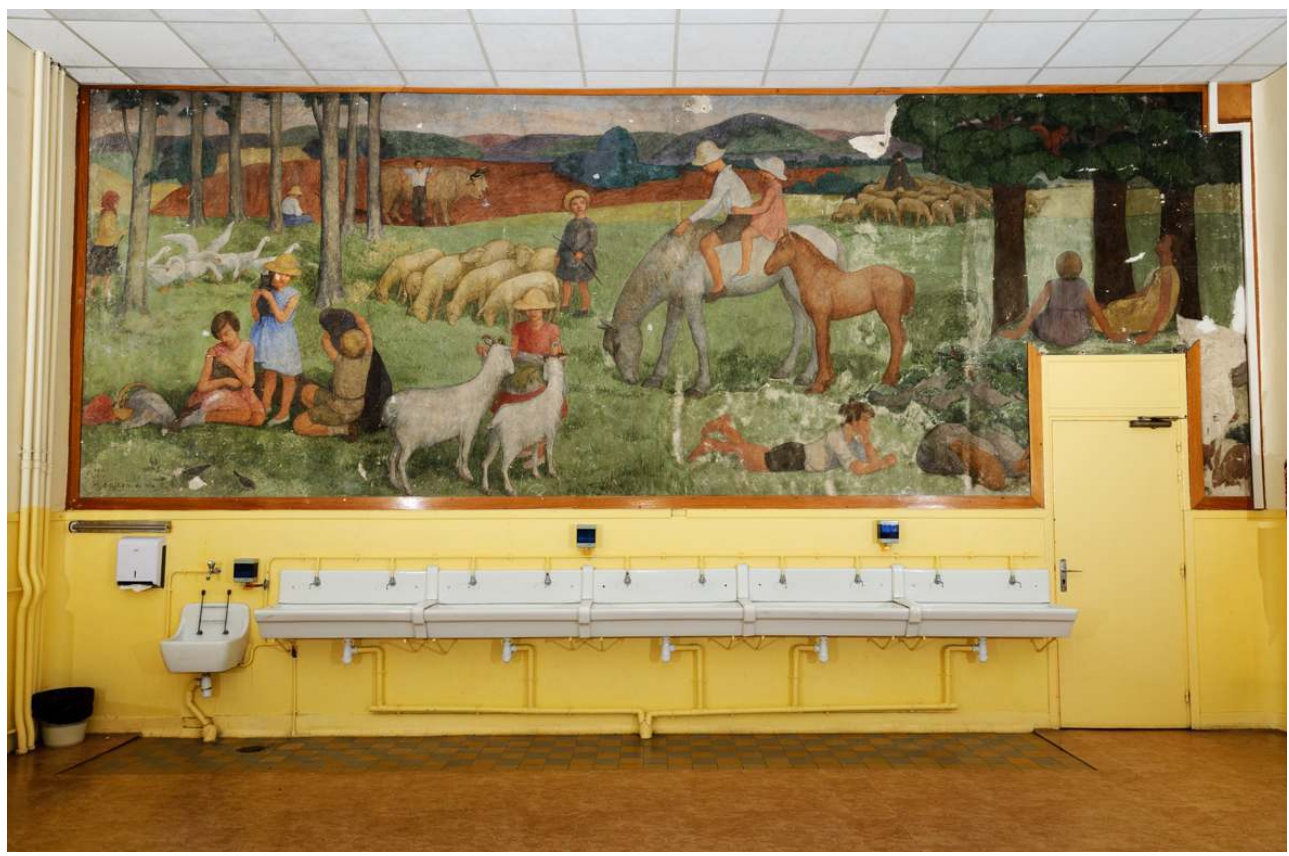

Myrthée Baillon de Wailly, Les enfants et les animaux, peinture à fresque, école de la rue Littré, après 1931.

Phot. Moser, Jean-Marc @ Jean-Marc Moser / COARC / Roger-Viollet.

17 Les sources mentionnent également un autre projet que l'on connaît par ailleurs grâce aux archives de ses créatrices, destiné au préau de l'école de filles de la rue Delambre (XIV e). C'est ici une note datée du 24 octobre 1933 du Directeur de l'Enseignement à l'endroit 
du Directeur des Beaux-Arts indiquant que Georges Pradelle ${ }^{43}$ sollicite le remboursement des frais assumés par l'association «La Fresque » pour la décoration de cette école (fourniture de chaux, sable, couleurs, pose d'échafaudage et salaire d'un maçon). Ce décor est l'œuvre de Marthe Flandrin ${ }^{44}$ et d'Élisabeth Faure ${ }^{45}$, en 1929, sur le thème de L'Italie ou la cueillette des olives ${ }^{46}$.

\section{Une réponse à la crise ? Les grands travaux et le "crédit des 10 millions »}

\section{La genèse du projet et les enjeux politiques et sociaux}

18 La crise économique frappe la France vers 1931, et les élus s'alarment rapidement de la dégradation de la situation matérielle de leurs concitoyens et électeurs, comme le révèlent les débats en conseil municipal lors de la réunion du 23 mars 1932. On peut y identifier les enjeux au cœur du processus de décision en faveur des «industries d'art, essentiellement parisiennes et dont relèvent des ouvriers d'élite, artisans, façonniers, toute cette main-d'œuvre spécialisée dont la production forme, dans son ensemble, l'article de Paris et dont la renommée est mondiale ${ }^{47}$ ». Le projet est ainsi d'agir «en protégeant cette main d'œuvre intelligente, impossible à remplacer si elle venait à disparaître et qui, pour beaucoup, a coûté un long apprentissage et des efforts constants ». Cette action est particulièrement véhémente chez les élus radicaux ou socialistes des quartiers où les artisans sont nombreux : Louis Peuch ${ }^{48}$, André Puech ${ }^{49}$ et Fernand Moriette pour le Marais, Georges Thomas ${ }^{50}$ pour Montmartre. Il faut ici en outre souligner l'influence notable d'un organisme, le « Comité intersyndical pour la protection des ouvriers et artisans d'art français ", association sans personnalité morale de représentants de chambres syndicales de métiers d'art (fig. $\left.\mathbf{n}^{\circ} \mathbf{1 6}\right)$ (fig. $\mathbf{n}^{\mathbf{0} 17}$ ). Son Président d'honneur est Georges Contenot et il est avéré que ce Comité effectue un puissant lobbying auprès des instances municipales parisiennes, en se positionnant dès 1931 comme intermédiaire entre les pouvoirs publics et les artisans, et en développant notamment l'idée du rôle de la dépense publique dans la reprise économique. 
Figure 16

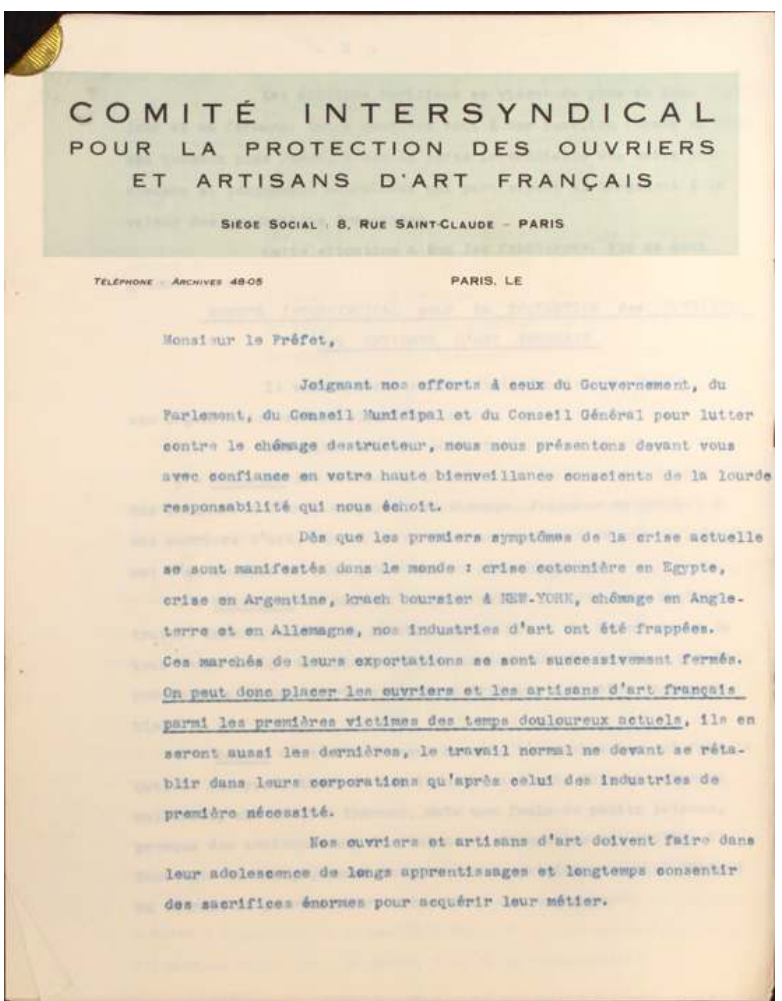

Brochure du "Comité intersyndical pour la protection des ouvriers et artisans d'art français », sans date, page 1. Cote Archives de Paris VR 589.

Phot. service photographique des Archives de Paris @ Archives de Paris, 2012. 


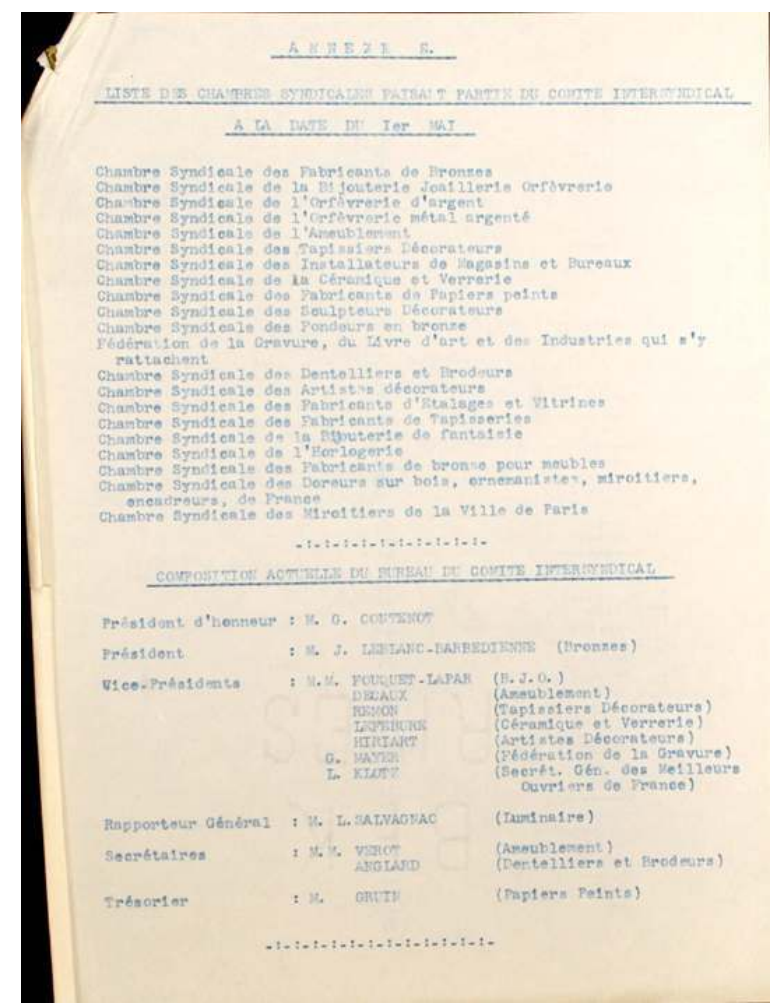

Brochure du « Comité intersyndical pour la protection des ouvriers et artisans d'art français », sans date, page d'annexe. Cote Archives de Paris VR 589

Phot. service photographique des Archives de Paris @ Archives de Paris, 2012.

Cet argument se fait jour en 1932 : les travaux d'art et d'artisanat qui seront commandés «ne constituent pas des dépenses somptuaires et inutiles... [mais] des travaux qui, en d'autres temps, se seraient répartis sur plusieurs exercices ${ }^{51} »$. Il s'agit donc de s'adapter aux circonstances dramatiques et de hâter des réalisations prévues sur de plus longues périodes. Le conseiller Eugène Fiancette ${ }^{52}$, désigné comme le « père » du projet, souligne d'ailleurs qu'en employant des ouvriers, la Ville évite le versement d'allocations chômage : " par conséquent, ce n'est pas une dépense inutile que nous faisons, c'est une dépense productive ${ }^{53} »$.

Plus tard, en 1934, à l'heure des bilans et parce que l'initiative a beaucoup plu, d'autres idées sont formulées par des élus qui veulent poursuivre la politique de commande. Plusieurs évoquent ainsi l'exercice d'un devoir social ${ }^{54}$ : acheter des œuvres, cela revient à verser une allocation de chômage. D'ailleurs, en 1932 comme en 1934, les missions de l'emprunt, les dépenses des bureaux de bienfaisance et les bourses aux artistes et scientifiques sont associées dans la même réflexion. Cette analyse se vérifie en fait tout au long de la $\mathrm{III}^{\mathrm{e}}$ République, les pouvoirs publics s'estimant dépositaires d'une responsabilité à l'égard des artistes et, à ce titre, devant être neutres en face des créations artistiques $^{55}$.

21 Le rôle pédagogique de l'art est aussi mis en valeur: accrocher des tableaux dans les écoles permet d'éveiller les enfants à l'art voire, comme le signale Jean Ferrandi ${ }^{56}$ en novembre 1934 en ce qui concerne les «tableaux coloniaux placés dans les salles de classe », sont susceptibles d'« inspirer aux enfants le goût de la vie d'outre-mer ». De 
manière également assez caricaturale, certains élus évoquent la nécessité de soutenir les professions intellectuelles dont la « grogne " pourrait fournir des cadres à la contestation de l'ordre social...

Mais c'est Léon Riotor ${ }^{57}$, fervent soutien de la "Société française de l'Art à l'école », qui trouve en 1934 les mots les plus symboliques pour définir une politique de décoration: "Je ne ferai pas l'historique de la question de la décoration des écoles (...). Jadis l'école était une sorte de lieu sans air et sans charme (...), c'était l'école-prison, puis ce fut l'école-manufacture, ce fut l'école-atelier; nous voulons maintenant l'école joyeuse et parée (...). Nous voulons que des couleurs claires accueillent l'enfant sur le seuil de l'école; son œil s'en charmera, son esprit s'en inspirera et vous aurez façonné des artisans qui non seulement porteront loin le renom français mais qui embelliront leur demeure et leurs foyers. L'école heureuse enfantera le foyer heureux. C'est une œuvre de haute moralisation que de faire d'une école triste une école gaie, une école joyeuse ${ }^{58} »$. Le vocabulaire employé, notamment la vocation morale et civique de l'entreprise, rappelle celui de Viollet-le-Duc.

\section{Les modalités d'application du projet}

Le fonctionnement de ce projet de décoration est bien documenté. Un bilan détaillé figure dans le compte-rendu des débats en Conseil municipal du 26 novembre 1934, mais plusieurs cartons aux Archives de Paris permettent de suivre assez fidèlement les prises de décisions et l'avancée des travaux ${ }^{59}$.

Votée le 21 mars 1932 par le Conseil municipal, l'autorisation d'un emprunt de 40 millions de francs fait suite à un rapport de l'administration des Beaux-Arts du 16 mars, rendu public par Georges Contenot ${ }^{60}$. Le Conseil d'État est saisi pour délibérer sur l'emprunt et donne le 7 juin un avis réservé, considérant que le programme d'opération n'est pas clair, que les dépenses ne revêtent aucun caractère d'urgence ou d'utilité et que le chômage ne sera pas efficacement combattu de cette manière, laquelle constitue d'ailleurs un précédent exploitable par les autres industries, d'autant plus risqué que les finances municipales sont « fort à l'étroit » $\left(\mathbf{f i g} \mathbf{n}^{\circ} \mathbf{1 8}\right)$. D'autres documents trahissent un échange de correspondance durant l'été entre le Conseil d'État et la Préfecture de la Seine, celle-ci insistant sur l'argument de la sauvegarde de la main d'œuvre et sur le caractère exceptionnel de la procédure. Le Conseil d'État autorise finalement l'emprunt à hauteur de 10 millions de francs, le décret du Président de la République étant daté du 15 octobre 1932. 
Figure 18

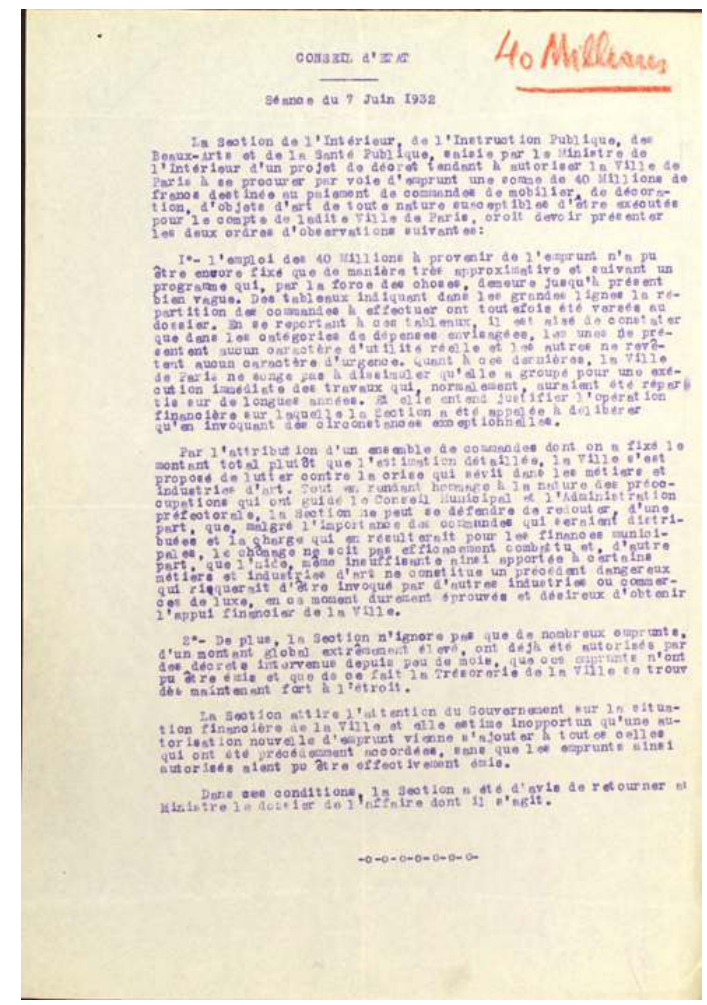

Extrait de séance du Conseil d'État, 7 juin 1932, Cote Archives de Paris VR 589 Phot. service photographique des Archives de Paris @ Archives de Paris, 2012.

Sans attendre l'autorisation d'emprunt, le Conseil municipal décide la composition d'une sous-commission ad hoc, dite «Commission d'aide à l'artisanat et aux artistes » composée de dix-sept élus, qui effectue la répartition des commandes selon le principe du concours restreint et qui se réunit pour la première fois dès le 23 avril 1932 (fig. n 19 ). Lors de cette réunion, et dans les mois qui suivent, sont essentiellement mis au point des éléments de procédure. 


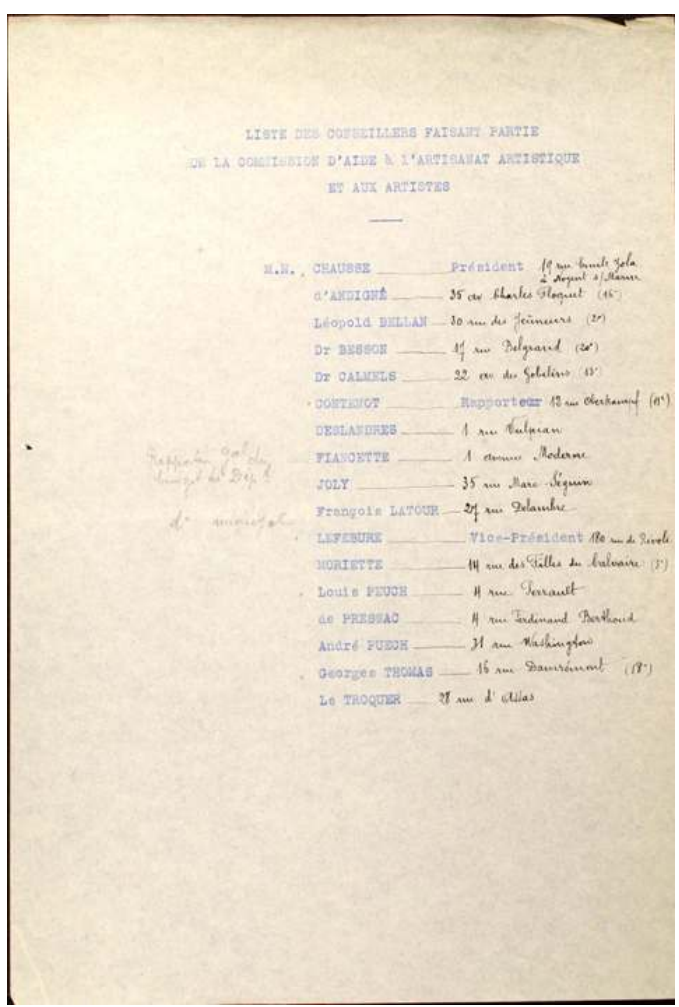

Liste des membres de la Commission d'aide à l'artisanat et aux artistes, sans date. Cote Archives de Paris VR 589

Phot. service photographique des Archives de Paris @ Archives de Paris, 2012

Pour les artisans, la Commission fait appel au « Comité intersyndical pour la protection et la défense des artisans et ouvriers d'art » déjà mentionné, qui saisit la chambre syndicale concernée (orfèvrerie, peinture, etc.). Ces chambres, organisées de façon tripartite (patrons, ouvriers, contremaîtres) et où la Confédération Générale du Travail est représentée, détermine les entreprises susceptibles d'exécuter le travail. Les artisans sont sélectionnés selon des critères d'aptitude technique et de précarité économique, et entrent ensuite en rapport avec l'architecte d'opération qui les met en concurrence sur la base de son projet décoratif. Enfin, la Ville passe avec le fournisseur choisi un marché de gré à gré.

Pour les artistes, les nombreuses associations et sociétés d'artistes ${ }^{61}$ sont sollicitées, dans le cadre d'une mise en concurrence, parfois interne même à l'association. Mais l'administration s'adresse essentiellement aux artistes qu'elle connait, probablement à travers des acquisitions lors des Salons, et en réunit plusieurs à qui elle demande des esquisses. La Ville s'engage, lors de sa pré-sélection, à tenir compte du talent et de la situation matérielle de l'artiste: seront notamment exclus les salariés, titulaires d'enseignements ou de charges rémunératrices, pour privilégier les artistes compétents et "nécessiteux ». Lorsque, le 12 avril 1933, le Directeur des Beaux-Arts présente son choix d'artistes pressentis pour concourir sur chaque projet, il souligne clairement qu'il n'a pas été dicté en fonction des recommandations politiques qu'il pourrait recevoir...

La Commission exige par ailleurs que, dès le lancement du concours, les artistes concurrents entrent en relation avec l'architecte d'opération, « de façon à harmoniser la 
décoration picturale avec l'architecture » (réunion du 12 avril 1933) ; le lien avec l'édifice est de toute façon consolidé avec la présence, au sein de la Commission, de l'architecte d'opération, qui restera en relation avec l'artiste lauréat. C'est sur la base de ces documents préparatoires que la Commission tranche. Le souci de salut social occupant les pensées des élus, les candidats malheureux des concours restreints reçoivent un dédommagement compris entre 500 et 1000 francs. En outre, la Commission incite les lauréats à constituer des équipes, pour aller plus vite et donner du travail au plus grand nombre.

Le programme municipal de travaux qui accompagne le rapport de mars 1932 est élaboré par la Direction des Beaux-Arts et la Direction des services d'architecture et des promenades. S'agissant des écoles, les édifices étant pour la plupart à peine achevés ou encore en cours de construction, il est facile de consulter l'architecte pour obtenir plans, croquis ou encore souhaits de collaborations artistiques. Dans un premier temps, l'administration produit ainsi des propositions de décors répartis en plusieurs thématiques: "peintures artistiques et d'ornement», "sculptures artistiques et d'ornement ", "vitraux neufs », "staffs, stucs, dorures ", "mosaïques, céramiques», "fers forgés, bronzes ", "treillages ", avec à chaque fois une estimation de la surface à décorer et du montant de l'opération (fig. $\mathbf{n}^{\circ} \mathbf{2 0}, \mathbf{n}^{\circ} 21, \mathbf{n}^{\circ} 22$ ).

Figure 20

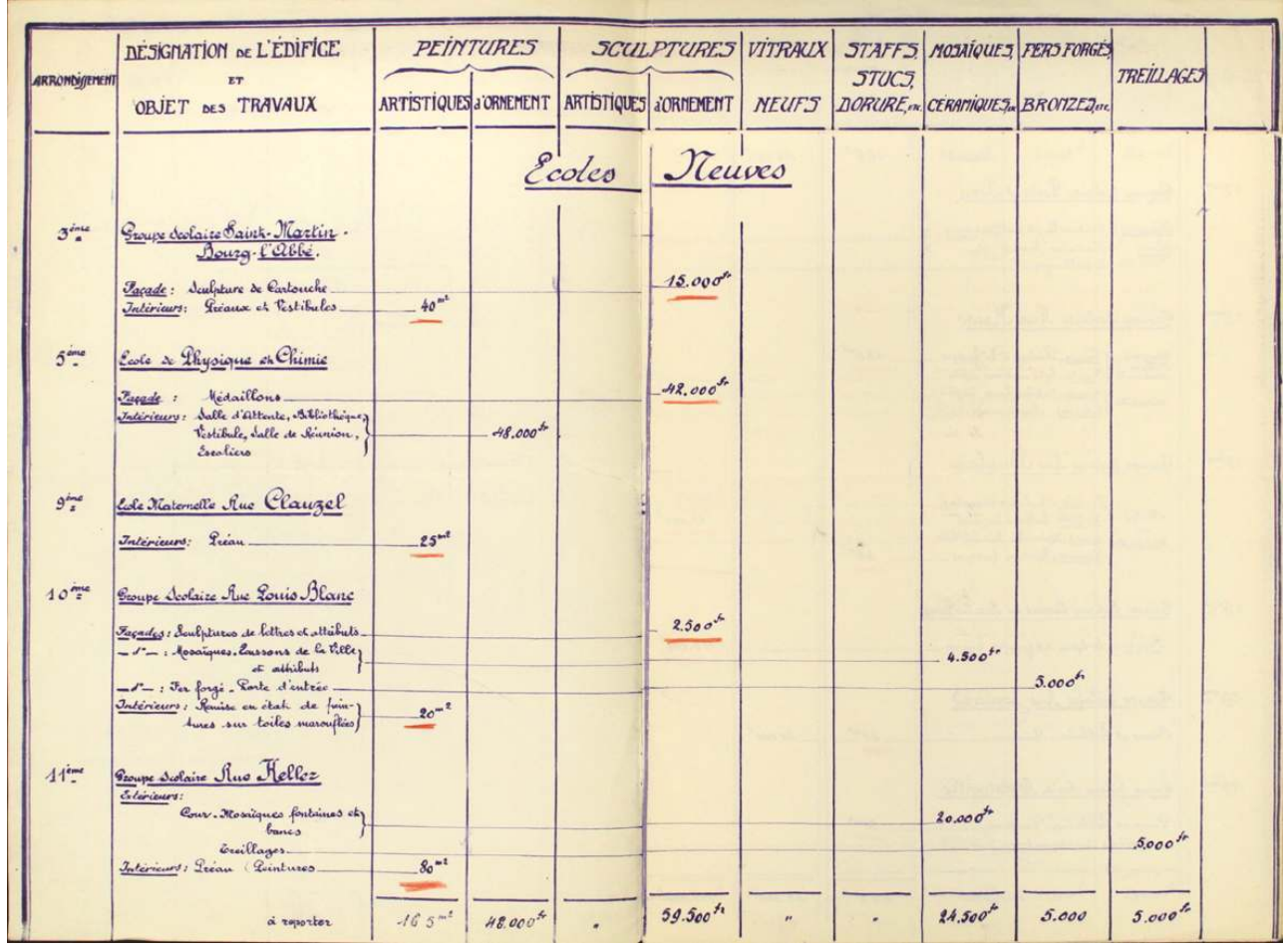

Tableau récapitulatif des projets de décor, sans date, page 1. Cote Archives de Paris VR 588.

Phot. service photographique des Archives de Paris (c) Archives de Paris, 2012. 
Figure 21

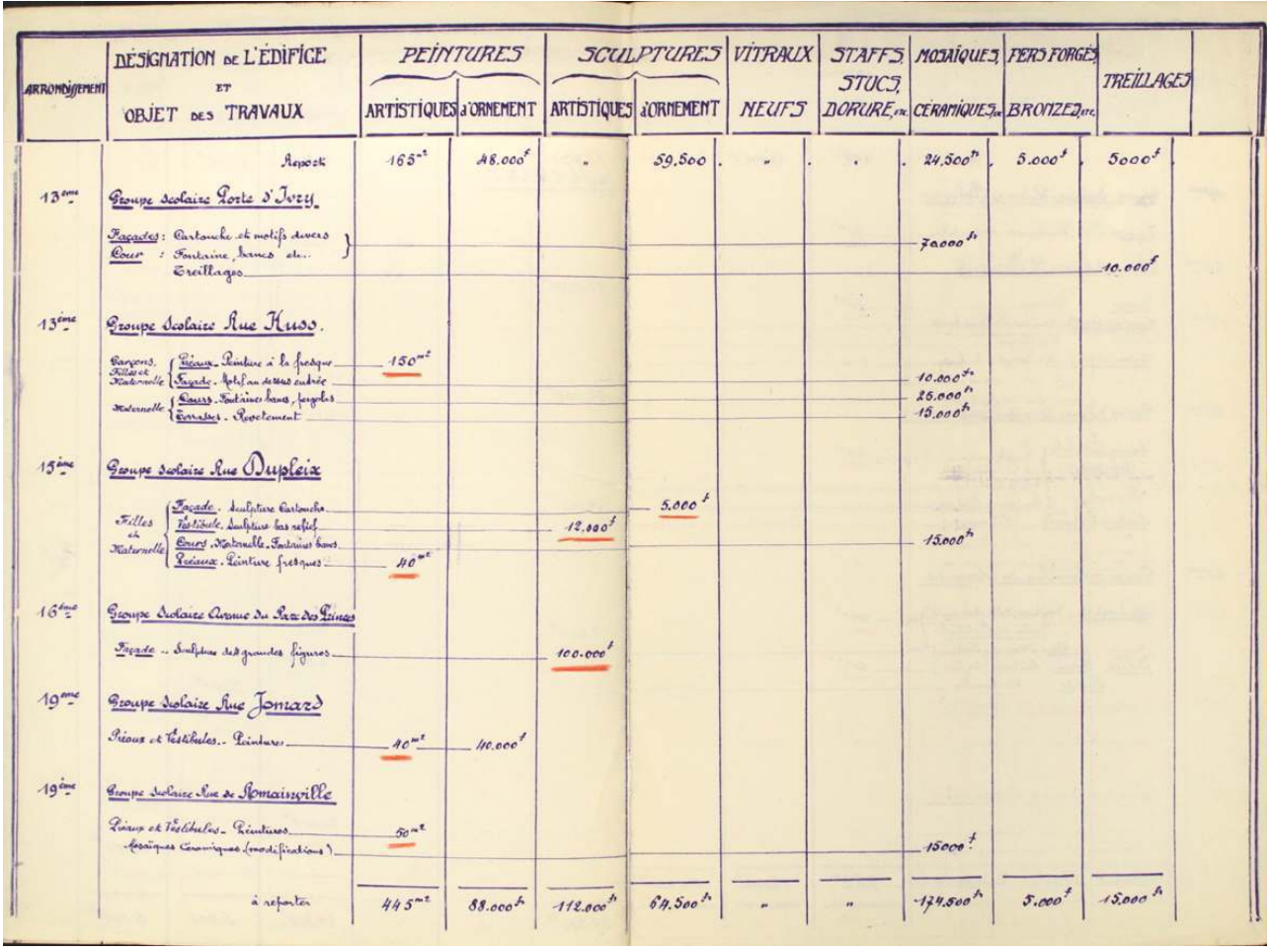

Tableau récapitulatif des projets de décor, sans date, page 2. Cote Archives de Paris VR 588.

Phot. service photographique des Archives de Paris (c) Archives de Paris, 2012.

\section{Figure 22}

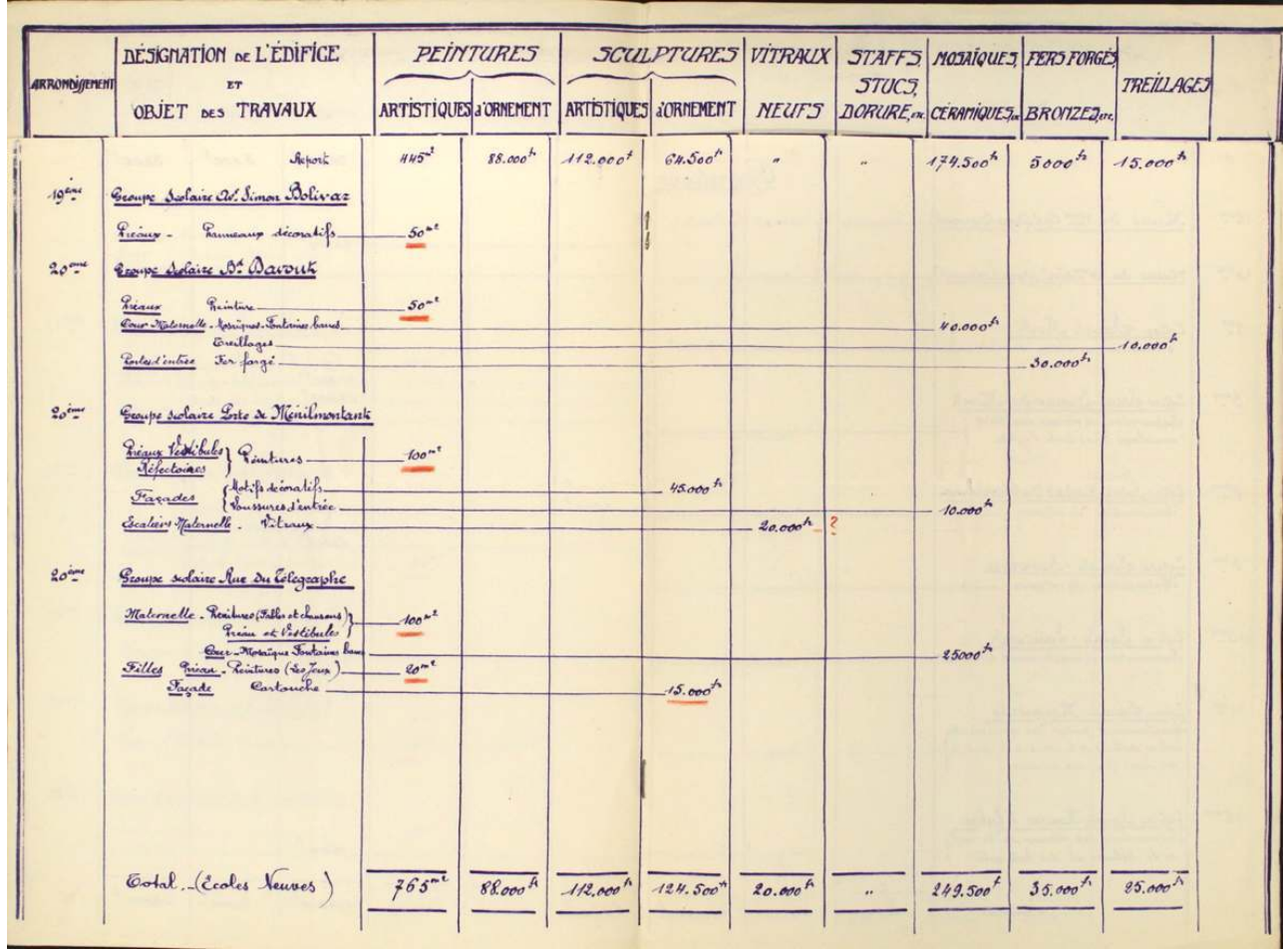

Tableau récapitulatif des projets de décor, sans date, page 3. Cote Archives de Paris VR 588.

Phot. service photographique des Archives de Paris @ Archives de Paris, 2012. 
cix des artistes et des sujets à figurer débute réellement, au sein de la Commission, lors de la réunion du 12 avril 1933 : après avoir présenté un choix d'artistes à départager pour chaque décor, le Directeur des Beaux-Arts propose une liste de sujets couvrant un vaste répertoire: "Fables de La Fontaine; Contes de Perrault; Paysages de France; Travaux de l'été, de l'hiver, etc.; Métiers parisiens (du quartier de l'école quand c'est possible); Le travail et les jeux; La mer, la montagne, les champs, les fleuves; Vieux costumes régionaux vus dans le pays; Les sports (ceux qui ne datent pas) : course, natation, rugby, boxe, aviron, etc. ; L'eau, le feu, l'air, la terre ».

Parmi les décisions affectant l'ensemble des projets de décors muraux dans les écoles, deux d'entre elles méritent d'être relevées. Le 12 juillet 1933, peut-être en raison de certains désaccords constatés sur le terrain, le Directeur des Beaux-Arts demande à la Commission de délibérer sur le rôle des conseillers municipaux dans le choix de l'esquisse qui décorera l'école de leur secteur: après discussion, la Commission décide de " commencer le travail malgré un avis défavorable d'un conseiller intéressé ». On verra que ce choix n'est pas si facilement appliqué.

En outre, le 4 octobre 1933, un débat nait au sujet du forfait payé aux artistes fresquistes : la Ville avait calculé ses estimations à partir de 750 francs le $\mathrm{m}^{2}$, mais beaucoup d'artistes se plaignent de frais supplémentaires : ciment, salaires de maçons, coût de la préparation des murs et des échafaudages, et demandent d'élever le prix à 1000 francs le $\mathrm{m}^{2}$. L'architecte en chef de la Ville, Gaston Lefol, fait valoir que les architectes ont déjà effectué les travaux préparatoires pour faciliter l'intervention des artistes, ces derniers devant se charger des enduits. Le prix initial est finalement maintenu ${ }^{62}$.

Une fois la décision d'attribution prise par un décret global le 4 août 1933, la Commission continue son travail grâce aux rapports réguliers du Directeur des Beaux-Arts qui suit l'exécution des décors. La dernière opération s'achève en janvier 1934 et le dernier compte-rendu de la Commission est daté du 2 mai 1934.

\section{Les chantiers}

\section{École du 211 , rue Saint-Martin (IIle arrondissement)}

Après une visite de la Commission des Beaux-Arts, André Berry, architecte de l'opération, envoie un rapport le 11 février 1933 au Service Technique d'Architecture qui fait état de « divers emplacements pour ouvrages décoratifs à confier à des artistes ou à des artisans d'art » dans le préau, dans la bibliothèque et au-dessus du portail d'entrée ${ }^{63}$ et produit les plans à remettre aux artistes et artisans pour qu'ils exécutent leurs projets et maquettes et pour "que les apprêts qui pourraient être nécessaires à l'application des ouvrages décoratifs puissent être faits en temps utile» (fig. $\mathbf{n}^{\circ} \mathbf{2 3}$ ). 


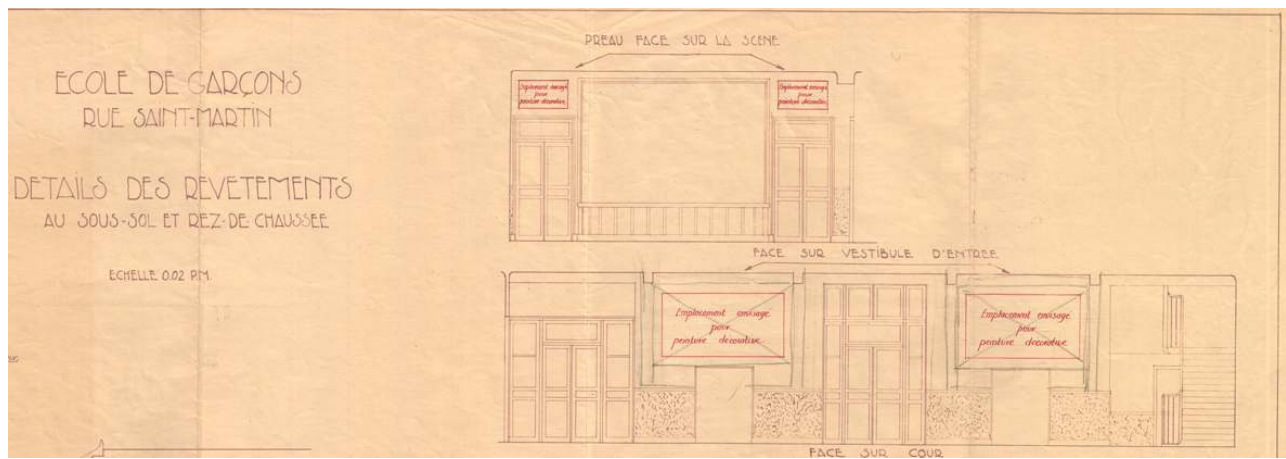

École de garçons rue Saint-Martin : détail des revêtements, sans date. Cote Archives de Paris VR 594 Phot. service photographique des Archives de Paris @ Archives de Paris, 2012.

Le 12 avril 1933, le Directeur des Beaux-Arts propose plusieurs artistes pour concourir (Hugues de Beaumont ${ }^{64}$, Jean Julien ${ }^{65}$, Clément Serveau ${ }^{66}$ et Roger Picard ${ }^{67}$ ) et indique que le sujet choisi, avec le conseiller municipal Louis Peuch, est «l'activité nationale : travaux de la campagne, mines, etc. » Lors de ce débat, Georges Contenot souligne qu' « un tableau pourrait représenter le Port de Marseille, porte de l'Orient et de nos colonies, [et] expliquerait aux enfants que la France ne s'arrête pas là et que par les différents débouchés qu'elle possède il est facile de se rendre dans ces possessions lointaines. Pour le Nord, on représentera le travail métallurgique, les mines de charbon, etc. Enfin, une vue du plateau central avec les bergers et les troupeaux, complèterait cet ensemble. »

Le 29 juin 1933, c'est le projet de Jean Julien qui est adopté, sous réserve de fournir de nouvelles maquettes de dessus-de-porte " qui n'aient pas un air $18^{\mathrm{e}}$ siècle »; les esquisses conservées par la Ville montrent en effet que les dessus-de-porte ont largement recours aux puttis joufflus, supprimés par l'artiste qui recompose entièrement son œuvre dans un second temps. L'arrêté est pris le 4 août : les candidats refusés reçoivent 1000 francs et le lauréat obtient la somme de 37500 francs et un délai de cinq mois pour réaliser, à l'huile sur toile marouflée, les décors. En définitive, seuls les sujets sur Marseille et sur les travaux des champs occupent les deux grands panneaux, alors que les quatre dessus-deporte représentent des natures mortes sur le thème des fruits de la terre et de la mer : les vendanges, la chasse, la moisson, la pêche (fig. $\left.\mathbf{n}^{\circ} \mathbf{2 4}\right)$ (fig. $\left.\mathbf{n}^{\circ} 25\right)$. 


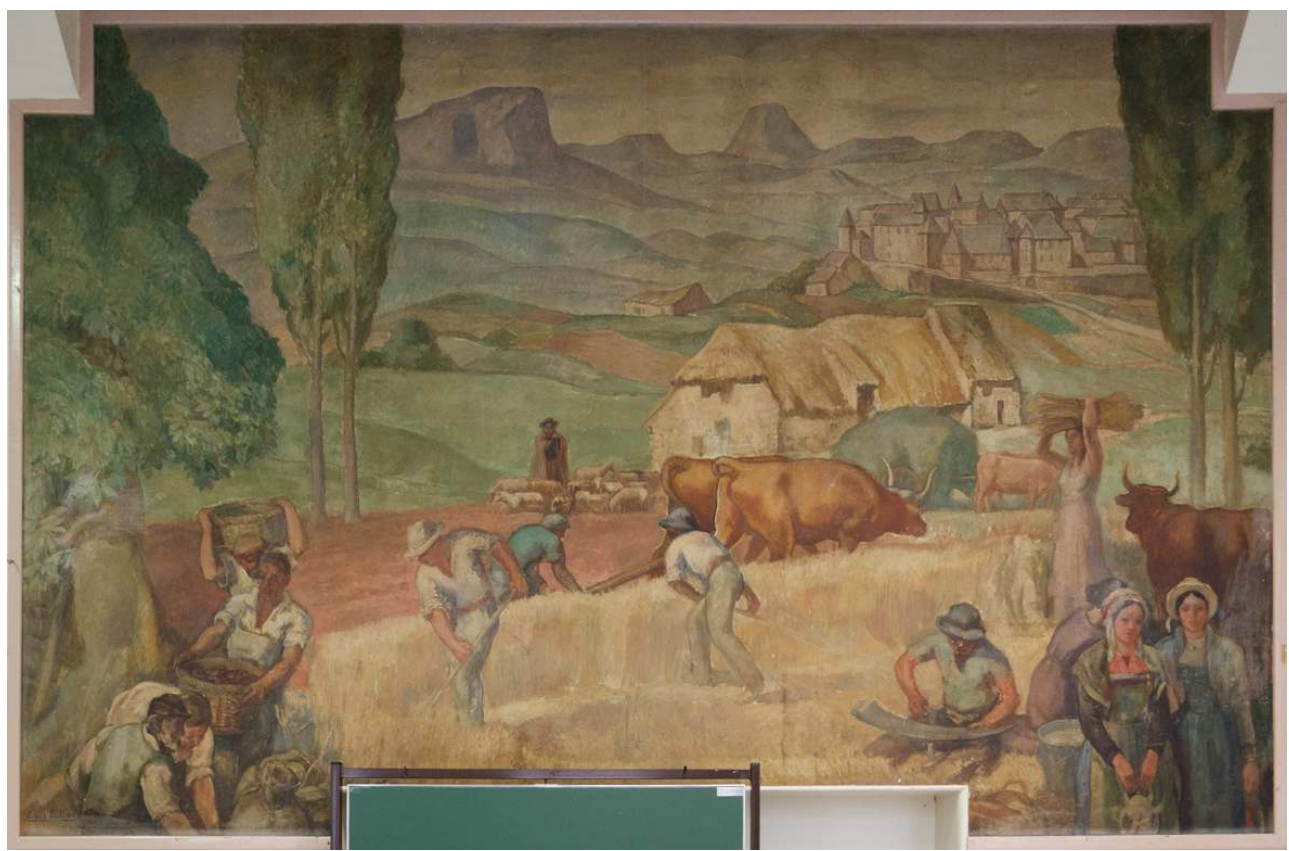

Jean Julien, Les travaux des champs, huile sur toile marouflée, 1933.

Phot. Pignol, Claire @ Claire Pignol / COARC / Roger-Viollet

\section{Figure 25}

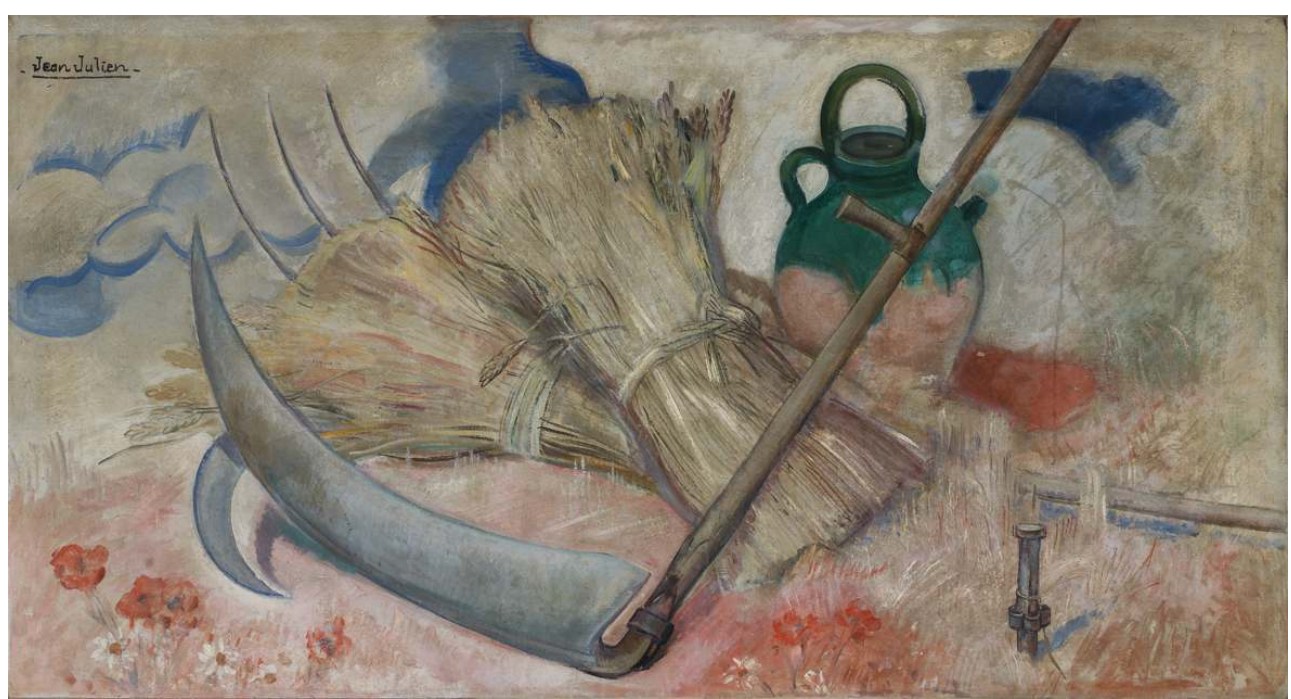

Jean Julien, La moisson (dessus-de-porte), huile sur toile marouflée, 1933.

Phot. Pignol, Claire (c) Claire Pignol / COARC / Roger-Viollet.

\section{École de filles de la rue Clauzel (IXe arrondissement, disparu)}

37 La transformation de l'école de filles de la rue Clauzel est confiée à Germain Debré. Le 12 avril 1933, le Directeur des Beaux-Arts apporte à la Commission le projet suivant, avec l'accord de l'architecte qui fournit une esquisse : « peindre une frise décorative autour du préau. Le sujet choisi, «Les jouets », peut être très intéressant à condition d'y mêler les 
enfants. » Deux spécialistes du jeu, de l'humour et de la conception de jouets sont invités peu après à proposer des esquisses : Henri Avelot ${ }^{68}$ et André Hellé ${ }^{69}$. Toutefois, le concours ne donne pas lieu à sélection car les deux projets sont retenus le 29 juin et l'arrêté du 6 août 1933 charge les deux artistes conjointement de la commande ; la technique choisie est la peinture sur toile marouflée et les dimensions sont les suivantes : $20 \mathrm{~m}$ de long sur $80 \mathrm{~cm}$ de large, soit $16 \mathrm{~m}^{2}$; logiquement, le prix proposé devrait être de 12000 francs pour l'ensemble mais les artistes semblent avoir négocié un arrangement plus favorable, chacun empochant la somme de 12000 francs, chiffrant ainsi l'opération à 24000 francs. Le délai est de cinq mois, et les deux lauréats s'entourent de collaborateurs: Maurice Marque, $\mathrm{M}^{\text {elle }}$ Chambon, Ch. Jedry, Roger Mallard. Ce décor a disparu dans les années 1970.

\section{Groupe scolaire du 8, rue Küss (XIIle arrondissement)}

La présentation du projet de décor à fresque a lieu le 12 avril 1933 par le Directeur des Beaux-Arts. Ce dernier propose trois artistes (Pierre Girieud ${ }^{70}$, Maurice Barbey ${ }^{71}$, JulesLouis Moreteau ${ }^{72}$ ) pour concourir sur le préau de l'école maternelle, alors que celui des filles pourrait être confié «à l'école de fresques; [avec] Zingg qui dirige maintenant l'école de Baudoin, je crois que nous aurions toutes les garanties désirables. » Ce choix est validé par la Commission, mais les sujets restent à déterminer.

\section{Figure 26}

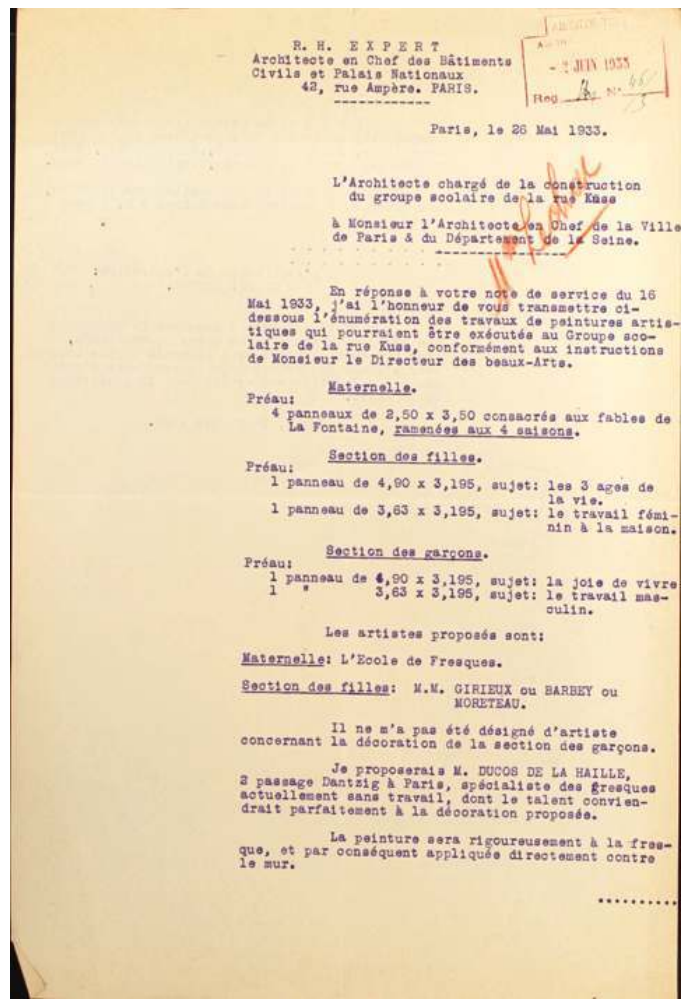

Énumération des travaux de peintures artistiques qui pourraient être exécutés au Groupe scolaire de la rue Küss, 26 mai 1933. Cote Archives de Paris VR 594.

Phot. service photographique des Archives de Paris @ Archives de Paris, 2012. 
Le 26 mai 1933, l'architecte Roger-Henri Expert transmet à l'Architecte en chef de la Ville et du Département « l'énumération des travaux de peintures artistiques qui pourraient être exécutés au Groupe scolaire de la rue Küss conformément aux instructions de M. le Directeur des Beaux-Arts » (fig. $\mathbf{n}^{\circ} \mathbf{2 6}$ ). Expert définit les espaces, en l'occurrence des préaux, fournit les dimensions, propose les sujets, répartit les artistes selon un ordre différent de celui de l'administration et définit le format des esquisses (sur carton, sans sous-verre, échelle 0,1 pour mètre, à l'huile, à la gouache ou à la détrempe) ${ }^{73}$.

Figure 27

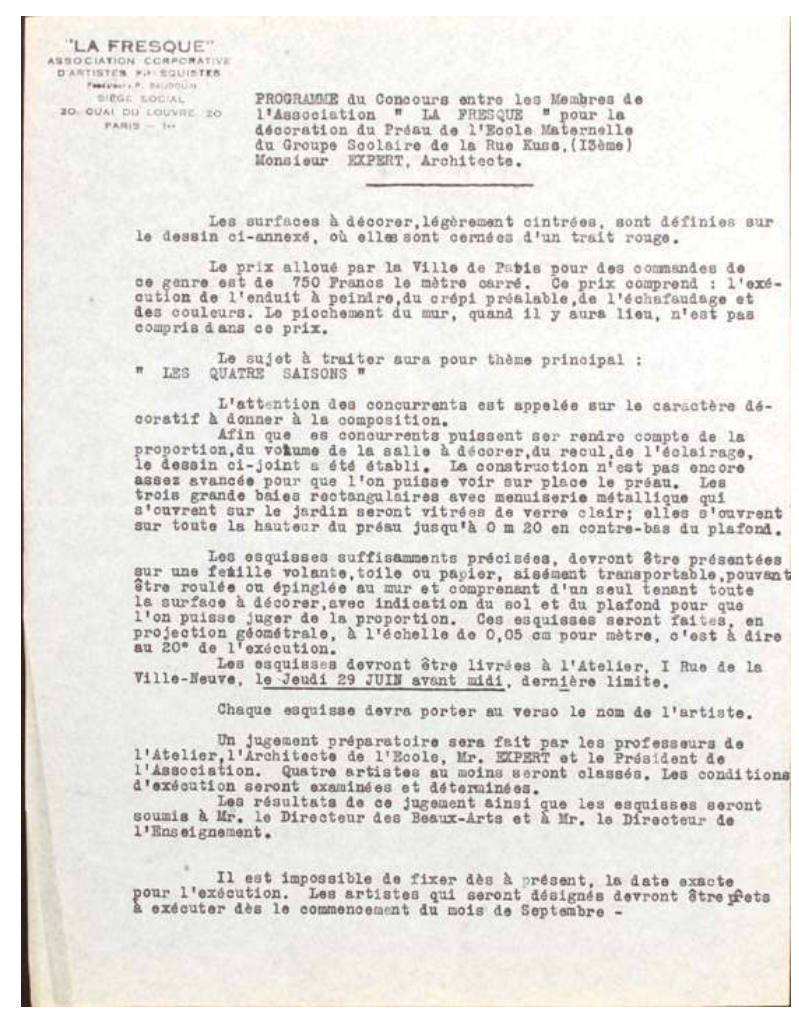

Programme du Concours entre les membres de l'Association « La Fresque » pour la décoration du préau de l'école maternelle rue Küss, 1933. Cote Archives de Paris VR 594.

Phot. service photographique des Archives de Paris ( $)$ Archives de Paris, 2012. 


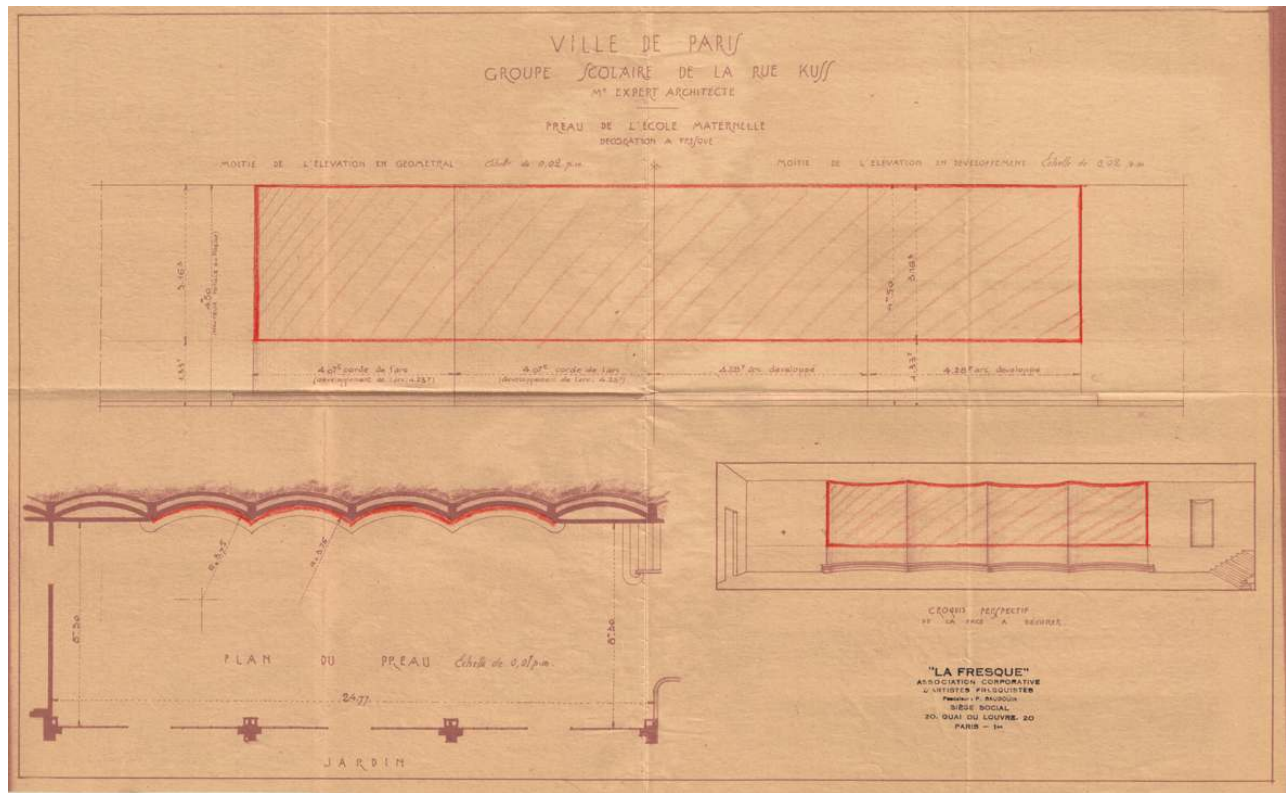

Plan et élévation du préau de l'école maternelle rue Küss, 1933. Cote Archives de Paris VR 594.

Phot. service photographique des Archives de Paris (c) Archives de Paris, 2012

Sollicitée pour le décor du préau de l'école maternelle, «La Fresque $»^{74}$ organise un concours interne : le 8 juin 1933, Georges Pradelle, son directeur, écrit au Directeur des Beaux-Arts pour le remercier et l'informer des modalités du concours : seuls les artistes domiciliés à Paris ou dans le département de la Seine et dépourvus de travail salarié ou de commande pourront participer. Pradelle s'engage à fournir les esquisses et résultats du jugement préparatoire le $1^{\text {er }}$ juillet suivant. Le dossier conserve encore le programme du concours pour le décor de l'école maternelle, ainsi qu'un plan destiné à renseigner les artistes (fig. $\mathbf{n}^{\circ} \mathbf{2 7}$ ) (fig. $\mathbf{n}^{\circ} \mathbf{2 8}$ ). La réunion de la Commission du 12 juillet 1933 examine les projets et tranche en faveur de celui de Myrthée Baillon de Wailly, avec l'accord de l'architecte ${ }^{75}$. Celle-ci sera aidée de Charles Lesacq, René Anxolabehere et Raymond Weill 76. Par arrêté du 4 août 1933, le groupement obtient la commande, payée 26250 francs, pour un délai de cinq mois à compter du 6 août (fig. n²9). 


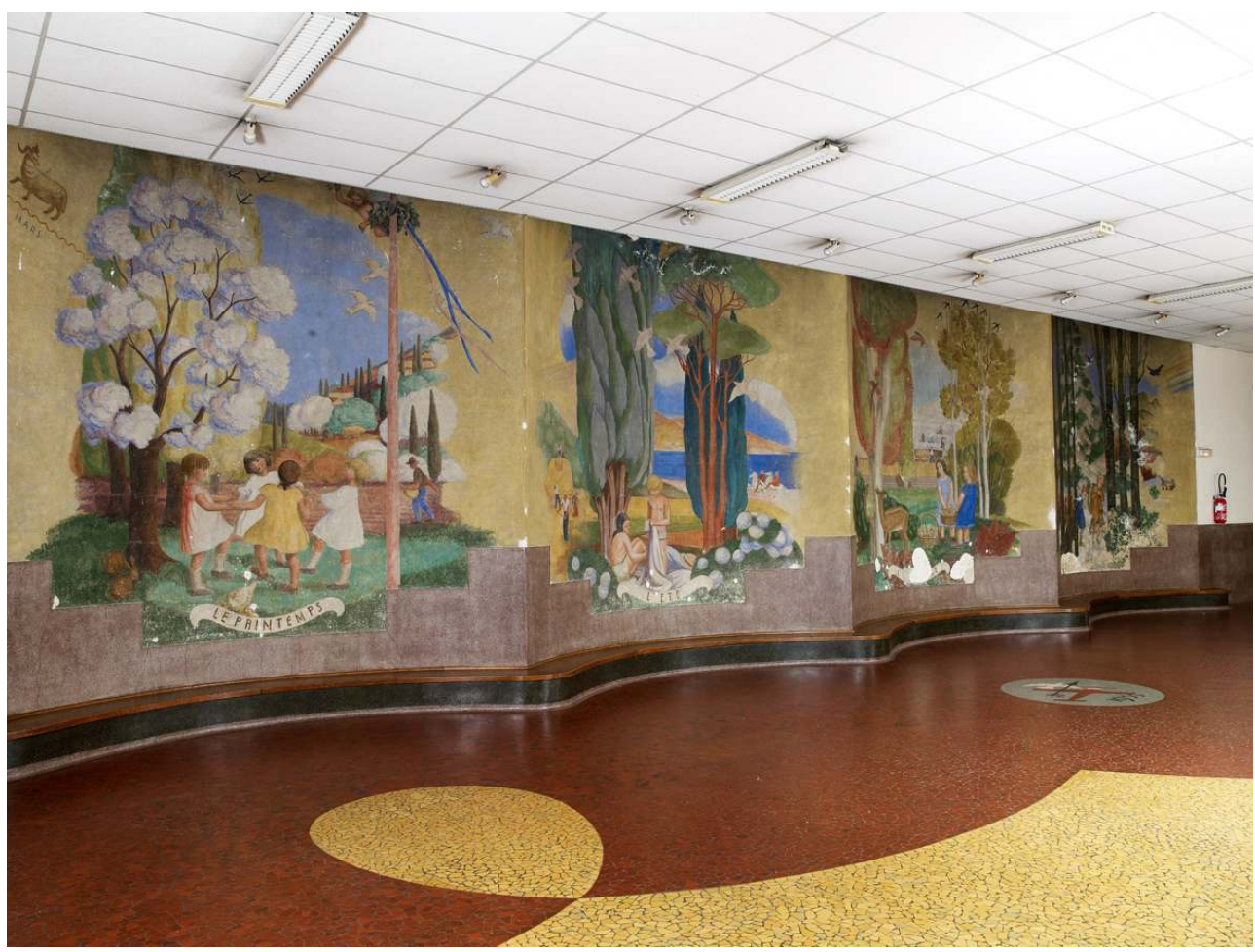

Vue d'ensemble du préau de la maternelle, école de la rue Küss.

Phot. Moser, Jean-Marc (c) Jean-Marc Moser / COARC / Roger-Viollet.

41 Concernant l'école de filles, sur le thème du "Travail féminin ", le projet a moins de réussite. Le concours organisé entre Pierre Girieud, Maurice Barbey et Moreteau permet la désignation, le 12 juillet, de ce dernier comme lauréat, pour la somme de 20625 francs, malgré la préférence de l'administration pour Girieud "peut-être le premier fresquiste français de notre temps » selon le Directeur des Beaux-Arts. Les deux candidats refusés reçoivent une prime de 1000 francs mais une longue maladie de l'artiste, ajoutée à la perte de ses esquisses par l'administration, ralentissent et annulent finalement le chantier.

Enfin, le concours pour le décor du préau de l'école des garçons réunit des projets de Constant Le Breton ${ }^{77}$ et Jean Adler ${ }^{78}$ sur les thèmes des Âges de la Vie et du Travail masculin. Robert Pougheon ${ }^{79}$, sollicité par le Directeur des Beaux-Arts, décline l'offre de participer au concours, soulignant qu'il est non seulement membre du jury pour l'école maternelle en tant que professeur au sein de l'association «La Fresque » mais aussi que «la Ville de Paris se doit de penser à [son] existence de peintre autrement qu'en [le] faisant entrer en compétition pour œuvrer hâtivement dans une partie de bâtiment à destination aussi domestique qu'un lavabo d'école primaire de garçons ${ }^{80}$ ». L'examen des esquisses a lieu le 12 juillet et Jean Adler emporte l'adhésion du jury. Un arrêté du 4 août lui attribue la somme de 20625 francs pour la réalisation de deux panneaux, dans un délai de cinq mois, alors que Le Breton est gratifié de 1000 francs. Le 25 janvier 1934, Adler écrit au Directeur des Beaux-Arts que le Travail des hommes est terminé et que les Trois âges de la vie est en cours et sera achevé sous dix jours. À la demande de l'administration probablement soucieuse du retard (dont il s'excuse), Adler a dû prendre un collaborateur, en la personne d'Étienne Hauville. La copie d'un courrier d'Expert à Adler daté du 
22 octobre 1934 nous apprend que ses fresques ont été très appréciées à l'inauguration (fig. $\mathbf{n}^{\circ} \mathbf{3 0}$ ).

Figure 30

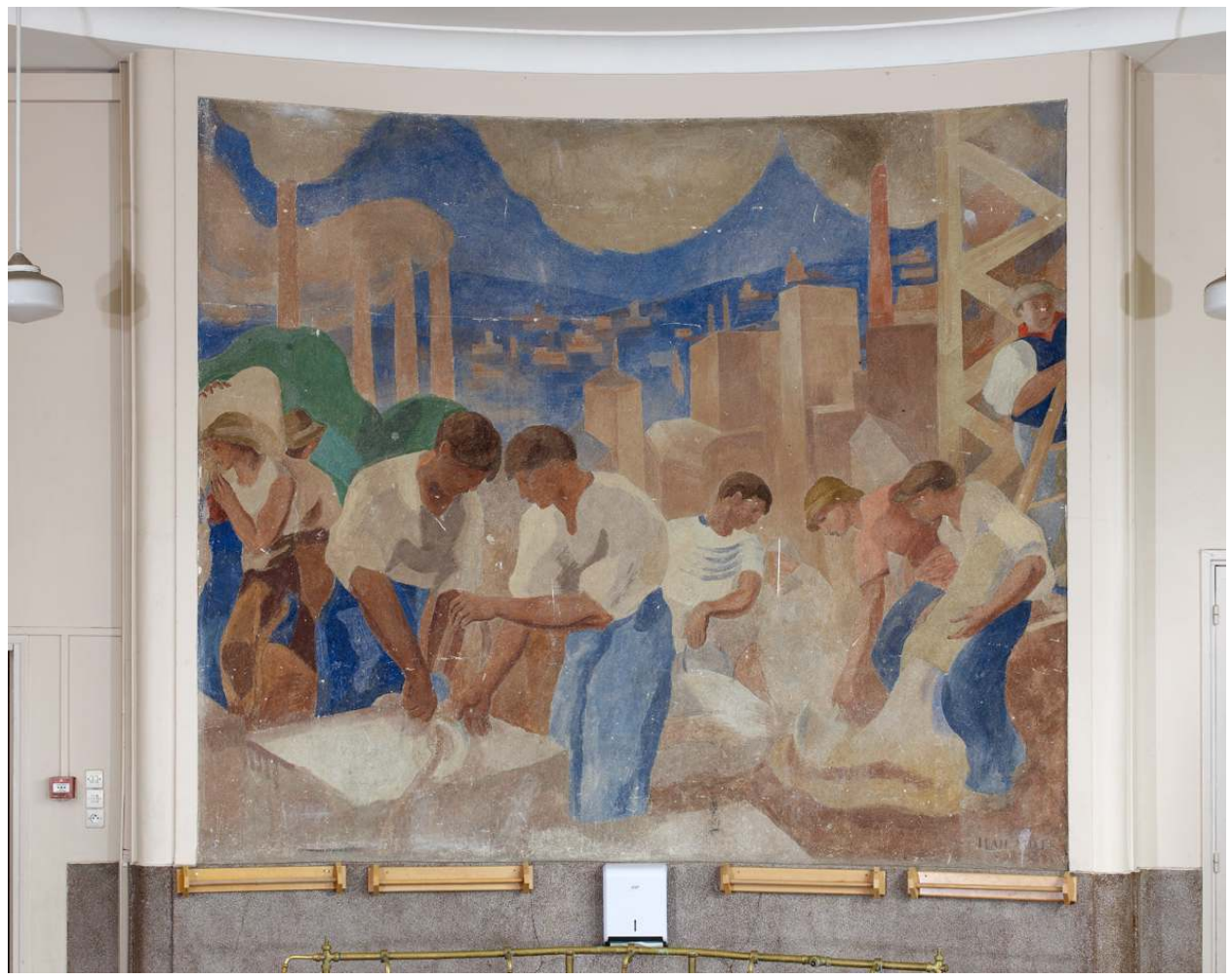

Jean Adler, Le travail des hommes, peinture à fresque, 1933, école de la rue Küss.

Phot. Moser, Jean-Marc (C) Jean-Marc Moser / COARC / Roger-Viollet.

\section{Groupe scolaire du 21, rue Dupleix (XVe arrondissement, disparu)}

Le 12 avril 1933, l'administration, d'accord avec l'architecte, opte pour un décor à la fresque pour le préau de l'école de filles, qui voit concourir Jean-Robert La Montagne Saint-Hubert, Louis Dussour ${ }^{81}$ et Constantin Font ${ }^{82}$. Les emplacements ${ }^{83}$ et les sujets sont proposés le 26 mai par l'architecte d'opération, Édouard Boegner, soutenu par l'architecte en chef de la Ville, Gaston Lefol : « pour les quatre panneaux, les artistes représenteront des scènes d'école dans les Colonies Françaises : pour le premier, un maître arabe entouré de ses élèves accroupis sur le sol; pour le second, une classe au Sénégal; pour le troisième, une classe à Tahiti; pour le quatrième, une classe en Indo-Chine » (fig. $\left.\mathbf{n}^{\circ} \mathbf{3 1}\right)$. Les deux architectes avaient préalablement obtenu l'aval du conseiller municipal, André Boulard. La suite du projet montre cependant que le sujet est retenu d'après la liste proposée antérieurement par le Directeur des Beaux-Arts (la mer, la montagne, les champs, les fleuves). 


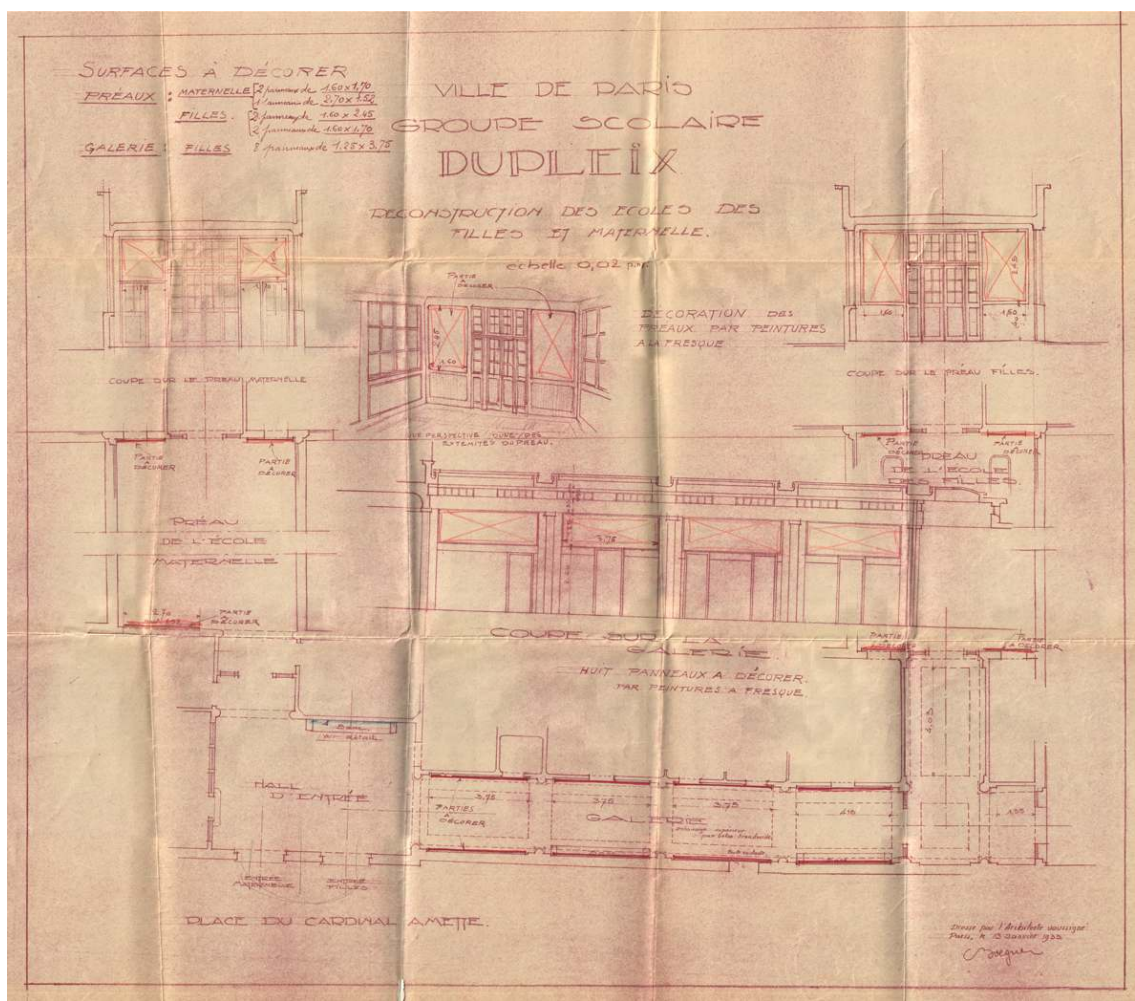

Plans et élévation du préau de l'école de la rue Dupleix, sans date. Cote Archives de Paris VR 594. Phot. service photographique des Archives de Paris @ Archives de Paris, 2012.

Par la suite, la Commission est encore confrontée au conseiller Boulard, qui soutient l'artiste Henri Nozais ${ }^{84}$ : l'élu insiste pour que l'administration l'associe au concours et critique « des désignations de concurrents aussi ténébreuses » en soulignant que «si les artistes que nous pouvons personnellement connaître et recommander à l'examen des services des Beaux-Arts doivent attendre de décrocher une médaille d'or au Salon pour avoir le droit d'être appelés à faire des esquisses pour la Ville, j'estime qu'il y a mauvaise interprétation des intentions du Conseil qui a voulu aider tous les artistes principalement ceux qui sont en chômage ${ }^{85}$ " (fig. $\mathbf{n}^{\circ}{ }^{32}$ ) (fig. $\mathbf{n}^{\circ}{ }^{33}$ ). Si le nom de cet artiste n'apparaît nulle part dans les comptes rendus, ses esquisses sont tout de même étudiées par la Commission. 


\section{Figure 32}

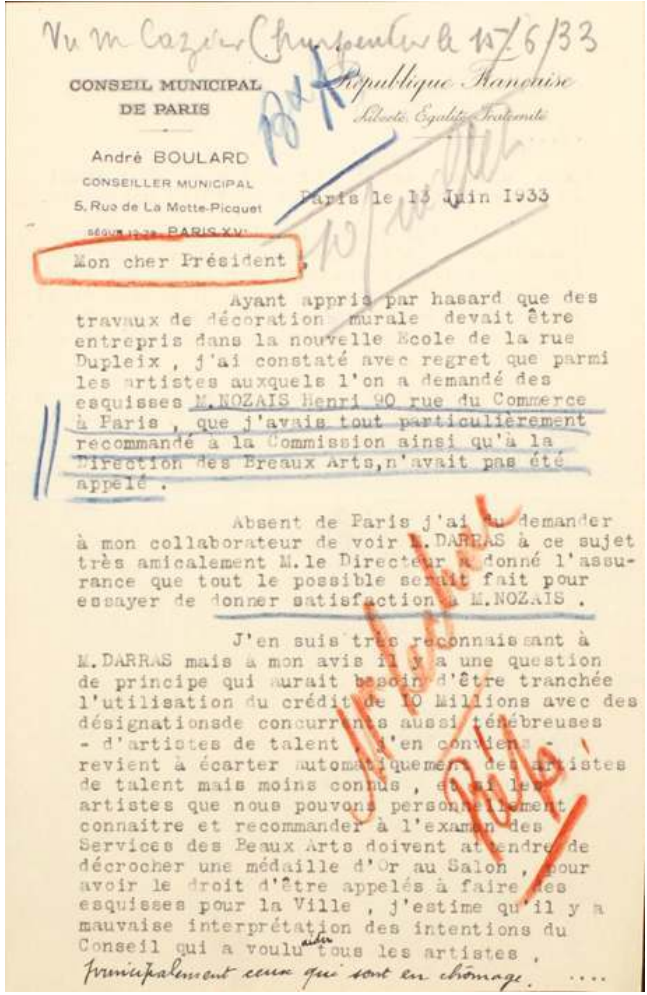

Lettre d'André Boulard pour soutenir Henri Nozais, page 1, 13 juin 1933. Cote Archives de Paris VR 594.

Phot. service photographique des Archives de Paris @ Archives de Paris, 2012. 


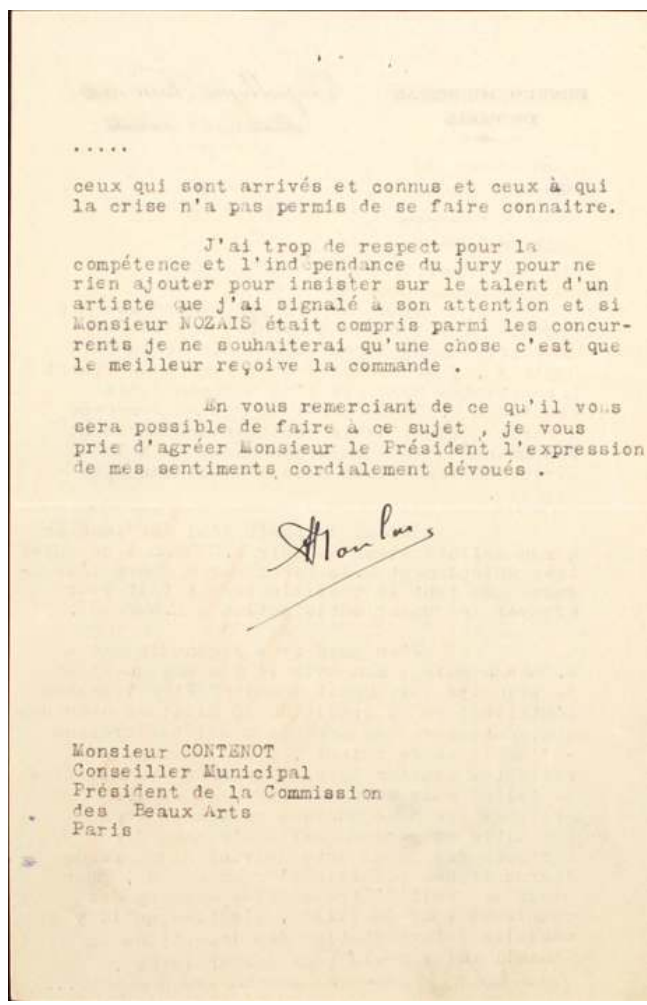

Lettre d'André Boulard pour soutenir Henri Nozais, page 2, 13 juin 1933. Cote Archives de Paris VR 594.

Phot. service photographique des Archives de Paris @ Archives de Paris, 2012

Le 7 juillet, cette dernière, après examen, décide que « le projet de M. La Montagne SaintHubert est infiniment supérieur aux autres » et adopte ses propositions concernant la mer et la campagne, et demande à faire modifier celles relatives à la ville et à la montagne: «la ville: enlever l'homme sur l'échafaudage; la montagne: incliner la schlitte ». L'arrêté pris le 4 août 1933 lui attribue donc la commande des quatre panneaux décoratifs de l'école de filles pour la somme de 12750 francs, avec un délai de cinq mois à compter d'août. La Ville alloue également la somme de 1000 francs à tous les candidats écartés.

Le dossier du décor du préau de l'école maternelle est plus rondement mené : deux artistes humoristes sont pressentis, Auguste Roubille ${ }^{86}$ et un nommé Bertin ${ }^{87}$, sur la base d'un programme de trois panneaux dédiés aux personnages de Guignol, du cirque et de la Comédie et peints sur toile marouflée ${ }^{88}$. L'esquisse de Roubille, seul à répondre, est acceptée le 29 juin en Commission et l'artiste reçoit la commande par l'arrêté préfectoral du 4 août 1933, pour un montant de 14250 francs.

\section{École du 57-59, rue de Romainville (XIXe arrondissement)}

47 Le 12 avril 1933, le Directeur des Beaux-Arts propose à la Commission d'orner le pourtour du préau de l'école maternelle d'un décor à la fresque, pour lequel il envisage de convoquer Henri Georges Charrier ${ }^{89}$, Carlos Reymond ${ }^{90}$ et Claude Poreau; ce dernier semble se désister, et c'est Jules Émile Zingg ${ }^{91}$ qui est sollicité ensuite. L'architecte 
d'opération, Julien-François Froux, après une conférence avec le Directeur en mai, rend son rapport le 7 juin 1933 : s'il n'a aucune objection quant au choix des artistes et des sujets $^{92}$, il a déjà rencontré les concurrents et propose le programme suivant: "Cette École est destinée à de jeunes enfants, il importe que la décoration parle à leurs yeux, tant par le choix des sujets que par leur exécution (...). Elle comportera une frise continue de $1,25 \mathrm{~m}$ de haut et sera exécutée à la fresque. La tonalité devra en être claire de façon à donner de la gaîté et de la fraîcheur. Les sujets auront une largeur de 2,30 m sauf audessus des portes où ils seront réduits à 1,40 $\mathrm{m}$. Le fond général du préau sera de tonalité claire, gris beige ou ton ocré. Le principal éclairage vient des portes du préau. Les motifs seront séparés par une composition d'arbres ou d'arbustes correspondant aux trumeaux entre les portes du préau qui, trop étroits, ne comporteront pas de chanson ».

Le projet de Zingg est adopté le 12 juillet, malgré le soutien apporté par le conseiller Georges Prade ${ }^{93}$ à son protégé Henri Georges Charrier. Par arrêté du 4 août 1933, l'artiste reçoit la commande d'une surface de $45 \mathrm{~m}^{2}$ pour la somme de 33750 francs, avec un délai d'exécution de cinq mois; le 30 décembre, la surface est accrue de $8,75 \mathrm{~m}^{2}$, et la somme allouée augmentée de 6562 francs. Interrogé par le Directeur des Beaux-Arts sur ses collaborateurs éventuels, Zingg évoque, par un courrier du 13 août 1933, soit Étienne Hauville, soit Jean-Alphonse Stival ${ }^{94}$, « un ancien camarade d'atelier qui connaît la fresque et a travaillé dans une église une dizaine d'années plus tôt » (fig. $\mathbf{n}^{\circ} \mathbf{3 4}$ ).

Figure 34

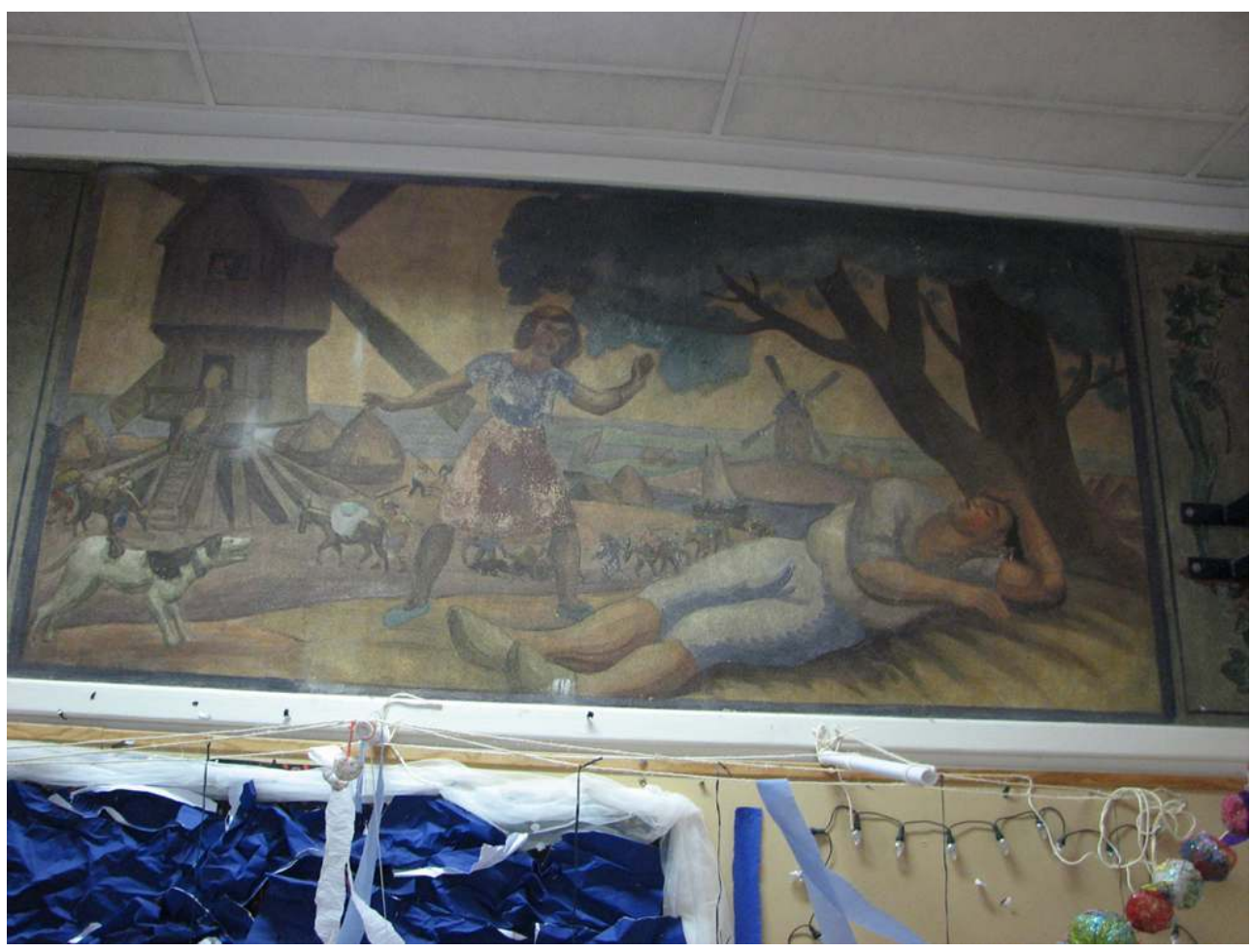

Jules-Émile Zingg, Meunier tu dors, peinture à fresque, détail du décor du préau de l'école de la rue de Romainville, 1933

Phot. Verdure, Marc, 2012. (c) Marc Verdure. 


\section{École du 9, rue Jomard (XIXe arrondissement)} les vestibules des deux écoles seront décorés de peintures sur toile marouflée ${ }^{95}$. Les artistes mis en concurrence sont Jean Émile Didier-Tourné ${ }^{96}$ et Odette Pauvert ${ }^{97}$ pour l'école de garçons; et Louis Valtat ${ }^{98}$ et Robert Lotiron ${ }^{99}$ pour l'école de filles. Après cette date, le sujet est choisi par le Directeur des Beaux-Arts : il s'agira de «La Mère et l'Enfant ». Le 29 juin, la commission valide l'esquisse d'Odette Pauvert « sous réserve de modifications à apporter aux personnages ». Le 12 juillet, des propositions complémentaires de Joseph Avy ${ }^{100}$ et Clairin ${ }^{101}$ sont présentées, mais elles portent sur un sujet différent, le Travail, proposé par l'architecte et le conseiller municipal : dès lors, la Commission refuse ces deux derniers projets (l'esquisse d'Avy est conservée), dédommage les artistes à hauteur de 1000 francs $^{102}$, attribue l'œuvre de Pauvert à l'école de filles et décide de relancer entièrement le concours pour l'école de garçons, estimant que les esquisses n'ont pas été concluantes (fig. $\mathbf{n}^{\circ} \mathbf{3 5}$ ).

Figure 35

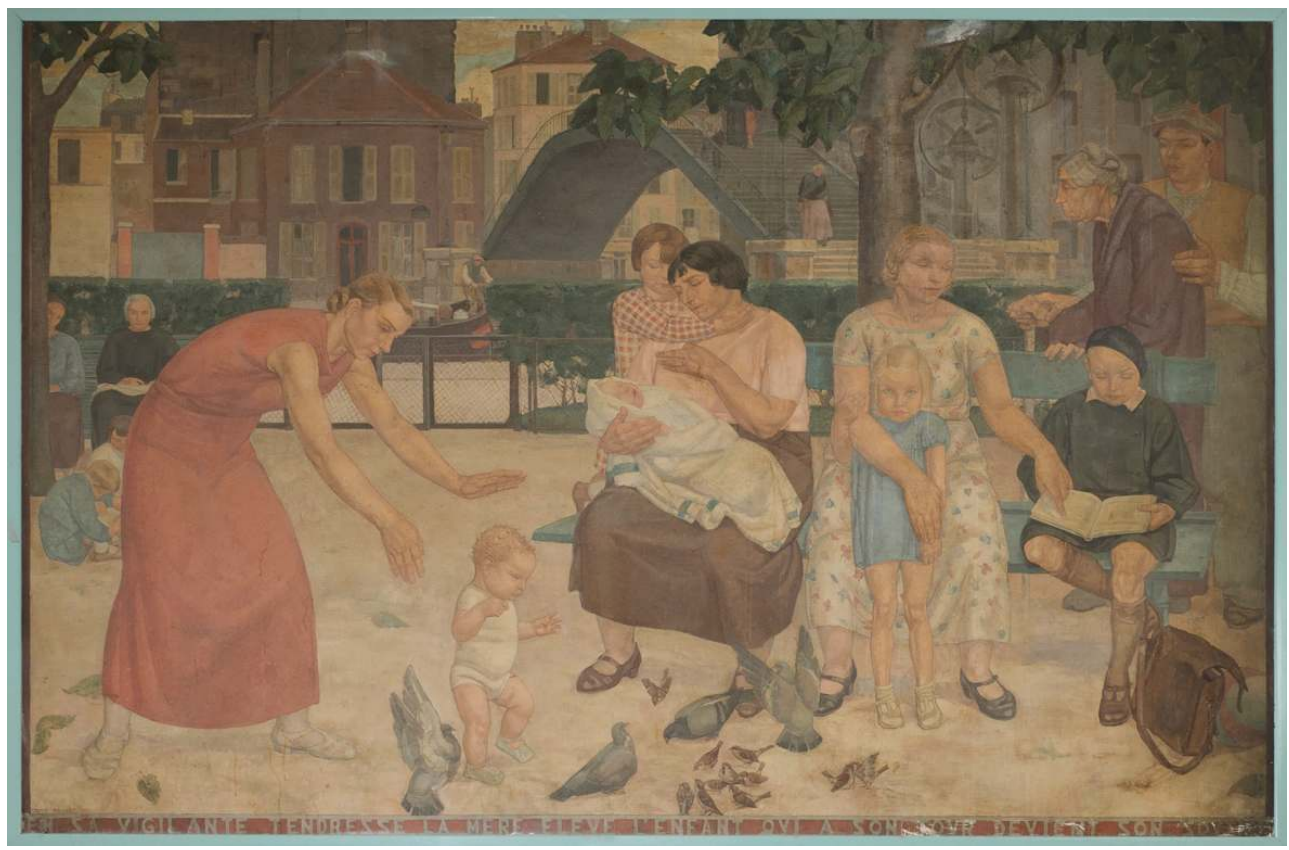

Odette Pauvert, La mère et l'enfant, huile sur toile marouflée, 1933, décor du vestibule de l'école primaire de la rue Jomard.

Phot. Pignol, Claire (c) Claire Pignol / COARC / Roger-Viollet.

Le 13 novembre 1933, le Directeur invite donc plusieurs artistes à concourir: André Herviault ${ }^{103}$, Robert Lotiron, René Thomsen ${ }^{104}$ et Jean Émile Didier-Tourné. Le 31 janvier, une lettre de refus est envoyée aux trois premiers qui obtiennent une compensation de 500 francs. Didier-Tourné reçoit enfin, le 3 mars 1934, l'arrêté lui attribuant la décoration, dans un délai de quatre mois et pour la somme de 9000 francs (le marouflage étant à sa charge), du vestibule de l'école de garçons de la rue Jomard avec une peinture représentant « La Mère et l'Enfant ». 


\section{Figure 36}

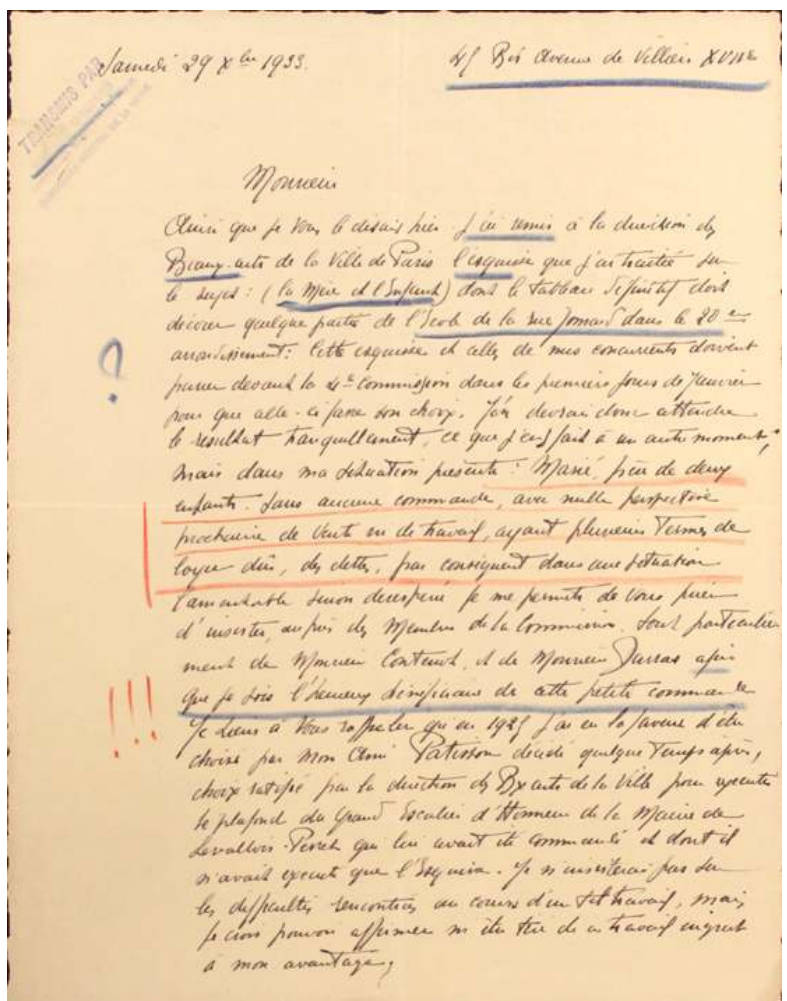

Lettre de sollicitation d'André Herviault, 29 décembre 1933, page 1. Cote Archives de Paris VR 594. Phot. service photographique des Archives de Paris @ Archives de Paris, 2012. 


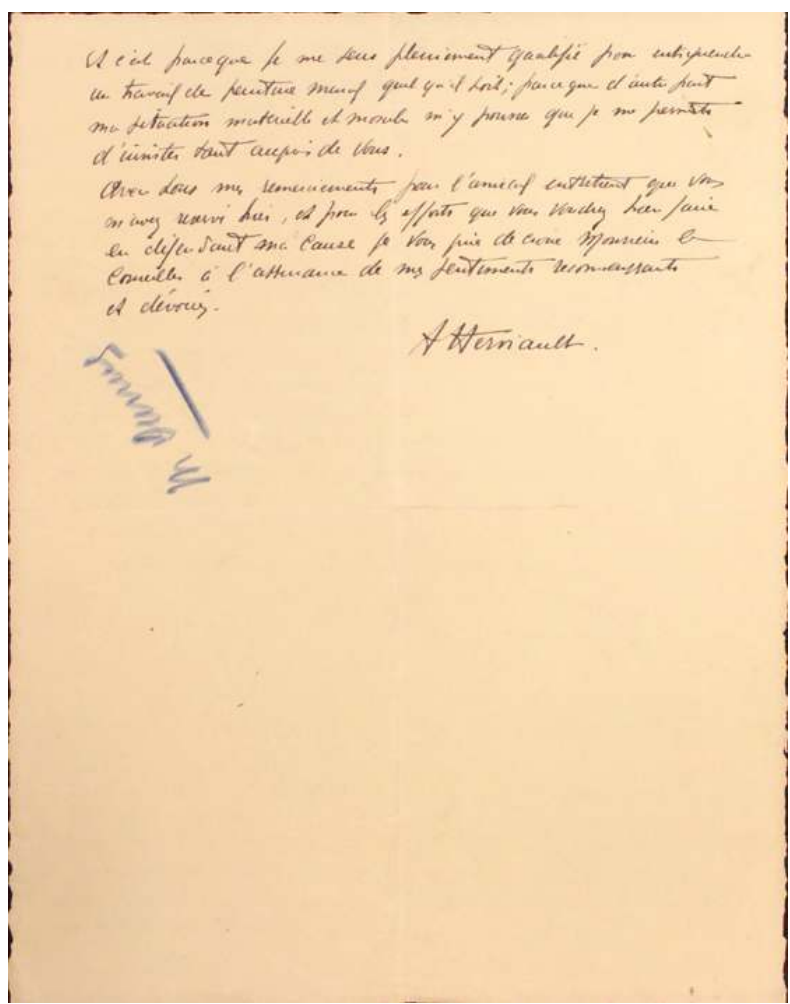

Lettre de sollicitation d'André Herviault, 29 décembre 1933, page 2. Cote Archives de Paris VR 594.

Phot. service photographique des Archives de Paris @ Archives de Paris, 2012.

51 Ce chantier met particulièrement en valeur plusieurs types d'interventions. Tout d'abord, le conseiller municipal Georges Beaufumé105 réclame (et obtient) que le fond du tableau d'Odette Pauvert représente le réaménagement du canal de La Villette; ensuite, l'architecte Albert Alexandre Melissent, d'accord avec le conseiller, demande à deux artistes (Avy et Clairin) de produire leurs esquisses sur le thème du travail, à l'encontre des préconisations de la Commission, ce qui provoque l'annulation du concours; enfin, de multiples courriers sont adressés à cette dernière de la part d'élus ou de personnalités pour soutenir tel ou tel artiste, notamment Herviault, particulièrement en difficulté (lettre du conseiller Jean Ferrandi) (fig. $\mathbf{n}^{\circ} \mathbf{3 6}$ ) (fig. $\mathbf{n}^{\circ} \mathbf{3 7}$ ), Pauvert (lettres du préfet des Bouches-du-Rhône (fig. $\mathbf{n}^{\circ} \mathbf{3 8}$ ) et du conseiller Guillaumin) ou Thomsen (soutenu par le conseiller Paul Fleurot). 
Figure 38

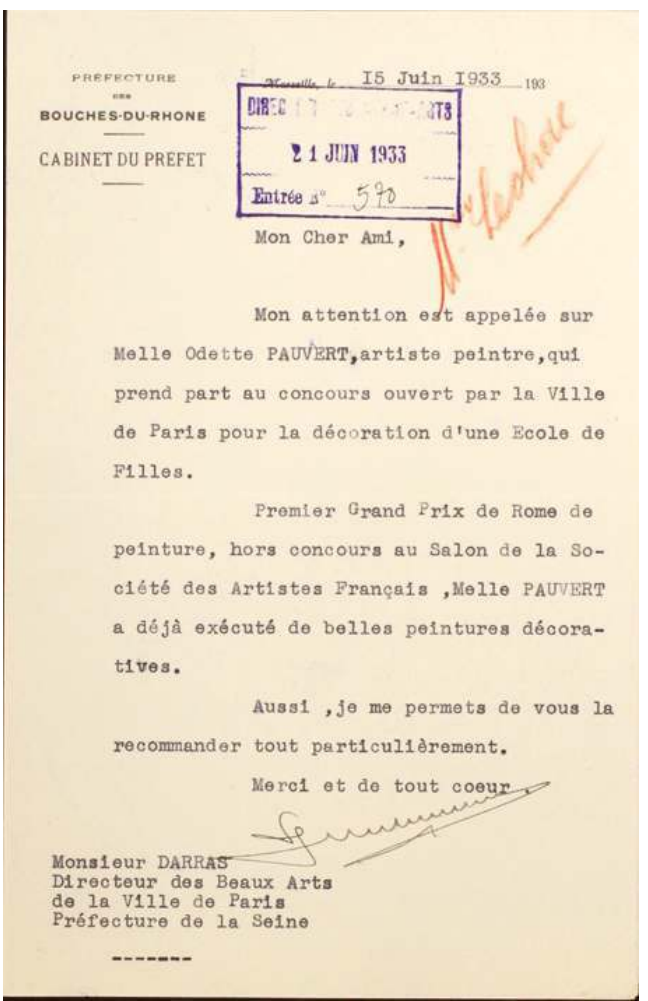

Lettre de soutien du Préfet des Bouches-du-Rhône en faveur d'Odette Pauvert, 15 juin 1933. Cote Archives de Paris VR 594.

Phot. service photographique des Archives de Paris @ Archives de Paris, 2012.

\section{Groupe scolaire du 65-67, avenue Simon-Bolivar (XIXe arrondissement)}

Le 12 avril 1933, le Directeur des Beaux-Arts indique avoir prévu, pour le préau de l'école de garçons, quatre panneaux sur toile marouflée qui pourraient être confiés à Jean Marchand ${ }^{106}$, René Thomsen, Henri $\mathrm{Zo}^{107}$, Georges d'Espagnat ${ }^{108}$, Yves Alix ${ }^{109}$ ou LouisWilliam Graux ${ }^{110}$. Pour le préau de l'école de filles, les trois dessus-de-porte à peindre sur enduit sec seront disputés entre Clairin, François Quelvée ${ }^{111}$ ou Jean Maxence.

Les esquisses de Quelvée, Marchand et Espagnat sont conservées au musée des Beaux-Arts de la Ville de Paris-Petit-Palais et indiquent que le sujet proposé aux artistes est double : "Le travail et le repos" (deux grands panneaux) et "Sport, danse, musique et jeux" (trois grands panneaux); le traitement étant laissé libre, Quelvée opte pour une inspiration très idéalisée et rurale, quand Marchand propose (dans sa seconde version) un paysage parisien avec la rotonde de La Villette (fig. $\mathbf{n}^{\circ} \mathbf{3 9}$ ). 


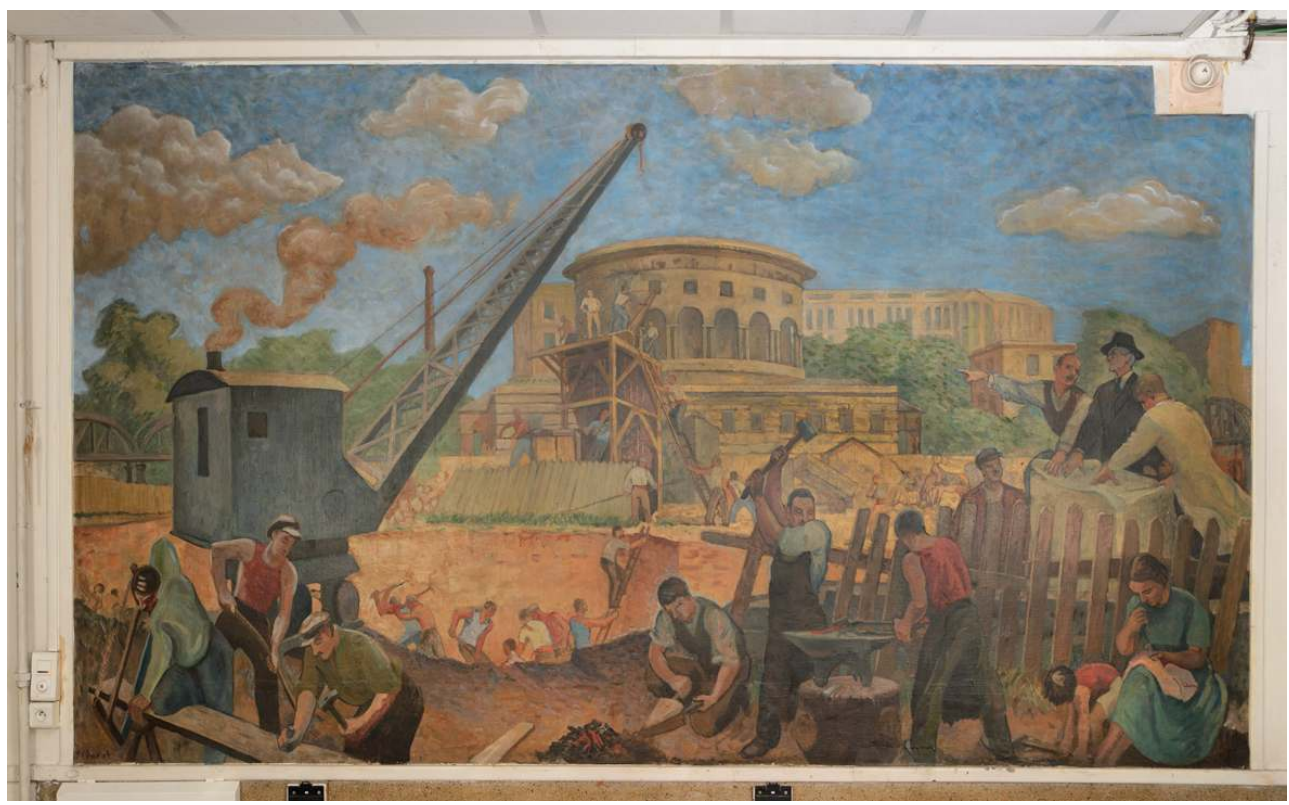

Jean Marchand, Le Travail, huile sur toile marouflée, 1933, préau de l'école de l'avenue Simon-Bolivar. Phot. Pignol, Claire (c) Claire Pignol / COARC / Roger-Viollet.

Le 29 juin 1933, les projets de Jean Marchand pour l'école de garçons sont adoptés : « Le repos » ne pose pas de difficulté mais «Le travail » doit être modifié pour s'inspirer d'une rue du XIXe arrondissement. En ce qui concerne l'école de filles, c'est l'esquisse de Quelvée qui est retenue (fig. $\mathbf{n}^{\circ} \mathbf{4 0}$ ). Le 12 juillet, une nouvelle esquisse de Jean Marchand est soumise et emporte l'adhésion. Les archives sont sommaires pour cette commande mais les projets sont réalisés.

\section{Figure $\mathbf{4 0}$}

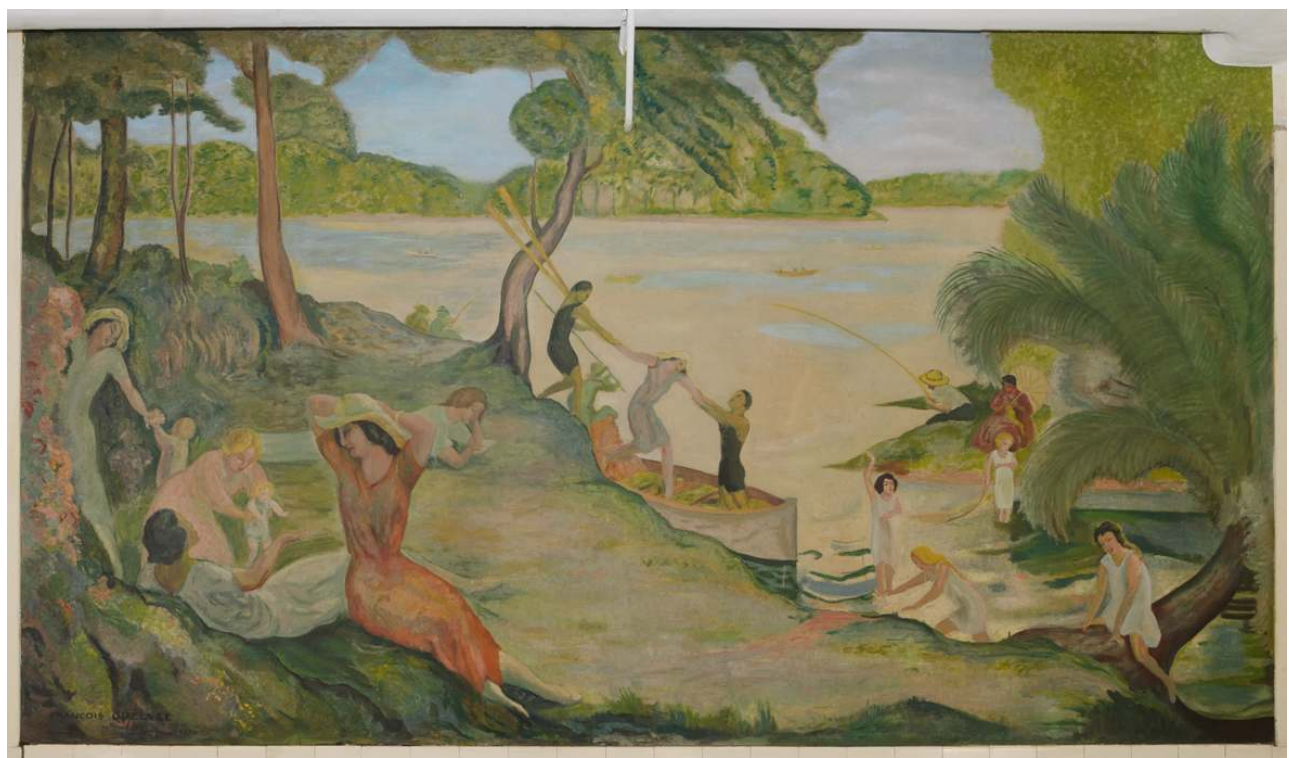

François Quelvée, Le repos, huile sur toile marouflée, 1933, préau de l'école de l'avenue Simon-Bolivar. Phot. Pignol, Claire (c) Claire Pignol / COARC / Roger-Viollet. 


\section{École du 51, boulevard Davout (XXe arrondissement, disparu)} de hauteur soit $32,93 \mathrm{~m}^{2}$ ) et les emplacements et indique que les peintures auront pour le sujet sera le même, et les dimensions sont identiques. Même démarche pour l'école maternelle : les dimensions sont revues $\left(1,25 \mathrm{~m}\right.$ de haut, $\left.39 \mathrm{~m}^{2}\right)$, les artistes validés et le sujet précisé : les jeux et les jouets. Dans tous les cas, l'architecte a fait réserver les emplacements, c'est-à-dire n'a pas fait faire d'enduit de plâtre, laissant les fonds en brique. Il indique également les caractéristiques exigées des esquisses (échelle de $10 \mathrm{~cm}$ par $\mathrm{m}$, sur toile ou carton, en couleur, avec un détail au $1 / 4$ d'une partie intéressante) et la date d'exécution des fresques (25 septembre), en raison d'une livraison des classes prévue le $1^{\mathrm{er}}$ octobre 1933.

\section{Figure 41}

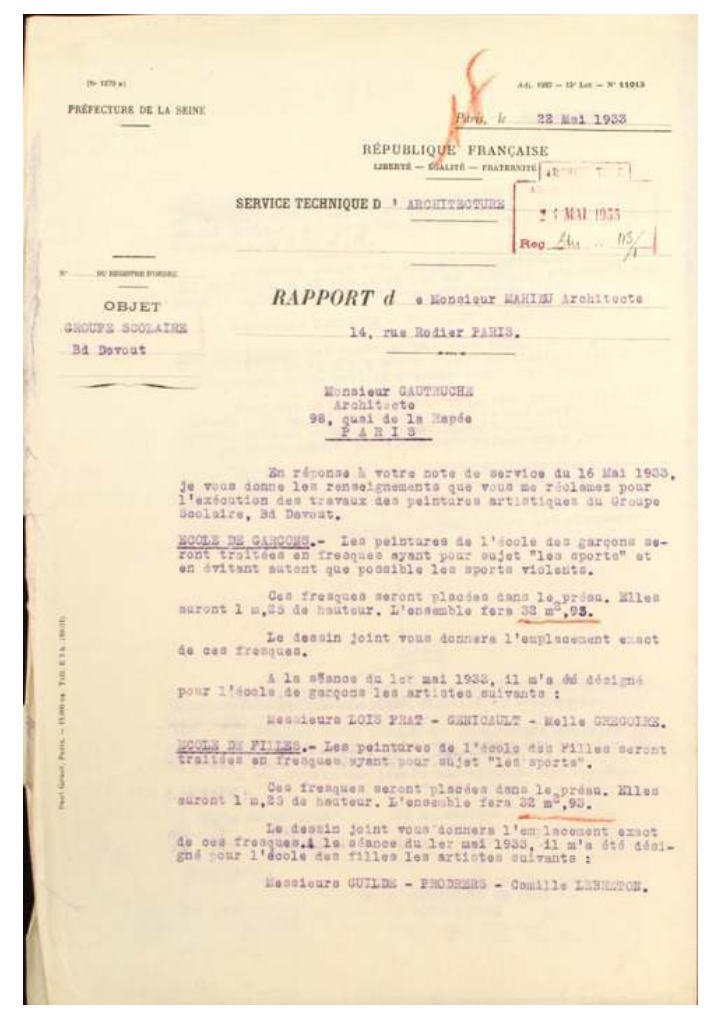

Programme de l'architecte Mahieu pour la décoration de l'école du Boulevard Davout, 24 mai 1933, page 1. Cote Archives de Paris VR 594

Phot. service photographique des Archives de Paris @ Archives de Paris, 2012. 


\section{Figure 42}

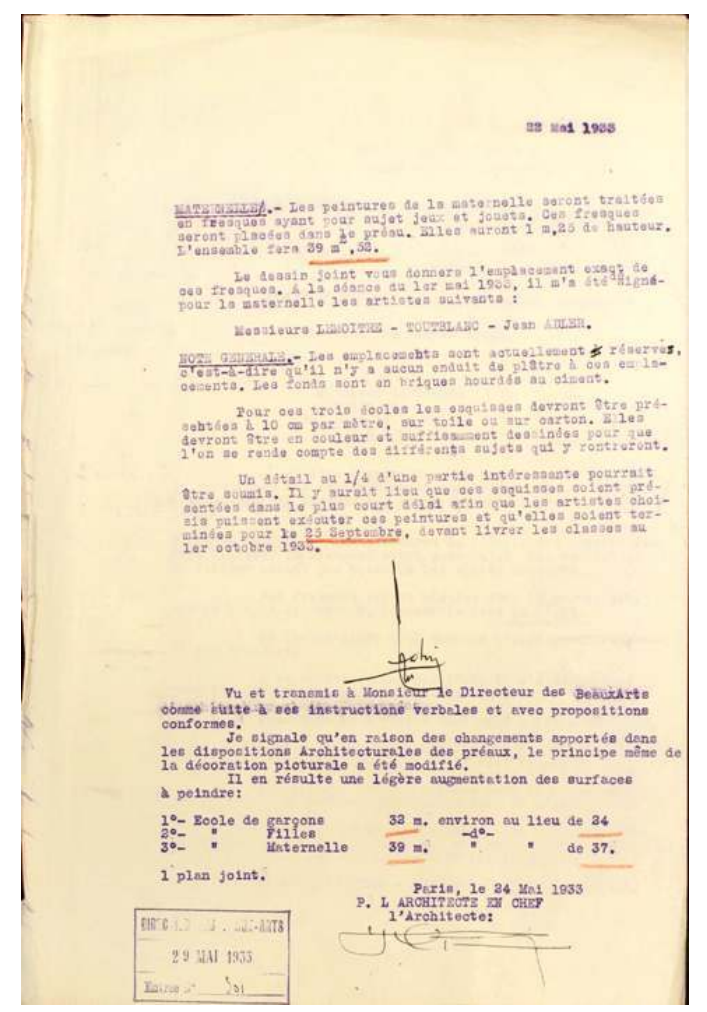

Programme de l'architecte Mahieu pour la décoration de l'école du Boulevard Davout, 24 mai 1933, page 2. Cote Archives de Paris VR 594

Phot. service photographique des Archives de Paris ( $)$ Archives de Paris, 2012.

Le 29 juin 1933, le projet de Loÿs Prat est adopté pour l'école de garçons. Seules subsistent les esquisses de Robert Génicot, qui illustrent en une grande frise divers sports collectifs ou individuels (fig. $\mathbf{n}^{\circ} \mathbf{4 3}$ ). 


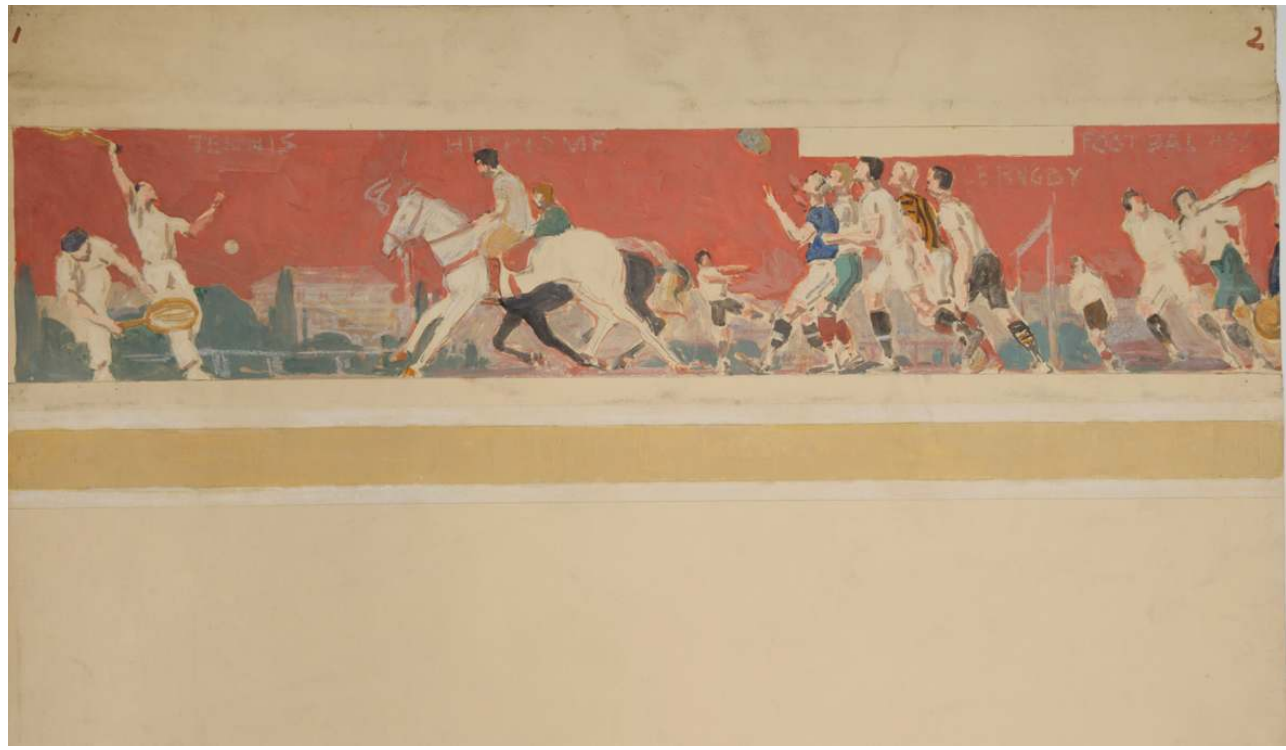

Robert Génicot, Tennis, hippisme, rugby, football, crayon et gouache sur papier, esquisse pour le décor de l'école de garçons du boulevard Davout, 1933.

Phot. Moser, Jean-Marc ( ) Jean-Marc Moser / COARC / Roger-Viollet.

À la même date, l'esquisse de Jeanne Gauzy ${ }^{119}$ remplace celle de Le Breton pour l'école de filles et l'examen final a lieu le 12 juillet. Une discussion s'élève autour du projet Broders, soutenu par le conseiller municipal du quartier (Maurice Levillain ${ }^{120}$ ) qui rapporte les propos du peintre : «ce n'est pas ce qui est beau qui plait, mais c'est ce qui plaît qui est beau ». Pour le conseiller, Broders « apporte de la beauté, de la joie, de la couleur. Songez que vous avez affaire à des enfants, et à des gens qui habitent la périphérie, qui apprécient ce qui leur plaît ». Au contraire, le Directeur des Beaux-Arts qualifie l'esquisse de «couverture de catalogue » ou d'« affiche » : «notre rôle est d'éduquer le goût des enfants, et non pas de nous conformer au leur». L'élu affirme au contraire que «les enfants aiment les catalogues. Pour éduquer les enfants, il faut d'abord les intéresser, et le projet dont nous parlons paraît répondre à ces desiderata »; il dit ensuite assumer pleinement ce choix, soulignant que «si on se plaint, ce n'est pas vous [l'administration] qui serez ennuyé, ce seront les conseillers ». Finalement, le Directeur des Beaux-Arts conseille de consulter l'architecte. Le même jour, le projet des époux Lemaître pour l'école maternelle est validé, sous réserve d'une modification à effectuer.

L'architecte semble avoir validé le choix politique, puisque l'arrêté pris le 4 août 1933 indique que Loÿs Prat ${ }^{121}$ et Roger Broders sont chargés de décorer à fresque chacun dix panneaux, pour un montant de 25500 francs, respectivement dans l'école de garçons et l'école de filles.

De leur côté, les époux Lemaître sont chargés de six panneaux à fresque dans l'école maternelle, pour un montant de 31500 francs (fig. $\mathbf{n}^{\circ} \mathbf{4 4}$ ). Leurs esquisses sont conservées ainsi que celles de Léon Toublanc, et l'on s'aperçoit que les artistes bénéficient d'une certaine latitude dans le choix des sujets, à partir du moment où ils respectent la thématique d'ensemble. Alors que Toublanc choisit des scènes de jardin (les Canots, la Balle, la Ronde, l'Escarpolette) et de jouets (la Poupée, la Construction), les Lemaître trouvent des idées plus variées : une scène de Guignol, des paysages (L'Hiver au village et 
La Ville), des jeux d'enfants (Les Jeux et Jouets; Les jeux de la plage) et des activités enfantines (Les enfants et les bêtes ; L'Escarpolette, la forêt, la promenade à ânes).

Figure 44

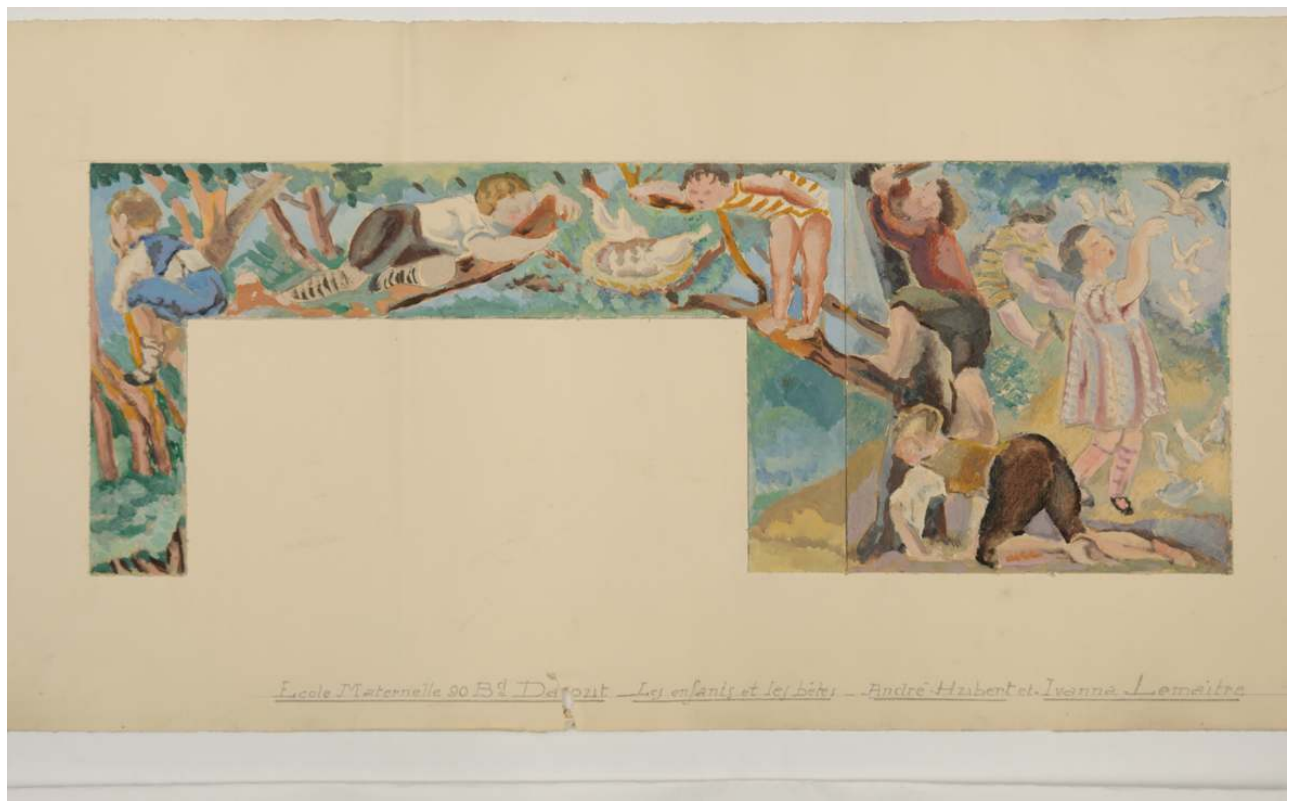

André Hubert et Ivanna Lemaître, Les enfants et les bêtes, crayon et huile sur papier, esquisse pour le décor de l'école maternelle du boulevard Davout, 1933.

Phot. Moser, Jean-Marc (c) Jean-Marc Moser / COARC / Roger-Viollet.

61 Pour tous, le délai d'exécution est de cinq mois à compter du 6 août 1933. Les candidats refusés sont dédommagés par la somme de 1000 francs; les soutiens manifestés pour Guy-Loë (du Ministre de la Marine) (fig. $\mathbf{n}^{\circ} 45$ ) ou Jean Maxence (du conseiller municipal Jean Ferrandi) n'ont donc pas été déterminants. 
Figure 45

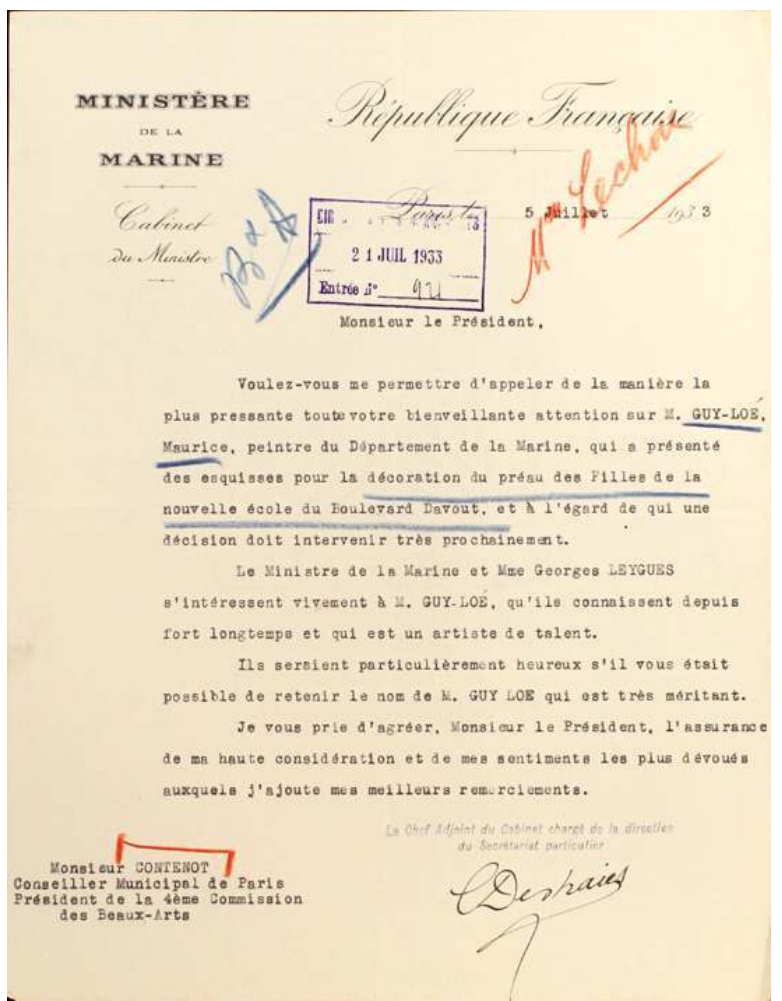

Lettre de soutien à Guy-Loë par le ministère de la Marine, 5 juillet 1933. Cote Archives de Paris VR 594. Phot. service photographique des Archives de Paris @ Archives de Paris, 2012

Groupe scolaire dit de la Porte de Ménilmontant (8 rue PierreFoncin, XXe arrondissement) 


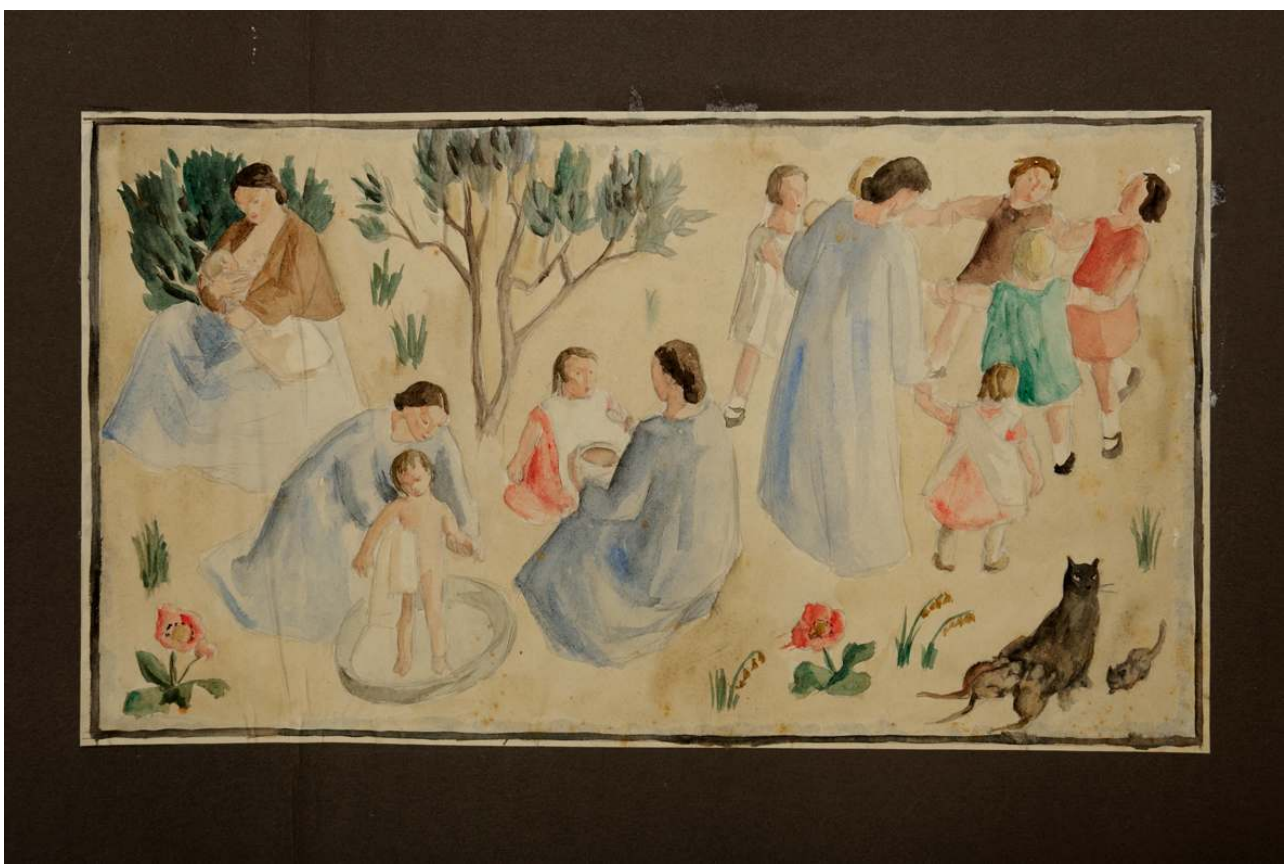

Marthe Flandrin, Devoirs et plaisirs maternels, aquarelle sur papier, 1933, projet pour le décor de la salle d'attente de l'école de filles de la Porte de Ménilmontant.

Phot. Moser, Jean-Marc ( ) Jean-Marc Moser / COARC / Roger-Viollet.

Le 12 avril 1933, le Directeur des Beaux-Arts introduit le projet de décoration du Groupe scolaire de la porte de Ménilmontant en proposant de convoquer les artistes suivants: Henri Navarre, suivant l'avis de l'architecte d'opération Raymond Rousselot, et Marthe Flandrin. L'artiste lauréat devra se charger des trois écoles (soit environ $50 \mathrm{~m}^{2}$ ), sur les thèmes suivants : les Saisons (école maternelle), les Métiers (hall d'entrée des écoles de filles et de garçons), les Arts des Jeux (réfectoire des garçons). Le 29 juin, les esquisses de Navarre sont préférées à celles de Flandrin et la commande lui est attribuée tardivement, probablement en raison de l'avancement du chantier de construction, le 30 décembre 1933, pour un montant de 37500 francs, alors que Flandrin est dédommagé à hauteur de 500 francs. Les esquisses de cette dernière ${ }^{122}$ montrent un décor ample et majestueux, composé parfois à la manière des tapisseries (fig. $\mathbf{n}^{\circ} \mathbf{4 6}$ ). Le 5 février 1934, Navarre écrit au Directeur des Beaux-Arts que les travaux préparatoires sont achevés; l'exécution des décors est programmée en accord avec l'architecte, "sans gêner l'organisation de l'école " et sera réalisée en collaboration avec [André] Nivard ${ }^{123}$ et Mayance (fig. $\mathbf{n}^{\circ} \mathbf{4 7}$ ). L'architecte et l'artiste semblent avoir œuvré de concert, tous deux ayant cosigné les dessins préparatoires aux décors (fig. $\mathbf{n}^{\circ} \mathbf{4 8}$ ). 
Figure 47

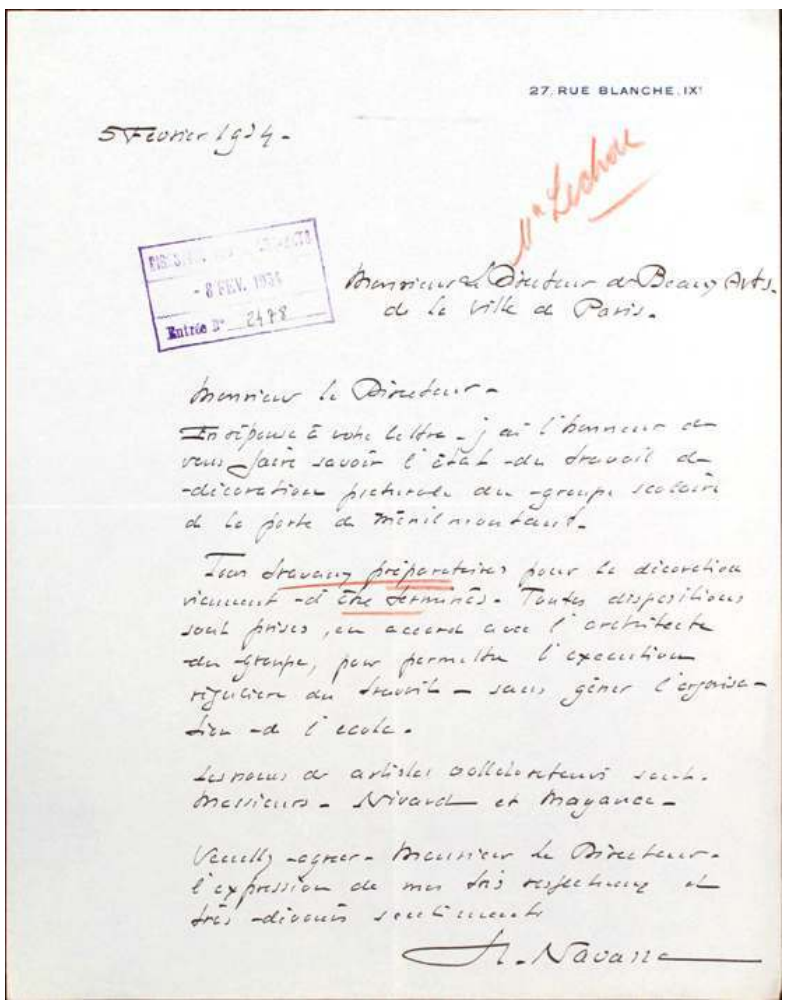

Courrier de Navarre au Directeur des Beaux-Arts, 5 février 1934. Cote Archives de Paris VR 594. Phot. service photographique des Archives de Paris (c) Archives de Paris, 2012. 


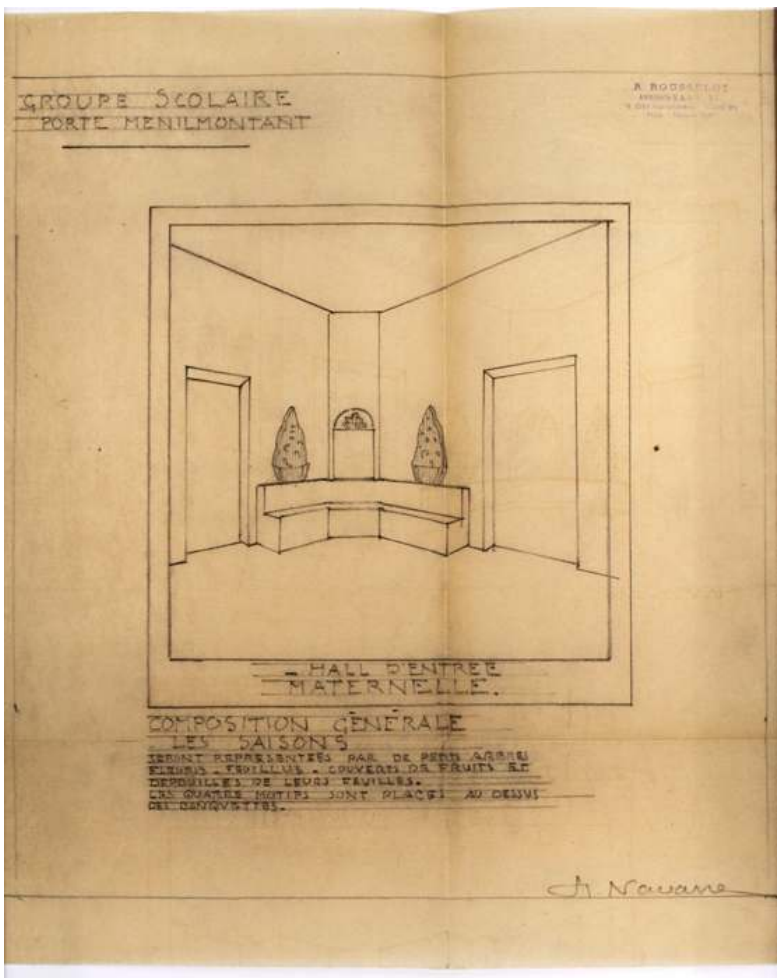

Dessins préparatoires de Navarre et Rousselot, sans date. Cote Archives de Paris VR 594.

Phot. service photographique des Archives de Paris @ Archives de Paris, 2012.

\section{Bilan d'une politique}

\section{Est-il possible d'établir un bilan artistique?}

Sitôt obtenu, l'emprunt des 10 millions est critiqué par la presse spécialisée. Le 17 octobre 1932, L'CEuvre décrit l'initiative de la Ville de Paris comme un «miroir aux alouettes", soulignant les promesses de millions chimériques alors que l'enveloppe financière paraît dédiée presque exclusivement aux artisans, à des « travaux de praticiens plus que des travaux d'artistes ». Qu'en est-il véritablement?

Considéré sur un plan général, le chiffre des dépenses s'élève à 3,5 millions de francs pour les artistes, et 7,5 millions pour les artisans (au nombre de 328). Comme le montre le tableau récapitulatif, le décompte du nombre d'artistes sollicités lors des concours relatifs aux décors monumentaux des écoles se monte à 48 personnes « représentant les diverses tendances actuelles et de situation pécuniaire modeste", pour un montant de 444247,50 francs $^{124}$. De fait, sur ces 48 artistes, on peut compter environ 27 élèves de l'École des Beaux-Arts ou des Arts Décoratifs, environ 22 exposants aux Salons, 6 Prix de Rome, 2 Peintres de la Marine, 6 illustrateurs.

Ces quelques chiffres, ainsi que la description des différents chantiers ci-dessus, peuvent souligner la diversité d'origine des artistes : majoritairement issus des instituts officiels de formation (avec notamment un grand rôle joué par Fernand Cormon et Paul Baudoüin), présents aux différents Salons, les artistes sollicités et lauréats sont aussi issus 
de certains circuits plus inattendus et discrets. Alors que les décors des années 1930-1933 sont en totalité réalisés par l'école de Paul Baudoüin et offrent ainsi une belle unité artistique, il est en revanche impossible de dégager, à partir de la liste des artistes sollicités en 1933-1934, des groupes stylistiques, des influences ou une idéologie dominante, tant les horizons sont divers. Si généralement leur formation et leur expérience témoignent d'une aptitude aux décors monumentaux, le jury toutefois soucieux d'équité sociale et soumis à des opinions contradictoires concernant la psychologie de l'enfant met aussi en avant des critères étrangers au domaine artistique, comme au sujet de l'école du boulevard Davout.

\section{Un pari politique face aux débats architecturaux contemporains}

Ferrandi réclamant un bilan de l'emploi du «crédit des 10 millions", les élus responsables, notamment Émile Chausse ${ }^{126}$ et Georges Contenot, respectivement président et rapporteur de la Commission ad hoc, sont pleinement conscients des lacunes du projet et attribuent les critiques à une erreur dans l'interprétation de la délibération municipale : les artistes se sont crus destinataires de l'ensemble des crédits alors que la répartition des 10 millions a été effectuée en fonction de l'importance des catégories intéressées; comme l'artisanat suppose l'emploi de matière première et d'une main d'œuvre nombreuse, il a été jugé nécessaire de lui attribuer la majorité des financements. Par ailleurs, les élus considèrent avoir tout de même financé l'art et l'idée créatrice, par le biais de l'artisanat. Enfin, ils soulignent qu'ils ont fait grand cas des artistes, en ayant l'idée « de rendre les écoles plus attrayantes par une décoration plus appropriée. Nous avons fait à cet égard des sacrifices considérables, énormes même aux yeux de certains, en dotant certaines écoles, surtout les écoles en construction, les écoles neuves, de peintures... de fresques! ».

Le pari politique quasi « sacrificiel » envisagé par Contenot est peut-être une allusion aux critiques récurrentes à l'égard des décors considérés, du fait de la crise, comme un accessoire de luxe. Avec l'arrivée au pouvoir de plusieurs socialistes et communistes en banlieue parisienne dans les années 1920, la plupart des groupes scolaires nouvellement construits ont de grands volumes, des formes modernes et des réalisations de secondœuvre recherchées (peintures gaies, porches avec bas-reliefs, fresques dans les escaliers ou les vestibules), et cette qualité formelle est relevée par les adversaires politiques comme un abus ${ }^{127}$. Toutefois, l'idée de la décoration comme épanouissement de l'enfant et développement du souci du beau fait son chemin, pour être reprise par Roger Hummel en 1938: «il faut que l'école serve à élever le niveau moral des masses, qu'elle serve à enseigner le beau et le respect du beau (...). Est-ce un luxe que de développer l'hygiène, l'air, les plantations, le souci du beau ? ${ }^{128} »$. Le rapporteur de la Commission est en effet conscient du débat contemporain au sujet de l'aspect que doit prendre l'architecture scolaire. Devenue un lieu de discussion, celle-ci n'échappe pas, selon lui, au divorce entre art et architecture.

Georges Contenot fait ainsi part, lors du même débat du 26 novembre 1934, de ce constat effectué durant les chantiers. D'un côté les architectes n'emploient que des matériaux pauvres, font de grandes maisons sans façades et uniformes «dans lesquelles ni les peintres ni les sculpteurs ne trouvent à s'employer "; de l'autre les artistes, quand ils ont les moyens, souhaitent «en mettre plein la vue » et déséquilibrent l'architecture. Le 
conseiller Raoul Brandon, architecte de formation, réplique en pointant les résistances des services d'architecture aux propositions décoratives de certains architectes, et pointe ironiquement que « vous ne pouvez pas demander à tous vos architectes, même en fin de carrière, de risquer leur situation simplement au service de l'art, mais si vous le demandiez, vous en trouveriez beaucoup. »

Brandon poursuit en citant le cas des habitations à bon marché en Allemagne, notamment en Bavière: «il n'y en a pas une seule qui ne présente une note d'art». Le reproche principal fait à la Commission par Brandon est donc simple : dans les sommes nécessaires pour la maçonnerie, le béton armé, la charpente et la couverture, aucun crédit n'a été réservé pour donner une place aux artistes... Il serait facile, aux dires du conseiller, de montrer que "certaines décorations en staff, en plâtre, ou certains travaux secondaires coûtent beaucoup plus cher que la véritable décoration faite par les artistes. »

Cette évocation du cas allemand amène à s'interroger sur les sources du projet. L'exemplarité architecturale allemande est souvent mentionnée en ces années, elle a ainsi joué un rôle dans les réalisations de banlieue parisienne, grâce aux voyages d'Henri Sellier, maire de Suresnes. Mais l'allusion de Brandon fait aussi écho à une déclaration du Directeur des Services d'Architecture en Commission du 12 avril 1933 qui prend acte des récentes livraisons de la presse spécialisée (peut-être notamment le numéro thématique de L'Architecture d'aujourd'hui en 1933): celle-ci n'évoque pas les créations parisiennes mais s'intéresse longuement aux œuvres allemandes; en retour, il propose de faire un bilan de l'action menée par la Ville dans la revue Science et Industrie, avec une préface de Contenot. Ce désir d'exemplarité est tout à fait remarquable, il souligne que l'administration a conscience de participer à un débat majeur et veut faire partager son expertise.

\section{Une exemplarité sans lendemain?}

S'il est possible que ce projet soit né du lobbying d'un groupement syndical, il a d'autant mieux pris forme et vigueur qu'il s'est appuyé sur le sens politique de certains élus membres du parti radical, traditionnel défenseur des intérêts d'un électorat majoritairement non salarié, composé d'artisans et de petits boutiquiers. Léopold Bellan ${ }^{129}$, Fernand Moriette, Louis Peuch et André Puech prennent ainsi fortement position dans les débats en assemblée plénière pour faire partie de la Commission ad hoc.

Cet ancrage n'empêche pas de trouver, au sein de cette Commission d'aide, des personnalités courageuses et volontaristes, comme Albert Besson ${ }^{130}$ ou François Latour ${ }^{131}$, ce dernier étant particulièrement fervent à l'égard des travaux d'urbanisme parisiens et se prononçant même en faveur d'une "dictature de l'urbanisme». De même, la Commission se compose de bons connaisseurs des questions de travaux (Georges Thomas est employé à la surveillance des travaux de la Ville), des impératifs budgétaires (François Latour est rapporteur du budget départemental, Eugène Fiancette du budget municipal) et des questions patrimoniales (Fortuné d'Andigné ${ }^{132}$ et Pierre de Pressac ${ }^{133}$ sont membres de la Commission du Vieux Paris) ou relatives au chômage (Émile Deslandres fait partie de la Commission Travail et Chômage). En d'autres termes, les élus en charge du programme connaissent la thématique dans laquelle ils s'inscrivent, faisant en outre partie de la $4^{\mathrm{e}}$ Commission des Beaux-Arts.

Au niveau politique encore, il semble possible de s'interroger sur le lien entre la stratégie des élus et le courant qualifié de "socialisme municipal ${ }^{134}$ ». En effet, la présidence de la 
Commission est attribuée au socialiste Émile Chausse et il faut relever la présence de plusieurs membres de la SFIO ou d'anciens ouvriers devenus politiques. S'il est vrai que Paris est, dans l'entre-deux-guerres, une ville ancrée à droite, elle est aussi très disputée et la gauche l'emporte au nombre de voix ${ }^{135}$. Certains éléments peuvent ainsi être relevés en faveur de ce parallèle: l'importance prépondérante accordée à l'enfance et à l'instruction, dans la lignée des programmes et des valeurs radicales-socialistes et républicaines; le souci de crédibilité, d'efficacité et de transparence, en lien avec les nombreux rapports présentés en assemblée plénière, les documents comptables, les comptes rendus et les bilans compilés dans les archives.

En définitive, tous les élus admettent que leur ambition est inachevée, surtout aux yeux des parties prenantes, et que les 10 millions étaient insuffisants et en appelaient d'autres, réclamés d'ailleurs dès le lancement du projet où il était question d'une "première phase ». L'initiative parisienne n'a pas non plus été renouvelée malgré les demandes d'une partie du Conseil municipal. Elle n'a pas davantage bénéficié des honneurs de la presse, étant tout à fait occultée dans les publications dédiées à certains édifices comme l'école de la rue Küss ou celle de la rue Saint-Martin ${ }^{136}$. En effet, malgré les contacts étroits noués avec les architectes, ceux-ci ne jugent pas nécessaire d'évoquer le chantier du décor monumental ni le rôle qu'ils attribuent par exemple à la fresque. Le bilan artistique de ce programme décoratif n'a par ailleurs jamais été rendu public. Cette contribution espère avoir modestement pallié cette lacune.

\section{NOTES}

1. - Rapport présenté par M. Viollet-le-Duc au nom de la $5^{\mathrm{e}}$ Commission : $1^{\circ}$ ) sur l'article $33 \mathrm{du}$ chapitre 8 du Budget des dépenses de 1876 (travaux de peinture, sculpture, gravure en médailles et taille-douce) ; $2^{\circ}$ ) sur la répartition du crédit de 200000 francs inscrit sous le même article au Budget des dépenses de 1875, Annexe au procès-verbal de la séance du 2 août 1875. - Rapport présenté par M. Viollet-le-Duc, au nom de la Commission spéciale des Beaux-Arts, sur la répartition du crédit de 300000 francs inscrit au budget de 1879 pour travaux de peinture, sculpture, gravure en médailles et en taille-douce, Annexe au procès-verbal de la séance du 11 février 1879.

2. - Archives de Paris, VR 589. Statistique fournie par l'office départemental du Placement et de la Statistique du Travail.

3. - COMBEAU, Yvan, NIVET, Philippe. Histoire politique de Paris au XXe siècle. PUF, 2000, p. 73 et suiv.

4. - SALY, Pierre. «La politique française des grands travaux 1929-1939 fut-elle keynésienne? ». Revue économique, 1980, volume 31, $\mathrm{n}^{\circ} 4$, p. 706-742.

5. - Bulletin Municipal Officiel, mercredi 23 mars 1932, p. 1699.

6. - Georges Contenot (1868-1948) est conseiller municipal de Paris (XII ${ }^{\mathrm{e}}$ arrondissement), membre de la droite municipale et responsable du logement social de la ville. Il est aussi président de l'entreprise de bronzier Contenot et Lelièvre.

7. - Rapport présenté par M. Viollet-le-Duc..., op. cit., 1879, p. 5.

8. - Ibid., p. 22-23. 
9. - CHATELET, Anne-Marie (dir.). Paris à l'école, «qui a eu cette idée folle... ». Paris : Éditions du Pavillon de l'Arsenal ; Picard, 1993.

10. - André Joseph Berry (1869-1960), auteur de l'école de la rue Saint-Martin (1930-1935), voir Archives de Paris, Pérotin 40124/64/1_4.

11. - Raoul Jacques Ernest Brandon (1878-1941), auteur du Groupe scolaire de l'avenue du Parcdes-Princes (1934-1937), voir Archives de Paris, Pérotin 40124/64/1_43.

12. - Édouard Boegner (1887-1962), auteur du Groupe scolaire rue Dupleix.

13. - Julien-François Froux (1875- ?), auteur du Groupe scolaire de la rue de Romainville.

14. - Raymond Rousselot (1876- ?), auteur du Groupe scolaire Porte de Ménilmontant (septembre 1932-octobre 1934, voir notice descriptive aux Archives de Paris, Pérotin 40124/64/1_61).

15. - Louis-Hippolyte Boileau (1878-1948), auteur du Groupe scolaire rue Keller.

16. - Germain Debré (1890-1948), auteur du réaménagement de l'école de la rue Clauzel (1932), voir Archives de Paris, Pérotin 40124/64/1_13.

17. - Roger-Henri Expert (1882-1955), auteur du Groupe scolaire de la rue Küss.

18. - Victor-Abel Mahieu (1879- ?), auteur du Groupe scolaire du boulevard Davout.

19. - Albert Alexandre Melissent ( ?- ?), auteur du Groupe scolaire rue Jomard.

20. - Pierre Winter (1906-?), auteur du Groupe scolaire rue Simon-Bolivar (1931-1932), voir Archives de Paris, Pérotin 40124/64/1_53.

21. - RUBIO, Marian. «L'élan brisé d'une nouvelle architecture scolaire ». Dans CHATELET, AnneMarie (dir.). Paris à l'école, "qui a eu cette idée folle... ». Paris : Éditions du Pavillon de l'Arsenal ; Picard, 1993, p. 142-152.

22. - BARRET, Maurice. "L'éducation nouvelle et l'architecture scolaire ». L'Architecture d'aujourd'hui, 1936, n 5, p. 13-15.

23. - VAISSE, Pierre. La troisième république et les peintres. Paris : Flammarion, 1995, p. 192.

24. - Voir la commande en 1890 d'un buste en marbre de Sophie Germain à Zacharie Astruc pour l'école éponyme rue de Jouy $\left(\mathrm{IV}^{\mathrm{e}}\right)$, ou encore le dépôt d'une statue de Léon Roussel intitulée L'Innocence dans l'école de la rue Félix-Pécaut en 1908 (XVII $\left.{ }^{\mathrm{e}}\right)$. Ces projets figurent dans des dossiers aux Archives de Paris, carton VR 573.

25. - « Le système de décoration mobile est souvent préférable avec alternance et interruption, de façon que l'œil de l'enfant se repose, que son attention renaisse, que son désir s'éveille et que son émotion se renouvelle ». Voir RIOTOR, Léon. Article "Imagerie scolaire ». Dans BUISSON, Ferdinand. Nouveau Dictionnaire de Pédagogie et d'instruction primaire. Paris: Hachette, 1911, VIII-2087 p.

26. - Sur Paul-Albert Baudoüin, voir la notice de Diederick Backhuys dans MONFORT, Marie, MAYER, Jannie, VIGNES-DUMAS, Claire. Patrimoine des Hauts-de-Seine. Guide des peintures murales 1919-1960. Paris : Somogy, 2008, p. 180-182.

27. - Archives de Paris, VR 573, dossier «école du boulevard Raspail ». La délibération a été publiée dans le Bulletin municipal officiel du $1^{\mathrm{er}}$ juin 1920, p. 2547. Le décor a disparu.

28. - BAKHUIYS, Diederik, LAJOIX, Mylène. Paul Albert Baudoüin et les décors rouennais. Rouen : Musée des Beaux-Arts, [s. d.], 18 p.

29. - BAUDOÜIN, Paul. La Fresque, sa technique, ses applications. Paris : les éditions Albert Lévy, 1914, p. 11-12. Remarquons toutefois que, pour ses écoles, la Ville de Paris commande des décors sur toile marouflée mais pas de fresque avant la première guerre mondiale.

30. - Archives de Paris, VR 573, dossier «écoles rue Debelleyme, rue Brisemiche, rue des Jeûneurs, rue Miollis, rue Pecqueur, rue Parcheminerie ». La Montagne Saint-Hubert reçoit 5280 francs, Hauville 6900 francs, Loÿs Prat 6600 francs, Ducos de la Haille 7650 francs et Baudoüin 3000 francs, soit un montant total de 29430 francs à la charge de la Ville de Paris.

31. - Jean-Robert La Montagne Saint-Hubert (1887-?), auteur notamment des fresques de la Fondation des Etats-Unis à la Cité Universitaire de Paris (1930) et de l'American Memorial Hospital de Reims, avant de s'exiler aux États-Unis. Dès 1923, il donne des conférences devant 
l'American School of Fine Arts sur l'art de la fresque (The Art of fresco painting pure technique and actual renaissance. Paris : Jouve, 1923).

32. - Étienne Hauville (1896-1970) devient professeur de fresque à l'École des Arts Appliqués et invente un procédé de fresque appliqué au bas-relief. L'école de la rue Brisemiche fut détruite pour aménager le parvis du Centre Pompidou.

33. - Louis Joseph Prat dit «Loÿs Prat » (1879-1934), élève de Fernand Cormon à l'École nationale des Beaux-Arts, obtient en 1908 le Second Grand Prix de Rome. Il participe en 1910, avec Cormon, au décor de la galerie nord du Petit Palais, puis réalise en 1925 des fresques pour trois bâtiments de l'Exposition internationale des Arts Décoratifs et industriels modernes (Cour des métiers, pavillon Albert-Morancé-Corcellet, porte Saint-Dominique Fabert) et en 1929-1932 des toiles pour l'hôtel de ville de Colombes.

34. - Pierre Henri Ducos de la Haille (1889-1972), élève de Raphaël Collin et d'Ernest Laurens, obtient le Grand Prix de Rome en 1922. En 1929, il remplace Baudoüin au poste de chef d'atelier de peinture à fresque à l'École nationale des Beaux-Arts (VAISSE, Pierre. La troisième république et les peintres. Paris : Flammarion, 1995, p. 211 et note 154).

35. - Voir dans ce même numéro d'In Situ. MONFORT, Marie. «Paul Baudoüin, Georges Pradelle et l'association « La Fresque » ».

36. - Le préau a été remanié : La Terre est dans une salle de dessin, La Mer dans le réfectoire.

37. - La recherche dans les procès-verbaux des débats à l'assemblée municipale est restée vaine. Les Archives de Paris conservent toutefois un document, intitulé Écoles primaires supérieures et professionnelles. Tableau des emplacements susceptibles de recevoir des œuvres d'art, non daté, mais placé dans un dossier des années 1920, montrant que le souhait d'orner les écoles s'étend à l'ensemble des établissements scolaires. Ce programme ne semble pas avoir connu d'exécution (Archives de Paris, VR 573).

38. - Eugène Chapleau (1882-1969) : auteur, entre 1913 et 1924, de nombreux sujets religieux et mythologiques, et sollicité fréquemment pour la reconstruction en Picardie. Voir CAPPRONNIER, Jean-Charles, FOURNIS, Frédéric, GÉRARD, Alexandra, TOUZET, Pascale. "L'art sacré entre les deux guerres : aspects de la Première Reconstruction en Picardie ». In Situ, revue des patrimoines [en ligne], 2009, $\mathrm{n}^{\circ} 12$ [consulté le 26/07/2012].

39. - Archives de Paris, VR 573, dossier « école de la rue Dussoubs ». Délibération du 9 juillet 1923 pour la réalisation de deux fables.

40. - Constant Louche (1880-1965) : peintre orientaliste. Il signe La laitière et le pot au lait et Le laboureur et ses enfants.

41. - Archives de Paris, VR 573, dossier « école rue Littré ».

42. - Myrthée Baillon de Wailly (fin XIXe- ?) : élève de Paul Baudoüin et Pierre Laurens, elle participe au chantier de décoration de la cathédrale de Nanterre (1935). Voir MONFORT, Marie, MAYER, Jannie, VIGNES-DUMAS, Claire. Patrimoine des Hauts-de-Seine. Guide des peintures murales 1919-1960. Paris : Somogy, 2008, p. 180. Les dimensions du panneau de l'école rue Littré sont : 295 $\mathrm{cm} \times 650 \mathrm{~cm}$ environ.

43. - Georges Pradelle (1865-1934) : architecte, il entame sa collaboration avec Paul Baudoüin en 1905 et ils travaillent notamment ensemble pour la cathédrale de Nanterre (1926-1936). Voir MONFORT, op. cit., p. 56 et 116.

44. - Marthe Flandrin (1904-1987) : élève à l'École nationale des Beaux-Arts dès 1926, chez Pierre Laurens puis Pierre Ducos de la Haille. Elle travaille notamment à la décoration de l'église du Saint-Esprit (1932), à Sainte-Geneviève de Nanterre (1935) et au baptistère du Pavillon pontifical en 1937. Voir la notice de Séverine Muteau dans MONFORT, op. cit., p. 184-185.

45. - Élisabeth Faure (1906-1964) : élève de Paul Baudoüin et de Pierre Laurens, elle obtient le Second Prix de Rome. À partir de 1930, elle s'inscrit dans le courant des Ateliers d'art sacré et réalise des fresques dans les domaines religieux et civils, notamment au Pavillon des missions de 
l'Exposition Coloniale (1931), à l'église du Saint-Esprit (1932), au Pavillon pontifical et au Pavillon de l'hygiène (1937). Voir la notice de Jannie Mayer dans MONFORT, op. cit., p. 184.

46. - Archives de Paris, VR 573, dossier «écoles rue Littré et rue Delambre »; VR 594, dossier «école rue Küss - $10 \mathrm{M}$ - Peintures à la fresque ». Le décor de la rue Delambre a disparu aujourd'hui. Voir Marthe Flandrin, catalogue d'exposition Avranches-Beauvais-BoulogneBillancourt-Roubaix. Paris : Gourcuff Gradenigo, 2010, p. 88-92 (reproductions anciennes).

47. - Intervention de Georges Contenot le mercredi 23 mars 1932, dans le Bulletin Municipal Officiel , p. 1707.

48. - Louis Peuch (1852-1947), avocat et conseiller municipal de Paris entre 1893 et 1898, député de la Seine (III ${ }^{\mathrm{e}}$ arrondissement de Paris) de 1898 à 1932, ministre des Travaux publics (1910-1911). Au cours de ses trente-quatre années de mandat, il est inscrit au groupe des Républicains de gauche (radicaux).

49. - André Puech : conseiller municipal radical.

50. - Georges Thomas (1881 ou 1883-1957) : ouvrier tailleur de pierre puis conseiller municipal de Paris (quartier des Grandes-Carrières, XVIII') de 1929 à 1935, membre de la SFIO jusqu'en 1934. Voir MAITRON, Jean (dir.). Dictionnaire biographique du mouvement ouvrier français, 1977, t. 15, p. 229 et 1992, t. 42 , p. 169-170.

51. - Intervention de Georges Contenot, op. cit., p. 1707.

52. - Eugène Fiancette (1881-1949) : cocher de fiacre, puis responsable du syndicat des cochers de fiacre et des chauffeurs, conseiller municipal du XIX arrondissement de Paris de 1913 à 1940, député SFIO de la Seine de 1928 à 1936, puis sénateur de la Seine de 1936 à 1940. Rapporteur général du budget du Département. Voir JOLLY, Jean (dir.). Dictionnaire des parlementaires français. Paris : Presses universitaires de France.

53. - Intervention d'Eugène Fiancette, op. cit., p. 1710.

54. - Interventions de Jean Ferrandi et Georges Prade, dans le Bulletin Municipal Officiel du mardi 26 novembre 1934, p. 4220 et suivantes.

55. - VAISSE, Pierre. La troisième république et les peintres. Paris : Flammarion, 1995, p. 60.

56. - Jean Ferrandi (1882-1935) : lieutenant-colonel, conseiller municipal du VI ${ }^{\mathrm{e}}$ arrondissement.

57. - Léon Riotor (1865-1946) : homme de lettres (il publie de la poésie et des romans satiriques), critique d'art, homme politique : vice-président du Conseil municipal de Paris et du Conseil général de la Seine.

58. - Intervention de Léon Riotor, op. cit., p. 4222-4223.

59. - Bilan réalisé dans une intervention de Georges Contenot, Bulletin Municipal Officiel, 1934, p. 4226-4228. Les Archives de Paris conservent de nombreux cartons sur «l'emprunt des 10 millions » : 1) VR 589 et 591 pour les réunions de la Commission d'aide à l'artisanat et aux artistes (1932-1934), le $1^{\mathrm{er}}$ carton comportant en outre des documents sur la constitution et l'organisation de ladite commission ; 2) VR 594 pour les dossiers concernant les projets scolaires ; 3) VR 588 pour des propositions ou des bilans sous forme de tableaux, notes administratives, rapports présentés en commission, et pour un livre de comptes général.

60. - « Le Conseil (...) délibère : article 1) M. le Préfet de la Seine est invité à solliciter des pouvoirs publics l'autorisation d'émettre en une ou plusieurs fois un emprunt remboursable en vingt années au maximum, devant lui procurer une somme nette de 40 millions destinée au paiement de commandes de mobilier, de décoration, d'objets d'art de toute nature susceptibles d'être exécutés pour le compte de la Ville de Paris (...). Article 4) Le programme des commandes à effectuer (...) sera établi par l'Administration, en accord avec une Commission du Conseil municipal spécialement désignée. »

61. - La liste est donnée dans le Bulletin Municipal Officiel du 26 novembre 1934, p. 4227 : Association des Artistes de Paris, Cercle artistique et littéraire, Cercle de l'Union artistique, Société des aquarellistes, Union des Artistes Modernes, Société des artistes lithographes français, Société artistique de la gravure sur bois, Société des Artistes français, Société nationale des 
Beaux-Arts, Société des peintres de montagne, Société de l'école française, Salon d'automne, société des artistes indépendants, Société des peintres orientalistes, Salon des Tuileries, Société artistique La Horde, Union des femmes peintres, Société des artistes décorateurs, Société «La Samothrace", Société des artistes humoristes, Société des aquafortistes, Société des vrais indépendants, École nationale des Beaux-Arts, École des Arts décoratifs.

62. - À titre de comparaison, les fresques réalisées par Marthe Flandrin pour le Pavillon de l'Élégance lors de l'Exposition de 1937 lui sont payées 25000 francs pour $75 \mathrm{~m}^{2}$ (y compris dessins préparatoires, esquisses et exécution), soit 330 francs le $\mathrm{m}^{2}$. Voir Marthe Flandrin, op. cit., p. 60.

63. - 1) Peinture : dans le préau, 2 panneaux de $4 \mathrm{~m} \times 2,50 \mathrm{~m}=20 \mathrm{~m}^{2} ; 4$ dessus-de-porte de $1,50 \mathrm{~m}$ $\mathrm{x} 0,80 \mathrm{~m}=5 \mathrm{~m}^{2}$; soit $25 \mathrm{~m}^{2}$ dans la technique de l'huile sur enduit. 2) Sculpture : au-dessus de la porte d'entrée de l'école, un motif sculpté sur pierre en bas-relief (concours); dans le préau, un bas-relief sculpté encadrant la plaque des morts de la guerre.

64. - Hugues de Beaumont (1874-1947) : élève de Gustave Moreau, Théobald Chartran et Albert Maignan. Expose au Salon des Artistes Français de 1892 à 1945 et à la Société Nationale des Beaux-Arts après 1902. Chevalier de la Légion d'Honneur en 1930.

65. - Jean Julien (1888-1975) : élève de Fernand Cormon, sociétaire du Salon des Artistes Français où il expose de 1910 à 1967. Il décore la salle des mariages de la mairie de Saint-Ouen (1928-1930), l'opéra et le tribunal de commerce de Marseille, la mairie du XX $\mathrm{X}^{\mathrm{e}}$ arrondissement de Paris.

66. - Clément Serveau, dit Clément-Serveau (1886-1972) : peintre, graveur et illustrateur. Élève de l'École des arts décoratifs puis de l'École nationale des Beaux-Arts, il expose en 1905 au Salon des Indépendants et participe ensuite aux Salons des artistes français, aux Salons d'automne, aux Salons des Tuileries. Chevalier de la Légion d'Honneur en 1936. Il réalise un grand nombre de fresques (lycée de Meaux), dirige l'atelier de fresques de l'École nationale des Beaux-Arts et décore le pavillon du tourisme à l'Exposition universelle de 1937.

67. - Deux esquisses sont conservées au musée des Beaux-Arts de la Ville de Paris-Petit-Palais (PPP04208 et PPP04209).

68. - Henri Louis Avelot (1873-1935) : peintre, dessinateur humoriste français. Il expose aux Salons de la Société nationale des beaux-arts, aux Salons des Artistes Français et aux Salons des Humoristes. Il est président de la République de Montmartre de 1931 à 1934 et est l'inventeur du calembour graphique.

69. - André Hellé (1871-1945) : peintre et décorateur, illustrateur et créateur de jouets français. Il crée des modèles de jouets en bois à partir de 1910 et reçoit une médaille d'or et un diplôme d'honneur de la Société d'Encouragement à l'Art et à l'Industrie.

70. - Pierre Girieud (1876-1948) est l'auteur de nombreuses fresques : chapelle Saint Pancrace du château de Pradines à Grambois (Vaucluse) vers 1912, Tour des Métaux à l'Exposition des Arts Décoratifs de 1925, salle du Conseil de l'Université de Poitiers en 1931.

71. - Maurice Barbey (1880- ?) expose au Salon des Indépendants de 1912 à 1938. Son esquisse est conservée au musée des Beaux-Arts de la Ville de Paris-Petit-Palais (PPP03813).

72. - Jules Louis Moreteau (1886-1956), peintre d'inspiration orientaliste, étudie la peinture sous la direction de Charles Fouqueray. Il expose au Salon des Artistes Français à partir de 1922.

73. - « Maternelle : - Préau : 4 panneaux de 2,5 m x 3,5 m consacrés aux fables de La Fontaine, ramenées aux 4 saisons. - Section des filles : préau : 1 panneau de 4,9 $\mathrm{m}$ x 3,195 m, sujet: les 3 âges de la Vie ; 1 panneau de 3,63 m x 3,195 m, sujet : le travail féminin à la maison. - Section des garçons : préau : 1 panneau de 4,9 m x 3,195 m, sujet : la joie de vivre [ou les 3 âges de la Vie]; 1 panneau de 3,63 $\mathrm{m} \mathrm{x} \mathrm{3,195} \mathrm{m,} \mathrm{sujet} \mathrm{:} \mathrm{le} \mathrm{travail} \mathrm{masculin.} \mathrm{-} \mathrm{Les} \mathrm{artistes} \mathrm{proposés} \mathrm{sont} \mathrm{:} \mathrm{Maternelle} \mathrm{:}$ l'École de fresques; Section des filles: MM. Girieud ou Barbey ou Moreteau. Il ne m'a pas été désigné d'artiste concernant la décoration de la section des garçons. Je proposerais M. Ducos de la Haille spécialiste des fresques actuellement sans travail. » (VR 594).

74. - Voir dans ce même numéro d'In Situ. MONFORT, Marie. «Paul Baudoüin, Georges Pradelle et l'association « La Fresque » ». 
75. - «J'estime que le projet de Melle Baillon de Wailly est le meilleur. Il est traité d'une façon plus décorative. J'aimerais que sur le fond des peintures que vous devez faire dans mon préau, les éléments soient composés comme sur un nu. Le principe de cette composition m'avait séduit. L'artiste a mis des pilastres peints, il faut les enlever mais au point de vue de la composition l'esquisse est bonne. Le ton rose passe partout, il remplacera le pilastre, les éléments viendront s'y poser comme sur un nu. Si vous me permettez de continuer, je vous dirai que comme il y a quatre élèves différents qui vont travailler à cette décoration, il y en aura un qui sera chargé de la direction du travail, les autres se renfermeront dans la discipline générale et travailleront sous la direction du premier. "

76. - René Anxolabehere ( ?- ?) est né à Boulogne et est membre de «La Fresque », tout comme Charles Lesacq. Ce n'est pas le cas de Raymond Weill.

77. - Constant Le Breton (1895-1985): illustrateur et portraitiste, élève de l'École des Arts Décoratifs. Trois esquisses sont conservées au musée des Beaux-Arts de la Ville de Paris-PetitPalais (PPP04071 et PPP04072).

78. - Jean Adler (1899-1941) : élève de Paul Baudoüin et secrétaire de la "Corporation de la Fresque ", diplôme d'honneur des Arts Décoratifs (1925). Une esquisse est conservée au musée des Beaux-Arts de la Ville de Paris-Petit-Palais (PPP03793).

79. - Eugène Robert Pougheon (1886-1951), Grand Prix de Rome en 1914, devient, après la guerre, membre de la Société des Artistes Français et y expose régulièrement. Il est également décorateur, à l'occasion de l'Exposition Universelle à Paris, en 1937, mais aussi lors de sa participation au chantier de l'église du Saint-Esprit (1932-1934).

80. - Archives de Paris, VR 594, dossier « école de la rue Küss », lettre au Directeur des Beaux-Arts du 26 juin 1933.

81. - Louis Dussour (1905-1986) : né à Riom, élève de Paul Baudoüin, il décore l'église SaintFrançois-de-Sales de Saint-Maur-des-Fossés (1929), la chapelle du lycée Massillon (1935) et celle de l'évêché à Clermont-Ferrand (1936) et des édifices publics, notamment des palais lors des expositions universelles. Voir MONFORT, op. cit., p. 183-184. Ses esquisses sont conservées à la Conservation des Euvres d'Art Religieuses et Civiles.

82. - Constantin Font (1890-1954) : élève de Fernand Cormon, membre de la Société des Artistes Français en 1910, prix de Rome en 1921, chevalier de la Légion d'Honneur en 1935. Ses esquisses sont conservées au musée des Beaux-Arts de la Ville de Paris-Petit-Palais (PPP04017 et PPP04018). 83. - « Le préau de l'Ecole de Filles est éclairé sur deux grands côtés par une suite de baies vitrées de grandes dimensions. Les panneaux à décorer se trouvent aux deux extrémités sur les petits côtés. Ils comprennent : $1^{\circ}$ ) deux panneaux égaux de 1,6 $\mathrm{m}$ de largeur sur $1,7 \mathrm{~m}$ de hauteur placés au-dessus de deux portes sur le côté Sud-Ouest du préau; $2^{\circ}$ ) deux panneaux égaux mesurant chacun 2,45 $\mathrm{m}$ de hauteur sur 1,6m de largeur situés à l'autre extrémité Nord-Est du préau » (Archives de Paris, VR 594, dossier « école rue Dupleix »).

84. - Henri Nozais (?- ?) : auteur du décor de la coupole de l'église Saint-Jean-Baptiste de Grenelle (1921). Ses esquisses sont conservées au musée des Beaux-Arts de la Ville de Paris-Petit-Palais (PPP04195, PPP04196, PPP04197, PPP04198.

85. - Lettre du conseiller municipal André Boulard au conseiller Georges Contenot, le 13 juin 1933. Archives de Paris, VR 594, dossier « Ecole rue Dupleix ».

86. - Auguste Roubille (1872-1955) : illustrateur, il travaille pour de nombreux journaux illustrés. Il réalise la frise décorative de la Maison du Rire à l'Exposition Universelle de 1900, ainsi que des panneaux pour le café d'Harcourt.

87. - S'agit-il d'Émile Bertin (1878-1957), spécialiste du décor de théâtre et sociétaire de divers salons (Automne, Indépendants, Humoristes, etc.) ou bien de S. M. Bertin, qui expose en 1929 au Salon des Humoristes?

88. - Dimensions : 2 panneaux de $1,7 \mathrm{~m} \times 1,6 \mathrm{~m}$ et 1 panneau de $2,7 \mathrm{~m} \times 1,5 \mathrm{~m}$. 
89. - Henri Georges Charrier (1859-1950) : élève de Jean-Paul Laurens, membre de la Société des Artistes Français. Chevalier de la Légion d'Honneur en 1933, il orne de fresques les églises NotreDame de l'Assomption de Fauville-en-Caux (Seine-Maritime) et Saint-Vincent à Chavonne (Aisne). 90. - Carlos Reymond (1886-1970) : il réalise beaucoup de paysages à Paris et dans le sud de la France, dans un style proche de l'impressionnisme. En 1925, il obtient deux médailles d'or aux Arts Décoratifs.

91. - Jules Émile Zingg (1882-1942) : élève de Fernand Cormon à l'École nationale des Beaux-Arts, Second Prix de Rome, chevalier de la Légion d'Honneur en 1930, Grand prix de l'Exposition universelle en 1937. Il réalise plusieurs fresques et cartons pour les manufactures d'Aubusson et des Gobelins, et occupe la place de Vice-Président de l'association «La Fresque ». Ses esquisses sont conservées au musée des Beaux-Arts de la Ville de Paris-Petit-Palais (PPD04032 à PPD04045). 92. - Le programme portera sur les chansons de France, parmi lesquelles « Nous n'irons plus au bois », « La tour prend garde », "J'ai du bon tabac », "Cadet Roussel », « Marlborough s'en vat'en guerre », « La Boulangère », « Le roi Dagobert », « Au clair de la lune ».

93. - Georges Prade : membre de l'Action française avant 1914, élu au Conseil municipal de Paris en 1929, vice-président du Conseil général de la Seine en 1934, il est aussi une personnalité mondaine, avec de nombreuses relations dans les milieux artistiques.

94. - Jean-Alphonse Stival (1879-1944), élève de Fernand Cormon, un des peintres de la brasserie « La Coupole » à Paris, décore aussi la chapelle du paquebot « Normandie ».

95. - On apprend ailleurs que le format des deux toiles est le suivant : $2 \mathrm{~m}$ x $3 \mathrm{~m}$.

96. - Jean Émile Didier-Tourné (1882-1967).

97. - Odette Pauvert (1903-1966) : élève de l'École nationale des Beaux-Arts, $1^{\mathrm{er}}$ Grand Prix de Rome en 1925. Elle participe au décor de l'église du Saint-Esprit à Paris en 1932. L'esquisse du décor de la rue Jomard est publiée dans CHAVANNE, Blandine, GAUDICHON, Bruno. Odette Pauvert (1903-1966). Première femme Grand Prix de Rome de peinture. Poitiers : Musée de la Ville de Poitiers et de la Société des Antiquaires de l'Ouest, 1986, notice $n^{\circ} 47$.

98. - Louis Valtat (1869-1952) : élève de l'École nationale des Beaux-Arts, Chevalier de la Légion d'Honneur. Son esquisse est conservée au musée des Beaux-Arts de la Ville de Paris-Petit-Palais (PPP04281).

99. - Robert Lotiron (1886-1966) : peintre de paysages de Paris et de l'île-de-France, de ports et scènes champêtres de Normandie et de Bretagne. Son esquisse pour l'école de la rue Jomard est conservée au musée des Beaux-Arts de la Ville de Paris-Petit-Palais.

100. - Joseph Marius Jean Avy (1871-1939) : peintre de genre, paysages, décorations murales, pastelliste, illustrateur. Élève de Maignan et de Bonnat, il expose au Salon des artistes français à Paris de 1900 à 1941, et au Salon de la Société nationale des Beaux-Arts de 1934 à 1939. Prix Marie Bashkirtseff en 1900, médaille de deuxième classe en 1903, diplôme d'honneur en 1937, Chevalier de la Légion d'Honneur et Croix de guerre. Gendre d'Albert Besnard, il participe au décor de la coupole du Petit Palais.

101. - Clairin (1897-1980) : élève de Cormon, proche de Maurice Denis, expose aux Salons après 1920.

102. - Le nom d'Achille Laugé (1861-1944) figure également dans le dossier VR 594 des Archives de Paris au sujet du concours de l'école de filles mais n'est jamais cité dans les débats.

103. - André Herviault (1884-1969) : élève de Fernand Cormon, expose souvent au Salon des Artistes Français et effectue plusieurs missions artistiques au service du Ministère des Colonies.

104. - René Thomsen (1897-1976) : élève de Louis Anquetin, Sociétaire du Salon d'Automne, pensionnaire de la Casa Velázquez. Son esquisse pour l'école de la rue Jomard est conservée au musée des Beaux-Arts de la Ville de Paris-Petit-Palais (PPP04280).

105. - Georges Beaufumé (1885- ?) : conseiller municipal socialiste SFIO du quartier de la Villette de 1925 à 1944. 
106. - Jean Marchand (1883-1940) : élève de Luc-Olivier Merson, Léon Bonnat et Henri-Martin. Il effectue une mission en Syrie qui lui permet d'exposer en 1931. Sociétaire du Salon d'Automne et du salon des Indépendants. Son esquisse est conservée au musée des Beaux-Arts de la Ville de Paris-Petit-Palais (PPP04105).

107. - Henri-Achille Zo (1873-1933) : peintre et illustrateur. Élève des peintres Léon Bonnat et de son père Achille Zo, avec lequel il partage une thématique commune: scènes d'Espagne et tauromachies. Il travaille à Paris aux peintures du Théâtre national de l'Opéra-Comique. Chevalier de la Légion d'honneur en 1910.

108. - Georges d'Espagnat (1870-1950) : collaborateur de Maurice Denis, cofondateur du Salon d'Automne, professeur chef d'atelier à l'École nationale des Beaux-Arts en 1934. Une esquisse est conservée au musée des Beaux-Arts de la Ville de Paris-Petit-Palais (PPP03992).

109. - Yves Alix (1890-1969) : élève à l'Académie Julian. Il participe à de nombreux décors muraux en région parisienne : hôtel de ville de Saint-Mandé, Poissy et Puteaux, lycée Camille-Sée, etc.

110. - Louis William Graux (1889-1962) : peintre et illustrateur, élève d'Ernest Laurent à l'École nationale des Beaux-Arts. Il expose notamment au Salon des Artistes français où il est plusieurs fois primé (Médaille d'or, Hors Concours en 1928). Chevalier de la Légion d'Honneur en 1937. Il réalise notamment un tableau de grand format, Les Méandres de la Seine, en 1935 pour la décoration du Paquebot « Normandie ».

111. - François Quelvée (1884-1967) : élève de Maurice Denis, présent aux Salons d'Automne et des Tuileries. D'inspiration orientaliste. Ses esquisses sont conservées au musée des Beaux-Arts de la Ville de Paris-Petit-Palais (PPP04221, PPP04222).

112. - Robert Albert Genicot (1890-1981) : élève d'Ernest Laurent, il expose au Salon des Artistes Français à Paris et obtient une médaille d'argent en 1925. Boursier du prix du Maroc en 1927, il opte pour une tendance orientaliste. Il travaille au chantier de l'église du Saint-Esprit (1933) et obtient une médaille d'or en 1937 à l'Exposition Internationale. Ses esquisses sont conservées à la Conservation des Æuvres d'Art Religieuses et Civiles.

113. - Madeleine Grégoire ( ?- ?) : titulaire d'une bourse de voyage en 1920, expose à la Société Nationale des Beaux-Arts et à la Société des Artistes Français. Elle réalise les fresques du chemin de croix de l'église du Sacré Cœur de Janval à Dieppe (Seine-Maritime).

114. - Maurice Guyot, dit Guy-Loë (1898-1991) : élève à l'Ecole des Beaux-Arts et à l'École des Arts Décoratifs, il réalise surtout des compositions murales : Cité Universitaire (salon de musique du Pavillon Deutsch de la Meurthe, 1931), Lycée Janson de Sailly (parloir, 1935), église SaintFerdinand-des-Ternes (1942). Il devient en 1929 peintre de la Marine militaire (jusqu'en 1941). Il est aussi connu pour avoir fondé la Maison nationale des artistes à Nogent-sur-Marne. Son esquisse est conservée au musée des Beaux-Arts de la Ville de Paris-Petit-Palais (PPP04033).

115. - Roger Broders (1883-1953) : illustrateur, surtout célèbre pour ses affiches concernant des destinations touristiques (Côte d'Azur, stations de ski des Alpes).

116. - André-Hubert Lemaître (1885-?): élève de l'École des Arts Décoratifs et de l'École nationale des Beaux-Arts. Il expose au Salon d'Automne à partir de 1920 et réalise beaucoup de décors monumentaux avec sa femme Hivannah : fresque du Salon Lyautey à la Cité de l'histoire de l'Immigration (1931), arc triomphal de l'église Sainte-Hélène à Paris (1933). Leurs esquisses sont conservées au musée des Beaux-Arts de la Ville de Paris-Petit-Palais.

117. - Léon Toublanc (1904-1982) : restaurant de l'École normale supérieure de Cachan, église Saint-Louis à Villemomble (1954). Ses esquisses sont conservées au musée des Beaux-Arts de la Ville de Paris-Petit-Palais.

118. - Jean Maxence (1901-1962) : élève d'Ernest Laurent. Expose au Salon des Artistes Français après 1920 (médaille d'argent puis d'or en 1925). Peintre officiel de la Marine en 1938.

119. - Jeanne Gauzy (1886-1968) : portraitiste, paysagiste, peintre d'intérieurs et fresquiste. Elle expose en 1927 au Salon colonial des Artistes français, et réalise les peintures murales de l'église Saint-Ephrem à Paris (1937). 
120. - Maurice Levillain (1892-1974), ouvrier mécanicien, est conseiller municipal SFIO de Paris (quartier de Charonne) et conseiller général de la Seine.

121. - Une lettre du 24 août 1933 indique que Loÿs Prat choisit comme collaborateurs Henri Roche et Rosette Prat.

122. - Conservées à la Conservation des CEuvres d'Art Religieuses et Civiles.

123. - André Nivard (1880-1969) : élève d'Octave Guillonnet, il expose au Salon des Artistes Français à partir de 1909. Nommé peintre officiel de la marine en 1914, il travaille aussi de 1922 à 1926 pour le décorateur Émile Jacques Ruhlmann.

124. - Voir une note non datée récapitulant les commandes effectuées sur les fonds de l'emprunt de 10 millions, Archives de Paris, VR 593 ; et une autre note datée du 20-11-1935, Archives de Paris, VR 588. Sur cette dernière, il est écrit que les collections municipales emportent le plus gros budget artistique (1,5 million de francs), suivies des Écoles, des Promenades (monuments des places et squares, 250000 francs), des Spectacles (150 000 francs), des Mairies (100 000 francs), de l'Hôtel de Ville (100 000 francs) et des Habitations à Bon Marché (50 000 francs).

125. - Séance du Conseil municipal du 26 novembre 1934, publiée dans le Bulletin Municipal Officiel du 27 novembre 1934, p. 4219-4230. La citation de ce paragraphe est extraite d'une intervention de MM. Contenot et Chausse (p. 4224-4225).

126. - Émile Chausse (1850-1941): ouvrier ébéniste, conseiller municipal socialiste de Paris (quartier de Sainte-Marguerite dans le XI ${ }^{\text {e) }}$ de 1893 à 1935.

127. - BRADEL, Vincent. « La modernité s'affiche en banlieue ». CHÂTELET, Anne-Marie, op. cit., p. 154-163.

128. - HUMMEL, Roger. «L'évolution scolaire en France ». L'Architecture d'aujourd'hui, 1938, n 8, p. 3-4.

129. - Léopold Bellan (1857-1936) : commerçant dans le textile, il acquiert une notoriété importante dans le IIe arrondissement (quartier du Mail) grâce à ses œuvres sociales. De tendance radical-socialiste, il est élu au conseil municipal à partir de 1893.

130. - Albert Besson (1896-1965) : médecin, élu conseiller général de la Seine et conseiller municipal de Paris en 1929, puis revient à la médecine en 1936 en tant que directeur général des laboratoires d'hygiène de la Ville de Paris et inspecteur général des services d'hygiène. Théoricien d'une architecture hygiéniste.

131. - François Latour est, dès 1922, rapporteur général du budget du département de la Seine. Bulletin Municipal Officiel Rapports et Documents, rapport $n^{\circ} 47,1934$.

132. - Marquis Fortuné d'Andigné (1868-1935): il fait carrière dans l'armée puis entre en politique en devenant conseiller du Quartier de la Muette en 1904, mandat qu'il conserve jusqu'à son décès. Vice-Président de la Commission du Vieux Paris, il s'intéresse à la préservation de la capitale et au développement de ses musées, plus particulièrement les musées Carnavalet, Galliera et le Petit Palais. En 1933, il est rapporteur du budget des musées municipaux. Voir JOLLY, op. cit.

133. - Pierre de Pressac (1878-?): archiviste paléographe, conseiller municipal du III ${ }^{\mathrm{e}}$ arrondissement de Paris (quartier Arts-et-Métiers) de 1929 à 1944. Chevalier de la Légion d'honneur en 1920, officier en 1925, commandeur en 1932. Membre de la droite parisienne.

134. - CHAMOUARD, Aude. « La mairie socialiste, matrice du réformisme (1900-1939)». Vingtième Siècle. Revue d'histoire, 2007/4 n 96, p. 23-33. DOI : 10.3917/ving.096.0023.

135. - Le Parti Communiste est le premier parti en nombre de suffrages, devant la SFIO. La droite est une coalition d'anciens royalistes, radicaux, républicains-socialistes et socialistes hostiles à toute alliance, « même d'une seconde » avec la SFIO. Voir COMBEAU, op. cit., p. 79.

136. - Seuls deux établissements, particulièrement ambitieux et soignés, sont publiés par la presse spécialisée. L'école de la rue Saint-Martin est publiée dans La Technique des Travaux ( $\mathrm{n}^{\circ} 2$, février 1934, p. 66-73) et dans L'Architecture d'Aujourd'hui (n 4, 1934, p. 57). - L'école de la rue 
Küss est publiée dans La Technique des Travaux ( $\mathrm{n}^{\circ}$ 7, juillet 1934, p. 386-294) et dans L'Architecture d'Aujourd'hui (n 5,1934$)$.

\section{RÉSUMÉS}

Dans les années 1930, la Ville de Paris lutte contre la crise et le chômage qui l'accompagne en organisant des grands travaux destinés à donner de l'ouvrage aux artistes et artisans de la capitale. Une dizaine de groupes scolaires sont ainsi construits entre 1932 et 1934 et des décors leur sont adjoints grâce à un emprunt exceptionnel de 10 millions de francs. Cette politique, qualifiée à l'époque d'«outillage municipal» par les élus parisiens, est illustrée par une documentation archivistique abondante et inédite, ainsi que par un certain nombre d'esquisses réalisées lors des concours. Après une analyse du contexte artistique et politique de l'époque, le présent article étudie chacun des projets de décoration picturale (fresque ou toile marouflée) en milieu scolaire et propose une analyse des enjeux à l'œuvre lors de la décision politique.

\section{INDEX}

Mots-clés : Paris, architecture scolaire, architecture de la première moitié du XXe siècle, décor scolaire, symbolique scolaire, enfant, pédagogie, politique scolaire, socialisme municipal, crise économique, grands travaux, artisans d'art, Eugène Viollet-le-Duc, architectes de la Ville de Paris et du Département de la Seine, concours, fresque, toile marouflée, sources des archives municipales

\section{AUTEUR}

\section{MARC VERDURE}

archiviste-paléographe, Conservateur du patrimoine à la Conservation des CEuvres d'Art

Religieuses et Civiles (COARC) de la Ville de Paris marc.verdure@paris.fr 